Bundesgesundheitsbl 2010 · 53:357-388

DOI 10.1007/s00103-010-1028-9

Online publiziert: 20. März 2010

๑) Springer-Verlag 2010
Kommission für Krankenhaushygiene und Infektionsprävention beim Robert Koch-Institut (RKI)

\title{
Anforderungen an die Hygiene bei der medizinischen Versorgung von immunsupprimierten Patienten
}

\author{
Empfehlung der Kommission für Kranken- \\ haushygiene und Infektionsprävention beim \\ Robert Koch-Institut (RKI)
}

1 Einleitung und Ziele

1.1 Hintergrund

1.2 Zielgruppen und Geltungsbereich

1.3 Struktur der Empfehlung

1.4 Bezug zu anderen Empfehlungen der KRINKO

2 Risikocharakterisierung

2.1 Ausgewählte Aspekte Immundefizienz und -suppression

2.2 Erregerspektrum

2.3 Risikogruppen immunsupprimierter Patienten

2.4 Gefäßkatheter als Infektionsrisiko

2.5 Hinweise auf Erregerreservoire aufgrund von Ausbruchsanalysen

2.6 Der Patient als Infektionsreservoir

2.7 Besucher

2.8 Medizinisches Personal (einschließlich Physiotherapeuten, MTAs)

2.9 Lebensmittel, keimarme Kost

2.10 Wasser

2.10.1 Wasser für den menschlichen Gebrauch

2.10.2 Wasser zum Trinken anderer Herkunft als Leitungswasser

2.11 Luft

2.12 Umgebungsflächen, Gegenstände des täglichen Lebens

2.13 Sanitärbereich

2.14 Tierkontakte

\section{Prävention}

3.1 Schulung der Patienten und ihrer Angehörigen

3.2 Anforderungen an die Besucherregelung (Kat IB)

3.3 Immunprophylaxe

3.4 Standardhygienemaßnahmen

3.5 Reinigung und Desinfektion

3.6 Anteil und Ausstattung von Zimmern zur Isolierung 3.6.1 Protektive Isolierung

3.6.2 Isolierung bei Besiedlung oder Infektion mit kontagiösen Erregern
3.7 Lebensmittel

3.8 Baulich-funktionelle Maßnahmen zur Gewährleistung des protektiven Umfelds

3.9 Anforderungen an die Raumluft

3.10 Anforderungen an die Wasserversorgung

3.11 Anforderungen an den Sanitärbereich

3.12 Anforderungen an die Hygiene bei Umbaumaßnahmen und Abrissarbeiten

3.13 Prävention der nosokomialen Harnwegsinfektion

3.14 Prävention der nosokomialen Wundinfektion

3.15 Prävention der nosokomialen Sepsis

3.16 Prävention der nosokomialen Gastrointestinalinfektion

3.17 Prävention von Zoonosen

4 Surveillance

4.1 Besonderheiten in der Surveillance von nosokomiale Infektionen bei Immunschwäche

4.2 Katheterassoziierte Infektionen

4.3 Empfehlungen zur Surveillance

4.4 Surveillance von invasiven Aspergillosen

4.5 Mikrobiologisches Screening von immunsupprimierten Patienten

4.6 Ausbruchs-Management

5 Infektionsrisiken im häuslichen Umfeld

5.1 Lebensmittel (s. hierzu auch Tabelle 5 in der Empfehlung)

5.2 Vorbeugung von lebensbedrohlichen Schimmelpilzinfektionen

5.3 Infektiöse Erkrankungen im häuslichen Umfeld

5.4 Prävention von Infektionen durch Tierkontakte

5.5 Sonstige Hinweise zu häufig gestellten Fragen

6 Literatur 


\begin{tabular}{|ll}
\hline Abkürzungen \\
\hline ADV & Adenovirus \\
\hline ARDS & Akutes Atemnotsyndrom (englisch: Acute Respiratory Distress Syndrome) \\
\hline BSI & $\begin{array}{l}\text { Blutstrominfektion (Infektion mit Nachweis eines Pathogens in der Blutkultur, klinisch } \\
\text { manifest als Bakteriämie, Fungämie oder Sepsis) [1] }\end{array}$ \\
\hline CFU & Koloniebildende Einheit (englisch: colony forming unit) \\
\hline CoNS & Koagulase-negative Staphylokokken \\
\hline CMV & Zytomegalievirus \\
\hline CVAD & $\begin{array}{l}\text { Central venous access device (dauerhaft implantierter zentraler Venenkatheter vom } \\
\text { Typ Broviac, Hickman oder Port) }\end{array}$ \\
\hline Device & $\begin{array}{l}\text { Medizinprodukt, dessen Einsatz mit einem erhöhten Infektionsrisiko assoziiert ist } \\
\text { (zum Beispiel Gefäßkatheter, Magensonde, perkutane endoskopische Gastrostomie, }\end{array}$ \\
\hline TrBL & Extended Spectrum Betalaktamase \\
\hline HHV & Humanes Herpes-Virus \\
\hline HMPV & Humanes Metapneumo-Virus \\
\hline HSV & Herpes-simplex-Virus \\
\hline GVHD & Graft versus Host Disease \\
\hline KMT & Knochenmarktransplantation \\
\hline KRINKO & Kommission für Krankenhaushygiene und Infektionsprävention beim Robert Koch-Institut \\
\hline MRSA & Methicillin- (Oxacillin-)resistenter S. aureus \\
\hline NTM & Nicht-tuberkulöse Mykobakterien \\
\hline OPSI & Overwhelming post-splenectomya sepsis syndrome \\
\hline PBSCT & $\begin{array}{l}\text { Transplantation peripherer Blutstammzellen (englisch: peripheral blood stem cell } \\
\text { transplantion) }\end{array}$ \\
\hline RSV & Respiratory Syncytial Virus \\
\hline SCT & Stammzelltransplantation (meist periphervenös separierte Blutsstammzellen) \\
\hline VRE & Vancomycin-resistente Enterokokken \\
\hline VZV & Varicella zoster virus \\
\hline &
\end{tabular}

\section{Definitionen}

\begin{abstract}
Allogene Stammzelltransplantation. Das Transplantat besteht aus Blutstammzellen von einem anderen Menschen. Es wird entweder von einem Familienmitglied oder von einer fremden Person gewonnen, vergleichbar einer Bluttransfusion, bei der das Blut auch von freiwilligen gesunden Spendern stammt.
\end{abstract}

Autologe Stammzelltransplantation. Das Transplantat besteht aus körpereigenen Blutstammzellen desselben Patienten. Diese werden aus dem peripheren Blut oder aus dem Knochenmark gesammelt, aufgearbeitet, dann eingefroren und dem Patienten zu einem späteren Zeitpunkt über eine Transfusion zurückgegeben.

Bakteriämie. Vorkommen lebensfähiger Bakterien im Blut; Nachweis eines bakteriellen Infektionserregers in der lege artis entnommenen Blutkultur.
Blutstrominfektion. Nachweis eines Infektionserregers in der lege artis entnommenen Blutkultur bei einem symptomatischen Patienten mit Infektionszeichen wie Fieber und gegebenenfalls weiteren klinischen und laborchemischen Manifestationen eines systemischen Inflammationssyndroms. Unter diesem Begriff werden andere Termini wie Bakteriämie, Sepsis, septischer Schock mit oder ohne Multiorganversagen (auch Candidämie oder Candida-Sepsis) subsumiert.

Fakultativ-pathogene Erreger. Erreger, die zur Auslösung von Infektionskrankheiten spezifische Voraussetzungen benötigen wie Eröffnen des Zugangs zu normalerweise sterilen Körperbereichen zum Beispiel durch Kathetersysteme beziehungsweise Fremdkörper und die auch bei fehlender Immunsuppression Infektionskrankheiten auslösen können.

Graft versus Host Disease (Transplantatgegen-Wirt-Reaktion). Zellen des spezi- fischen Immunsystems des Spenders erkennen körpereigene Antigene des Empfängers als fremd und verursachen eine Immunreaktion, durch die der Empfängerorganismus Schaden nimmt. Hauptmanifestationsorte sind die Haut, die Schleimhaut und die Leber (bei chronischer GVHD auch die Lunge) des Empfängers. Die Kontrolle der GVHD, die nach WHO in vier Schweregrade eingeteilt wird, erfordert gegebenenfalls eine Intensivierung der medikamentösen Immunsuppression.

Induktionstherapie. Bei einer akuten Leukämie verdrängen bösartige Zellen die gesunden Zellen des Knochenmarks. Deshalb kommt es beispielsweise zu Infektionen und Blutungsneigung. In dieser Situation sind die vorrangigen Therapieziele, die kranken Zellen zu zerstören, damit sich die verdrängten gesunden Zellen erholen können. Dazu wird eine intensive Chemotherapie eingesetzt. In der Regel sind hierzu mehrere Zyklen notwendig. Die zur Erreichung einer Remission verabreichte Chemotherapie wird Induktionstherapie genannt, während Chemotherapien in der Remission in der Regel als Konsolidierungstherapie bezeichnet werden.

Obligat-pathogene Erreger. Erreger, die bei fehlender spezifischer Immunität bei gesunden Personen Infektionskrankheiten auslösen.

Opportunistisch-pathogene Erreger. Erreger, die nahezu ausschließlich bei Einschränkung des Immunsystems Infektionskrankheiten auslösen.

Sepsis. Invasion von Mikroorganismen und/oder ihrer Toxine in den Blutstrom mit generalisierter hyperinflammatorischer Reaktion (englisch: systemic inflammatory response syndrome; SIRS) hervorgerufen durch eine Infektion.

Standardhygienemaßnahmen. Maßnahmen, die im Kontakt zu allen Patienten durchgeführt werden, um eine Übertragung von Infektionserregern auf den Patienten und das Personal zu verhindern und das Risiko einer nosokomialen Weiterverbreitung von Krankheitser- 
regern zu reduzieren. Hierzu gehören vor allem die hygienische Händedesinfektion und der situationsbedingte Einsatz von speziellen Barrieremaßnahmen:

- Einmalhandschuhe bei der Möglichkeit der Kontamination der Hände mit Blut, Atemwegssekreten oder anderen Ausscheidungen des Patienten,

- Schutzkleidung (Patienten-bezogene Schürzen oder Kittel) bei besonders kontaminationsträchtigen Arbeiten (zum Beispiel Pflege eines Patienten mit Diarrhö oder Erbrechen),

- Mund-Nasen-Schutz (bei engem Kontakt zu einem Patienten mit Tröpfcheninfektion).

$\mathrm{Zu}$ den Standardhygienemaßnahmen gehören auch die desinfizierende Reinigung sichtbar kontaminierter Oberflächen und Gegenstände und die sachgemäße Aufbereitung von Medizinprodukten.

\section{Einleitung und Ziele}

\subsection{Hintergrund}

Erhebliche Fortschritte in der Diagnostik und Therapie haben zu einem verbesserten Langzeitüberleben von Patienten mit Krebs oder anderen schwerwiegenden Grunderkrankungen geführt, die mit einer Immunschwäche (Defizienz) oder einer durch medizinische Behandlung bedingten (iatrogenen) Unterdrückung des Immunsystems ${ }^{1}$ (Immunsuppression) einhergehen $[2,3,4,5]$.

Daher nimmt in Krankenhäusern und Spezialambulanzen die Zahl von Patienten mit hochgradiger und lang anhaltender Immundefizienz oder -suppression stetig zu.

Bei diesen Patienten treten häufiger als bei Gesunden Infektionen auf, und zwar als Komplikationen

- der malignen Erkrankung oder der Autoimmunerkrankung selbst,

- nach intensiver medikamentöser Therapie von Krebserkrankungen $[6,7,8,9]$,

- nach Organ- oder Stammzelltransplantation $[10,11,12,13,14]$ sowie

\footnotetext{
1 Defizienz und Suppression des Immunsystems werden im Text unter dem Begriff „Immunschwäche" zusammengefasst.
}

- im Verlauf einer lang anhaltenden iatrogenen Immunsuppression bei verschiedenen Autoimmunerkrankungen.

Infektionen durch obligat pathogene Erreger können hier mit einem höheren Krankheitsschweregrad und einer höheren Letalität einhergehen. Außerdem sind diese Patienten durch spezifische Lücken ihres Abwehrsystems empfänglicher, sodass auch Infektionen durch fakultativpathogene sowie opportunistisch-pathogene Erreger vorkommen und lebensbedrohliche Konsequenzen nach sich ziehen können.

Infektionen können das Leben immunsupprimierter Patienten akut gefährden, schränken ihre ohnehin reduzierte Lebensqualität zusätzlich ein und erhöhen die Gesamtkosten der Behandlung $[15,16,17,18]$. Außerdem können sie relevante Abweichungen vom onkologischen Behandlungsplan nach sich ziehen und durch eine Verminderung der Therapieintensität das Risiko erhöhen, an der Grunderkrankung zu versterben [16, 19, 20, 21, 22]. Nach Organtransplantationen können Infektionen zum Verlust des Transplantats führen.

Wichtig ist neben der Art und dem Schweregrad der Immunschwäche (siehe Abschnitt 1.5) auch deren zeitlicher Verlauf. Patienten mit intermittierenden Phasen einer ausgeprägten Immunschwäche müssen von Patienten mit lang anhaltender Immunschwäche unterschieden werden.

Bei Patienten mit intermittierender hochgradiger Immunsuppression sind spezielle Maßnahmen insbesondere während dieser Behandlungsphasen erforderlich, bis es zu einer Rekonvaleszenz der körpereigenen Immunabwehr kommt. Bei Patienten mit lang anhaltender Immunschwäche müssen die entsprechenden Maßnahmen kontinuierlich weiter aufrechterhalten werden.

\subsection{Zielgruppen und Geltungsbereich}

Zu den Zielgruppen dieser Empfehlung gehören alle Berufsgruppen, die an der medizinischen Versorgung immunsupprimierter Patienten direkt oder indirekt beteiligt sind, vor allem Ärztinnen und Ärzte, Pflegepersonal, Krankenhaushygiene-Fachpersonal, Physiotherapeuten, technisches Personal, der öffentliche Gesundheitsdienst, Angestellte der Krankenhausverwaltung, Ärztinnen und Ärzte des medizinischen Dienstes der Krankenkassen sowie Auszubildende (Medizinstudenten, Auszubildende in der Gesundheits- und Krankenpflege).

Außerdem richtet sich diese Empfehlung ganz bewusst auch an die Patienten sowie in die Pflege einbezogene Familienangehörige. Die Patienten sollen als Partner in die Infektionsvermeidung (Prävention) einbezogen werden.

Diese Empfehlung soll zudem Rahmenbedingungen für eine am Ziel der Infektionsprävention ausgerichtete (Bau-) Planung von Stationen und Spezialambulanzen bereitstellen, in denen Patienten mit hochgradiger Immunschwäche behandelt werden.

Hochgradig immungeschwächte Patienten sind auch außerhalb des Krankenhauses besonderen Infektionsrisiken ausgesetzt. Daher wird versucht, dem Patienten selbst, dem nachbetreuenden Arzt und den Angehörigen im häuslichen Umfeld orientierende Hinweise zu geben, wie hochgradig immunsupprimierte Patienten während ambulanter Behandlungsphasen vor lebensbedrohlichen Infektionen geschützt werden können.

Die Beachtung von Hygienestandards in Spezialambulanzen $[23,24]$ und bei der häuslichen Betreuung durch ambulante Pflegedienste $[25,26,27]$ ist hierbei von erheblichem Interesse. Alle hier vorgelegten Empfehlungen müssen angemessen an die jeweilige Behandlungssituation des individuellen Patienten angepasst werden.

Die Details der Umsetzung in onkologischen Schwerpunktpraxen sind nicht Gegenstand dieser Empfehlung (hierzu soll gemeinsam mit den zuständigen Fachgesellschaften ein ergänzendes Konsensusdokument erarbeitet werden).

In diesem Zusammenhang wird der Begriff der nosokomialen Infektion (NI) gemäß seiner Legaldefinition in $\$ 2 \mathrm{Nr} .8$ IfSG nicht nur auf im Krankenhaus (oder in einer Spezialambulanz oder Arztpraxis) erworbene Infektion bezogen, sondern auf alle Infektionen, die im Zusam- 
menhang mit der medizinischer Versorgung der Patienten auftreten und nicht schon vorher bestanden [28]. Im Einzelfall handelt es sich zum Beispiel um Infektionen, die mit dem Einsatz von bestimmten Medizinprodukten (zum Beispiel Gefäßkatheter, Magensonde, perkutane endoskopische Gastrostomie, Tracheostoma, Fremdmaterialien im Zusammenhang mit Osteoprothesen usw.) verbunden sind und Wochen bis Monate nach der Anlage/Implantation auftreten. Zum Beispiel fällt auch die invasive Aspergillose, die der Patient während der Phasen der hochgradigen Immunsuppression zu Hause erwirbt, unter diese Kategorie, wenn die iatrogene Immunsuppression die Infektion begünstigt hat.

Die Infektionsprävention bei Patienten nach Organtransplantation erfolgt analog zu den hier gegebenen Empfehlungen, wenn die im Abschnitt Risikocharakterisierung näher umschriebenen Merkmale der Immunsuppression vorliegen. Spezielle Aspekte des Umgangs mit HIV-infizierten Patienten werden nicht behandelt.

\subsection{Struktur der Empfehlung}

In der vorliegenden Empfehlung werden die Hintergründe für die Notwendigkeit von Präventionsmaßnahmen bei immunsupprimierten Patienten vorgestellt und auf der Basis der internationalen und nationalen Studienlage für diese Patientengruppe entsprechende Empfehlungen zur Prävention von nosokomialen Infektionen abgeleitet.

Um vermeidbare Infektionen effizient zu verhüten oder unter Kontrolle zu bringen, bedarf es eines umfassenden Verständnisses der möglichen exogenen Ursachen für infektiöse Komplikationen und der prädisponierenden Faktoren aufseiten des Patienten. Die Empfehlung ist demnach in insgesamt vier Grundkapitel gegliedert.

Nach der einleitenden Darstellung der Ziele und der Struktur der Empfehlung im 1. Kapitel wird zunächst die Risikocharakterisierung im Kapitel 2 behandelt. Hierin werden exemplarisch verschiedene Aspekte der Immunsuppression, die spezifischen Risikogruppen, die Zeitpunkte der spezifischen Infektionsgefährdung unter
Immunsuppression und die relevanten Erreger behandelt.

Im 3. Kapitel werden Präventionsstrategien aus betrieblich-organisatorischer und baulich-funktioneller Sicht entsprechend $\$ 23$ des Infektionsschutzgesetzes [29] dargestellt.

Zur Schnellinformation über die konkreten Empfehlungen zur Prävention und Kontrolle nosokomialer Infektionen siehe Kapitel 3 ( $\rightarrow$ Inhaltsübersicht).

Das 4. Kapitel thematisiert die Aspekte der Surveillance, gibt Empfehlungen zur Surveillance von NI bei immunsupprimierten Patienten und verweist auf die Empfehlung zum Ausbruchsmanagement.

Das Kapitel 5 thematisiert Infektionsrisiken im häuslichen Umfeld und gibt orientierende Hinweise zur Infektionsprävention während ambulanter Behandlungsphasen.

\subsection{Bezug zu anderen Empfehlungen der KRINKO}

In der hier vorliegenden Empfehlung ergeben sich zahlreiche Überschneidungen zu anderen Empfehlungen dieser Richtlinie. Zitiert wird in dieser Empfehlung aus folgenden Mitteilungen der KRINKO:

- Surveillance (Erfassung und Bewertung) von nosokomialen Infektionen (Umsetzung \$23 IfSG) [29, 30],

- Händehygiene [31],

- Prävention Gefäßkatheter-assoziierter Infektionen [32],

- Prävention der nosokomialen Pneumonie [33],

- Prävention und Kontrolle Katheterassoziierter Harnwegsinfektionen [34],

- Anforderungen der Hygiene bei Operationen und anderen invasiven Eingriffen [35],

- Prävention und Kontrolle von Methicillin-resistenten Staphylococcus aureus-Stämmen (MRSA) in Krankenhäusern und anderen medizinischen Einrichtungen [36],

- Ausbruchsmanagement und strukturiertes Vorgehen bei gehäuftem Auftreten nosokomialer Infektionen [37],

- Anforderungen an die Hygiene bei der Reinigung und Desinfektion von Flächen [38],
- Infektionsprävention in der Zahnheilkunde [39],

- personelle und organisatorische Voraussetzungen zur Prävention nosokomialer Infektionen [40].

Zum Teil werden Aussagen von grundlegender Bedeutung nochmals wiedergegeben, um hier eine für die tägliche Praxis selbstständig verwendbare Empfehlung zu geben.

Die Kategorisierung der Empfehlungen nach ihrer wissenschaftlichen Evidenz erfolgt nach den üblichen Kategorien der KRINKO.

Die Mehrzahl aller Strategien und Detailfragen der gezielten Infektionsprävention bei hochgradig immunsupprimierten Patienten ist bisher nicht in prospektiv-randomisierten, kontrollierten Studien überprüft worden. Da die Patienten im Falle eines entsprechenden Ereignisses lebensbedrohlich erkranken können, wäre es nach dem Vorsorgeprinzip im Risikomanagement nicht vertretbar, auf eventuelle Publikationen solcher Studien zu warten und erst zu reagieren, wenn erhebliche Schäden bereits eingetreten sind.

\section{Risikocharakterisierung}

\subsection{Ausgewählte Aspekte Immundefizienz und -suppression}

Die Mehrzahl der Infektionen bei hochgradig immunsupprimierten Patienten ist endogenen Ursprungs (zum Beispiel Translokation von gramnegativen Infektionserregern aus dem Darm des Patienten während einer Chemotherapie-induzierten Mukositis) und somit eine nur bedingt vermeidbare Konsequenz der Grunderkrankung bzw. der intensiven Therapie $[7,41,42]$.

Die erfolgreiche Erkennung und $\mathrm{Ab}$ wehr von Infektionserregern durch das Immunsystem wird während der intensiven Therapie einer Krebserkrankung beeinträchtigt [20] durch

- die Grunderkrankung selbst (Leukämie, Lymphom, solider Tumor mit ausgedehnter Knochenmarksinfiltration),

- unerwünschte Wirkungen der gegen die Krebserkrankung gerichteten Therapie (Chemotherapie, Bestrah- 
lung, Operation, Stammzelltrans-

plantation),

- den Einsatz von Devices (siehe

Definition) $[43,44,45,46,47,48,49$,

50, 51].

Des Weiteren bestehen besondere infektionsepidemiologische Gegebenheiten, wie zum Beispiel ein verlängerter Krankenhausaufenthalt während der Induktionsoder der Konsolidierungstherapie, häufiger Wechsel zwischen stationärer und ambulanter Behandlung [25, 26, 27, 52, 53, 54], höheres Risiko der Besiedlung und Infektion mit fakultativ pathogenen (teils multiresistenten) Mikroorganismen [55, 56], erhöhter Exposition gegenüber breit wirksamen Antibiotika [8], intensive direkte und indirekte soziale Kontakte zwischen den Patienten (Familien) sowie zwischen den Patienten (Familien) und dem Behandlungsteam.

Die am besten charakterisierten Risikofaktoren für Infektionen bei Immunschwäche sind

- das Ausmaß und

- die Dauer der Granulozytopenie (nach angelsächsischem Sprachgebrauch „Neutropenie“) [57].

Patienten mit einer Granulozytopenie [Granulozytenzahl unter $0,5 \times 10^{9 / l}$ (weniger als 500 Granulozyten pro $\mu l)]^{2}$ haben ein signifikant erhöhtes Risiko, an Infektionen durch Bakterien oder Pilze zu erkranken.

Die Wahrscheinlichkeit einer Infektion korreliert zudem mit der Dauer der Granulozytopenie. Dies gilt analog für granulozytopenische Patienten mit schweren Formen einer angeborenen Granulozytopenie, einer aplastischen Anämie [58] oder einem myelodysplastischen Syndrom [59, $60,61,62]$.

Während bei einer Granulozytopeniedauer von bis zu 5 Tagen ohne andere potenzierende Faktoren nur ein gering erhöhtes Risiko besteht ${ }^{3}$, gelten Patienten mit einer Granulozytopeniedauer von

\footnotetext{
2 Der niedrigste Wert der Leukozyten (Granulozyten) wird als Nadir bezeichnet. Auch die Tendenz (fallende oder steigende Leukozytenzahl) ist beachtenswert.

$328 \%$, wenn die Granulozytenzahl im peripheren Blut unter $0,1 \times 10^{9} / \mathrm{l}$ liegt; dies entspricht $<100 / \mu \mathrm{l}$.
}

Tab. 1 Zusammenhänge zwischen bestimmten immunsuppressiven/antineoplastischen Medikamenten und einer Auswahl an infektiösen Komplikationen

\section{Medikamente}

Lymphopenie und eingeschränkte Granulozytenfunktion durch den hoch dosierten oder prolongierten Einsatz von Glukokortikoiden

Hoch dosiertes Cytarabin (Ara-C) bei Patienten mit akuter myeloischer Leukämie

Ausgeprägter, anhaltender Mangel an $\mathrm{T}_{\mathrm{CD} 4}$-Helferzellen nach hoch dosiertem Cyclophosphamid, nach Fludarabin oder 2-CDA (Cladribin)

Persistierender Mangel an Antikörpern nach Rituximab (Anti-CD20)

Antilymphozyten/-thymozyten-Globulin zur Kontrolle der GVHD nach allogener SCT

Therapie mit Alemtuzumab (Anti-CD52, Campath-1H)

Therapie mit monoklonalen Antikörpern gegen TNF oder den TNF-Rezeptor

6-10 Tagen als gefährdet (Risiko für eine Infektion 30\% aller Patienten bei Leukozyten $<1 \times 10^{9} / 1$ und $50 \%$ bei Granulozyten $\left.<0,1 \times 10^{9} / 1\right)$.

Patienten mit einer Granulozytopeniedauer über 10 Tage sind Hochrisikopatienten (Risiko bakterieller Infektionen $70 \%)[6,7,63,64]$. Die zuletzt genannte Gruppe weist außerdem ein signifikant erhöhtes Risiko für invasive Pilzinfektionen auf (zum Beispiel Candida spp., Aspergillus spp.) $[16,19,20,21,22,65,66,67$, 68].

Jedoch wird eine schematische Orientierung an der Granulozytenzahl und der zu erwartenden Dauer der Granulozytopenie der Komplexität der Abwehrschwäche bei onkologischen Patienten nicht gerecht [69]. Unter einer intensiven Therapie kommt es zusätzlich zu einer Störung unspezifischer Schutzfunktionen (Haut- und Schleimhautbarriere, mukoziliäre Clearance, gastrointestinale Motilität, Wundheilungsstörung) und anderer Elemente des zellulären und humoralen Immunsystems. B- und T-Lymphozyten sind nicht in ausreichender Zahl vorhanden [21] und zusätzlich in ihrer Funktion eingeschränkt [7o] (zum Beispiel eingeschränkte oder nicht vorhandene Produktion spezifischer Antikörper, Verlust der Impfimmunität, Störung der Abwehr viraler Infektionen und von Infektionen durch intrazelluläre Erreger).

Dies betrifft bei anhaltendem Immundefekt auch die Eindämmung und Kon-

\section{Komplikationen}

Pneumocystis jiroveci-Pneumonie zum Beispiel bei Hirntumorpatienten [405, 406, 407], disseminierte Herpes simplex oder VZV-Infektionen [21, 408] Sepsis und Pneumonie durch vergrünende Streptokokken $[1,409,410,411,412,413,414,415]$

Listeria monocytogenes, Legionella pneumophila, VZV, nicht-tuberkulöse Mykobakterien, CMV [416, $417,418]$

Reaktivierung einer latenten Hepatitis B $[76,418$, 419, 420]

EBV-Infektion/-Reaktivierung und lymphoproliferative EBV-assoziierte Erkrankungen [421]

CMV-Reaktivierung $[76,422,423]$

Reaktivierung einer latenten Tuberkulose [424, 425]

trolle latent persistierender Infektionen (zum Beispiel HSV, CMV, VZV, Tuberkulose, Hepatitis B oder C) und erhöht das Risiko spezieller opportunistischer Infektionen (Pneumocystis jirovecii, Cryptococcus neoformans, Cryptosporidien, Toxoplasmose, nicht-tuberkulöse Mykobakterien (NTM), Listeria monocytogenes).

Die Therapie mit Glukokortikoiden über der Cushingschwelle (beim Erwachsenen > 20 mg Prednisolon-Äquivalent/ Tag, bei Kindern mehr als o,2 mg/kg/Tag über mehr als 14 Tage) ist ein wichtiger zusätzlicher Risikofaktor.

Patienten nach einer intensiven Chemotherapie oder nach Behandlung mit speziellen monokolonalen Antikörpern zeigen im Verlauf häufig eine über Wochen bis Monate anhaltende Lymphopenie (Mangel an spezifischen B- und T-Zellen). Besonders gravierend ist die Lymphopenie nach Stammzelltransplantation und bei Patienten, die aufgrund einer „Graft-versus-Host-Erkrankung“ mit Medikamenten behandelt werden müssen, die das Immunsystem unterdrücken (Immunsuppressiva).

Patienten nach Splenektomie oder mit funktioneller Asplenie sind vor allem durch septische Infektionen gefährdet, die von bekapselten Bakterien ausgehen (Overwhelming-Post-Splenectomia-Sepsis-Syndrom) $[71,72,73,74]$.

Bestimmte therapeutische Interventionen sind erfahrungsgemäß mit einem spezifischen Risiko infektiöser Komplika- 


\section{Tab. 2 Erregerspektrum invasiver Infektionen bei Immunschwäche}

\section{Granulozytopenie:}

Koagulase-negative Staphylokokken (CoNS, zum Beispiel S. epidermidis),

Staphylococcus aureus, a-hämolysierende (vergrünende) Streptokokken (zum Beispiel S. mitis),

Enterococcus faecium

Enterobacteriaceae (E. coli, Enterobacter spp., Klebsiella oxytoca, Klebsiella pneumoniae, Proteus spp., Serratia marcescens),

Nonfermenter [Achromobacter xylosoxidans, Acinetobacter baumannii, Burkholderia cepacia,

Pseudomonas aeruginosa, Ralstonia pickettii, Stenotrophomonas maltophilia, Aspergillus- und

Candida-Spezies, Zygomyzeten (Mucor und andere)]

T-Zell-Defekt:

Viren (CMV, HSV, VZV, HHV-6, RSV, HMPV, ADV, Polyomaviren, zum Beispiel BK-Virus)

Pilze (siehe oben, sowie Cryptococcus spp., Pneumocystis jiroveci)

Mykobakterien (vor allem M. tuberculosis, aber auch NTM wie M. avium intracellulare, M. fortuitum,

M. marinum, M. septicum und andere)

Listeria monocytogenes und Nocardien

Parasiten (zum Beispiel Toxoplasma gondii oder Cryptosporidium parvum/-hominis)

Antikörpermangel:

Vorwiegend bekapselte Bakterien wie Pneumokokken, Haemophilus influenzae,

Viren (siehe oben), seltener: Pilze (Candida spp.),

Viren (CMV, HSV, Norovirus, Rotavirus, Adenovirus)

Splenektomie/funktionelle Asplenie:

Streptococcus pneumoniae, Haemophilus influenzae, Neisseria meningitidis, Staphylococcus aureus,

Salmonella enteritidis/typhimurium

Weitere Hinweise:

Mucositis des Gastrointestinaltrakts:

a-hämolysierende (vergrünende) Streptokokken (zum Beispiel S. mitis), Clostridium difficile,

(sehr selten auch: Clostridium septicum), Enterococcus faecium und faecalis, Leukonostoc spp.,

Rothia mucilaginosa, Campylobacter jejuni

Hautläsion/Venenkatheterinfektion:

Koagulase-negative Staphylokokken, Staphylococcus aureus, Corynebacterium spp.,

Pseudomonas aeruginosa (Ectyhma gangraenosum), Stenotrophomonas maltophilia sehr selten:

atypische Mykobakterien, Aspergillus spp.

tionen assoziiert [75], die durch ein entsprechendes Monitoring im Verlauf und gegebenenfalls durch eine antimikrobielle Prophylaxe verhindert oder frühzeitig erkannt werden können [76]. Eine Auswahl hierzu zeigt $\bullet$ Tab. 1.

Auch die Reaktivierung latenter Infektionen bei Patienten mit hochgradiger Immunschwäche kann aus krankenhaushygienischer Perspektive relevant sein und ein erhöhtes Infektionsrisiko für Mitpatienten und medizinisches Personal nach sich ziehen.

Zum Beispiel zeigen Patienten mit Reaktivierung einer Hepatitis B [77, 78, 79, 8o, 81, 82, 83] oder einer Hepatitis C [84] unter einer immunsuppressiven Therapie oft eine hohe Viruslast (hohe Kontagiosität) ohne wegweisende klinische und laborchemische Infektionszeichen $[85,86$, $87,88]$. Bei therapiebedingtem hochgradigem Mangel an spezifischen T-Zellen kann eine latente Tuberkulose reaktiviert werden. Auch die endogene Reaktivierung einer Varicella-zoster-Infektion, die sich klinisch als Herpes zoster manifes- tiert, wird häufiger beobachtet, wenn die T-Zell-Funktion und die humorale Immunität (Antikörper gegen VZV im Serum) nachhaltig beeinträchtigt sind.

Patienten mit gravierender Immunschwäche haben ein erhöhtes Risiko von Haut- und Weichteilinfektionen. Dies gilt sowohl für Patienten mit Granulozytopenie als auch für Patienten mit einem Mangel an $\mathrm{T}_{\mathrm{CD}_{4}}$-Helferzellen oder einem Antikörpermangel sowie insbesondere für die häufig vorkommenden Kombinationen solcher Formen der Immunsuppression.

Neben der höheren Inzidenz postoperativer Wundheilungsstörungen und Wundinfektionen (zum Beispiel unter hoch dosiertem Methotrexat oder nach Strahlentherapie) ist auch mit einem gegenüber nicht-immunsupprimierten $\mathrm{Pa}$ tienten deutlich unterschiedlichen Spektrum von Infektionserregern zu rechnen.

\subsection{Erregerspektrum}

In - Tab. 2 findet sich eine Zusammenstellung häufiger Infektionserreger im
Kontext bestimmter Aspekte der Immundefizienz.

Bei immunsupprimierten Patienten wird ein erheblicher Anteil der Blutstrominfektionen (meist assoziiert mit zentralen Venenkathetern) durch Koagulase-negative Staphylokokken verursacht $[89,90$, 91], die aufgrund einer Biofilmbildung im Katheterlumen letztendlich eine operative Entfernung des Katheters erforderlich machen können. Daher haben Infek tionen durch diese Erreger einen höheren klinischen Stellenwert als in anderen $\mathrm{Pa}$ tientenpopulationen.

\subsection{Risikogruppen immunsupprimierter Patienten}

Diese Empfehlung definiert nach dem Schweregrad der Immunsuppression exemplarisch drei Risikogruppen, in denen Patienten mit ähnlich gravierender Immunschwäche zusammengefasst werden. $\mathrm{Zu}$ beachten ist, dass es sich hier um ein dynamisches Konzept handelt, weil die spezifische Situation des Patienten sich im Laufe der Behandlung ändert, sodass ggf. die jeweilige Risikogruppe angepasst werden muss (Beispiel: Induktionstherapie versus Konsolidierungstherapie mit oder ohne Radiotherapie versus autologe Transplantation versus allogene Transplantation).

Da es häufig (aus Erfahrung) möglich ist, die wahrscheinliche Dauer der Granulozytopenie bei bestimmten Grunderkrankungen und therapeutischen Interventionen anzugeben, werden die Patienten von den behandelnden Ärzten vorausschauend der jeweiligen Risikogruppe zugewiesen.

Bei allogen transplantierten Patienten ist insbesondere der Schweregrad der "Graft-versus-Host-Erkrankung“ entscheidend für die Intensität der immunsuppressiven Behandlung und die Zuordnung in die jeweilige Risikogruppe. Patienten mit hochgradiger GVHD der Haut oder des Gastrointestinaltraktes haben ein besonders hohes Risiko für schwere exogene Infektionen (multiple Eintrittspforten, gestörte unspezifische Barrieren plus Immunsuppression; hoher Selektionsdruck auf resistente Erreger durch Antibiotikaprophylaxe und -therapie) (• Tab. 3) 


\subsection{Gefäßkatheter als Infektionsrisiko}

Der Einsatz von bestimmten invasiven Medizinprodukten, erhöht das Infektionsrisiko.

Dies gilt insbesondere für

- zentrale Venenkatheter [49, 50, 92], in der Onkologie meist dauerhaft implantierte Katheter vom Typ Hickman, Broviac, Port [32, 49, 92, 93, 94, 95] und

- periphervenöse Zugänge [32, 96].

Zur Definition des Gefäßkatheters als Infektionsquelle sind spezielle diagnostische Methoden erforderlich [46, 49, 51, 92, 94, 97, 98, 99, 100, 101]. Auch kontaminierte Parenteralia $[102,103,104]$, vor allem lipidhaltige Mischinfusionen zur parenteralen Ernährung [105, 106, 107, 108, 109, $110,111,112,113]$ sind wichtige potenzielle Medien der nosokomialen Infektionsübertragung.

\subsection{Hinweise auf Erregerreservoire aufgrund von Ausbruchsanalysen}

Ausbrüche sind Infektionen bei zwei oder mehr Patienten durch identische Erreger, die meist in engem zeitlichem und räumlichem Zusammenhang auftreten und die in etwa der Hälfte der Fälle auf einen Indexpatienten, eine externe Quelle oder einen gemeinsamen Übertragungsweg zurückgeführt werden können ( $\$ 6$ Abs. 3 IfSG) [114].

Systematische Analysen von publizierten Ausbrüchen ermöglicht die „outbreak-database“ [115]. Eine gezielte Abfrage dieser Datenbank zu Ausbrüchen bei Patienten mit Immunschwäche führte 2006 zu 214 Einzelpublikationen. Die häufigsten Infektionen in absteigender Häufigkeit waren Blutstrominfektionen [116], Pneumonien, gastrointestinale Infektionen inklusive Hepatitis, postoperative Wundinfektionen und Harnweginfektionen. Die im Zusammenhang mit nosokomialen Ausbrüchen dokumentierten häufigsten Infektionserreger waren Vancomycin-resistente Enterokokken (meist E. faecium), Aspergillus fumigatus, $P$. aeruginosa, Legionella pneumophila, HepatitisC-Virus, S. aureus (meist MRSA; wahrscheinlich ein Publikationsbias, das heißt

Tab. 3 Risikogruppen

Risikogruppe 1 (mittelschwere Immunsuppression/-defizienz)

- Granulozytopenie $<0,5 \times 10^{9} / \mathrm{l}\left(<500 / \mu \mathrm{l}\right.$ ) bis zu 10 Tage (analog Leukopenie $<1 \times 10^{9} / \mathrm{l} ;<1000 / \mu \mathrm{l}$ )

- Mangel an CD4-positiven T-Helfer-Zellen $<250 / \mu l$ (cave: altersentsprechende Normwerte bei Kindern); autologe Stammzelltransplantation bis drei Monate nach intensiver Therapiephase Patienten, die mehr als 1 Merkmal der unter Risikogruppe 1 aufgeführten Immunsuppression/-defizienz aufweisen, kommen in Risikogruppe 2.

Risikogruppe 2 (schwere Immunsuppression/-defizienz)

- Granulozytopenie $<0,5 \times 10^{9} / /(<500 / \mu l)$ über mehr als 10 Tage (analog Leukopenie $<1 \times 10^{9} /$; $<1000 / \mu l)$

- Schwere aplastische Anämie oder Makrophagen-Aktivierungssyndrom während einer intensiven immunsuppressiven Therapie

- Allogene Knochenmark- oder/Stammzelltransplantation bis 6 Monate nach Abschluss der intensiven Therapiephase (wichtig: Ausmaß der GVHD und der anhaltenden iatrogenen Immunsuppression)

- Akute stationäre Behandlungsphase bei autologer Stammzelltransplantation oder nach Transplantation solider Organe (bis zur Entlassung)

Risikogruppe 3 (sehr schwere Immunsuppression/-defizienz)

- Allogene KMT/PBSCT in intensiver Therapiephase (bis zum Engraftment = Regeneration der Granulopoese)

- Schwere GVHD Grad III oder IV unter intensiver Immunsuppression

Die Entscheidung über die Zuordnung zu Gruppe 3 bei Patienten nach allogener Stammzelltransplantation wird letztlich in Zusammenschau aller Befunde von den behandelnden Onkologen getroffen.

der Anteil von MRSA unter den S. aureus-Ausbrüchen ist zu hoch, da mehr MRSA-Ausbrüche publiziert wurden), Hepatitis-B-Virus und Clostridium difficile. In der Mehrzahl der Fälle konnte eine gemeinsame Quelle des Ausbruchs in absteigender Häufigkeit identifiziert werden: - die unbelebte Umgebung,

- Indexpatienten,

- kontaminierte Medikamente,

- besiedeltes Personal,

- Devices und Pflegeutensilien und

- Lebensmittel.

In Kenntnis der Ökologie des Erregers können schon bei Verdacht auf einen Ausbruch Rückschlüsse auf mögliche Reservoire und Übertragungswege gezogen werden. Ausgewählte Beispiele hierzu sind:

- Kontaktinfektionen (belebte und unbelebte Umgebung), zum Beispiel VRE, MRSA, ESBL-bildende Enterobacteriaceae, Norovirus, Rotavirus, EHEC, Clostridium difficile,

- Tröpfcheninfektionen (respiratorische Viren wie das Respiratory Syncytial Virus und viele andere),

- aerogene Infektionen zum Beispiel durch Aspergillus fumigatus, VZV, Masern, M. tuberculosis,

- Wasser-assoziierte Infektionen (auch Inhalationszubehör), zum Beispiel $P$. aeruginosa oder ande- re Nonfermenter, Legionella pneumophila (Trinkwasserinstallationen, Rückkühlwerke),

- Blut-übertragene Infektionen, zum Beispiel HBV, HCV,

- kontaminierte Medikamente, zum Beispiel Ralstonia pickettii (wurde wiederholt im Zusammenhang mit der Heparinspülung zentraler Venenkatheter genannt),

- kontaminierte Lebensmittel, zum Beispiel S. aureus, Salmonella enteritidis, Campylobacter jejuni, Yersinia enterocolitica.

\subsection{Der Patient als \\ Infektionsreservoir}

Die Immunschwäche und verschiedene therapeutische Interventionen begünstigen die Besiedlung mit fakultativ pathogenen Mikroorganismen. Besonders charakteristisch ist, dass die Ausscheidungsdauer wichtiger übertragbarer Infektionserreger bei immunsupprimierten $\mathrm{Pa}$ tienten gegenüber immunkompetenten Patienten deutlich verlängert ist (zum Beispiel VRE, RSV, Norovirus, Rotavirus) [117, $118,119,120,121]$.

Dies erfordert neben der konsequenten Anwendung von Standardhygienemaßnahmen einen erheblichen Mehraufwand bei der Erreger-spezifischen Isolierung und Kohortierung auf Stationen, 
die hochgradig immunsupprimierte Patienten betreuen.

Die interdisziplinäre Erkennung und Behandlung von vorbestehenden Infektionsherden vor Einleitung der immunsuppressiven Therapie ist eine wichtige Maßnahme zur Reduktion des Risikos schwer verlaufender Infektionen. Zur Fokussuche gehört zum Beispiel die Untersuchung von:

- Mund-Nasen-Rachen-Raum [122] (Gingivitis, orale Candidiasis, Parodontitis und andere Mundschleimhauterkrankungen),

- Zahnstatus [122, 123, 124] einschließlich Röntgenbefund (Karies, teilretinierte Zähne, apikale Parodontitiden),

- Prothesen (Druckstellen, orale Candidiasis),

- Sinus (Aspergillusherde, Sinusitis) [125],

- Inspektion der Haut (Hautläsionen, Furunkel, Karbunkel, Paronychie).

Vor Organ- oder Stammzelltransplantation ist ein erweitertes Spektrum an Untersuchungen empfehlenswert, das in den jeweiligen Therapieprotokollen vorgegeben wird [126]. Die Entscheidung über die Notwendigkeit einer Fokussanierung darf jedoch nicht ohne Rücksprache mit den behandelnden Onkologen gefällt werden, da das individuelle Risiko invasiver Interventionen nur von diesen umfassend beurteilt werden kann.

\subsection{Besucher}

Besonders für Kinder und Jugendliche und für langfristig protektiv isolierte Patienten sind Besuche von erheblicher emotionaler Bedeutung. Durch Kontakte zu Besuchern besteht jedoch für Patienten mit Immunschwäche prinzipiell die Möglichkeit der Übertragung kontagiöser Infektionskrankheiten (zum Beispiel Varizellen, Masern, Keratokonjunktivitis durch Adenoviren). Dies ist jedoch auch beim Kontakt zum Behandlungsteam (Ärzte, Schwestern, Physiotherapeuten und so weiter) der Fall.

Besondere Berücksichtigung erfordert in diesem Kontext neben zahlreichen anderen viralen Erregern von Atemwegsinfektionen das Respiratory Syncytial Virus (RSV) [127], das bei hochgradig immun- supprimierten Patienten schwere Infektionen der tiefen Atemwege bis zum ARDS auslösen kann [128, 129]. Typischerweise geht ein nosokomialer Ausbruch mit RSV auf einer Transplantationseinheit von infizierten Familienmitgliedern oder Mitarbeitern aus. Die Letalität der RSV-Infektion beträgt bei Patienten in der akuten Phase einer allogenen Stammzelltransplantation bis $80 \%$ [128].

\subsection{Medizinisches Personal (einschließlich Physio- therapeuten, MTAs)}

Nach wie vor ist die Kreuzinfektion von Patienten durch kontaminierte Hände eine der wichtigsten Ursachen nosokomialer Infektionen [130] und hierbei gibt es ein erhebliches Potenzial zur Verbesserung der Compliance beim Behandlungsteam [131].

Barrieren bei der Umsetzung von Standardhygienemaßnahmen, die auch dem Schutz des Personals dienen, sind Überlastung, Unterbesetzung, schlechtes Design der Einrichtungen sowie zu komplizierte, nicht verständliche Präventionsstandards. Oft wird nicht genug Fachpersonal für Hygiene und Infektionsverhütung beschäftigt [131, 132].

Mitarbeiterinnen und Mitarbeiter, die selbst Symptome einer möglicherweise ansteckenden akuten Erkrankung zeigen (Fieber, Atemwegsinfektion, Infektion der Haut, insbesondere im Bereich der Hände, unklares Exanthem, Diarrhö) oder bekanntermaßen mit multiresistenten Erregern besiedelt sind, können eine Infektionsquelle für die immunsupprimierten Patienten darstellen [121]. In diesem $\mathrm{Zu}$ sammenhang ist die Übertragung von Bordetella pertussis [133], Salmonella spp. [134] und MRSA [135] durch besiedelte bzw. infizierte Mitarbeiter auf immunsupprimierte Patienten beschrieben worden.

\subsection{Lebensmittel, keimarme Kost}

Besonders kritisch sind in diesem $\mathrm{Zu}$ sammenhang nicht ausreichend erhitztes Fleisch und Rohmilchprodukte sowie Lachs und andere geräucherte Fischsorten, weil sie mit klassischen Erregern von Lebensmittel-assoziierten Infektionen wie Salmonellen, Campylobacter, Shigellen,
EHEC 0157, Yersinien, Lamblien, Cryptosporidien $[136,137,138]$ oder mit opportunistischen Krankheitserregern (P. aeruginosa, Burkholderia cepacia, Listeria monocytogenes, Vancomycin-resistenten Enterokokken, Toxoplasma gondii) $[139,140$, 141, 142, 143, 144, 145, 146, 147] und Fadenpilzen (Aspergillus spp. und andere) kontaminiert sein können.

Auch Gewürze $[148,149]$ und Teeblätter $[150,151]$ können mit Krankheitserregern behaftet sein. Bei einigen Lebensmitteln werden Edelpilze zur Herstellung genutzt (Kefir, Schimmelkäse, spezielle Wurstsorten). Deren Bedeutung als Auslöser Lebensmittel-assoziierter Infektionen ist jedoch bislang nicht bewiesen. Besonders als gesund angesehene „Bioprodukte“, wie zum Beispiel selbst gezogene Sprossen („Keimlinge“) oder ungeputztes rohes Gemüse sowie „Bio-Brot“ aus unbehandeltem Getreide, können in erheblichem Ausmaß mit Krankheitserregern kontaminiert sein.

Bei hochgradig immungeschwächten Patienten können die Grunderkrankung und deren Therapie gravierende Einschränkungen gastrointestinaler Abwehrmechanismen zur Folge haben. Theoretisch ist vorstellbar, dass fakultativ pathogene oder opportunistische Mikroorganismen, die über Lebensmittel in den Darm des Patienten gelangen, in Phasen der ausgeprägten Immunsuppression bei gestörter Kolonisationsresistenz (zum Beispiel durch den Einsatz von Antibiotika) zum Auslöser lokaler oder systemischer Infektionen werden $[152,153,154,155]$.

Durch die Vorschädigung der gastrointestinalen Schleimhäute und gestörte Abwehrmechanismen haben immunsupprimierte Patienten bei akuter Infektion mit Gastroenteritiserregern (zum Beispiel Norovirus, Rotavirus, Campylobacter $s p p$.) ein höheres Risiko schwerwiegender Komplikationen (höhergradige Dehydratation, Elektrolyt- und Eiweißverluste, gastrointestinale Blutungen, sekundäre Sepsis) und scheiden den Erreger über einen längeren Zeitraum aus [136, 137, 156, 117, 118]. Infizierte Patienten können zum Indexpatienten eines nosokomialen Ausbruchs werden (zu den „Anforderungen an die Hygiene bei der Lebensmittelversorgung und ihre Qualität“ in Gesundheitseinrichtungen [157]). 
Andererseits erfordert die bei einem Teil der Patienten vorliegende Mangelernährung mit Gewichtsverlust bei konsumierender Erkrankung, Störung des Appetits, Veränderung des Geschmacksempfindens, Schmerzen und Übelkeit, besondere Bemühungen zur Verbesserung der Ernährungssituation. Allzu restriktive Verhaltensregeln im Bereich der Nahrungsmittelauswahl und -zubereitung beeinträchtigen die Lebensqualität der Patienten erheblich und können zu einem anhaltenden Konflikt innerhalb von Familien führen. Patienten, die restriktive Diätvorschriften nicht einhalten, dies jedoch gegenüber dem Behandlungsteam verheimlichen, sind dem zusätzlichen Risiko ausgesetzt, dass die Quelle einer exogenen Infektion nicht rechtzeitig erkannt und beseitigt wird.

Die meisten Zentren verabreichen $\mathrm{Pa}$ tienten mit Leukozytenzahlen $<1 \times 10^{9} / 1$ in infektionspräventiver Absicht spezielle Diäten [155]. In der Mehrzahl der Fälle wird den Patienten geraten, den entsprechenden Vorsichtsmaßnahmen auch zu Hause nachzukommen [158]. In verschiedenen Umfragen ergab sich eine erhebliche Variabilität der jeweiligen Empfehlungen, die wahrscheinlich auf dem Mangel an überzeugenden epidemiologischen oder klinischen Daten beruht $[159,160$, $161,162]$.

Dementsprechend kann es durchaus vorkommen, dass Ärzte, Schwestern oder Pfleger voneinander abweichende Empfehlungen ausgeben, was zu einer erheblichen Verunsicherung der Patienten und ihrer Familien führen kann.

Vergleichende Studien aus den Anfängen der Transplantationsmedizin, in denen KMT-Patienten in sogenannten sterilen „Life Island Units“ (total protective environment) betreut wurden, lassen keinen Schluss auf den speziellen Nutzen restriktiver Diäten zu, weil die Diätvorschriften nur Teil eines komplexen Regimes zur Verringerung der Exposition gegenüber Krankheitserregern waren und die Patienten alle eine selektive Darmdekontamination mit nicht-resorbierbaren Antibiotika erhielten [163].

Neben einer sterilen (meist autoklavierten) Kost [2, 164], deren Einsatz wegen des schlechten Geschmacks an schlechter Patientencompliance scheitert, gibt es weitere modifizierte Diäten für $\mathrm{Pa}$ tienten unter einer intensiven Chemotherapie [163], zum Beispiel die „Low bacterial (low microbial) diet" mit Nachweis von $<500$ CFU von Bacillus spp. pro g beziehungsweise pro $\mathrm{cm}^{3}$ [164].

\subsection{Wasser}

\subsubsection{Wasser für den menschlichen Gebrauch}

Wasser für den menschlichen Gebrauch kann grundsätzlich über

- den Ingestionsweg (Trinken),

- den Inhalationsweg (Einatmen),

- den direkten beziehungsweise indirekten Kontakt (zum Beispiel bei Waschen oder Betrieb medizinisch-technischer Geräte) zur Übertragung von Krankheitserregern führen.

Wasser für den menschlichen Gebrauch (hier vor allem: Trinkwasser) ist nicht keimfrei. Die nach der Trinkwasserverordnung vorgeschriebenen Untersuchungen zeigen mit den Indikatoren E. co$l i$, coliformen Bakterien und Enterokokken nur das mögliche Vorkommen eines eingeschränkten Spektrums von Krankheitserregern an, die zum Beispiel über Fäkalien in das Wasser gelangen können. Fakultativ-pathogene Krankheitserreger, die zu NI bei Immunsupprimierten geführt haben und im Trinkwasser nachgewiesen wurden $[141,165,166,167,168,169$, 170, 171, 172], wie Legionellen [173, 174, 175, 176], Pseudomonaden und andere nicht fermentierende Bakterien [177, 178, 179, 180], nicht-tuberkulöse Mykobakterien (NTM) $[181,182,183]$ sowie Protozoen [184], werden durch diese Indikatoren nicht erfasst.

Die Trinkwasserverordnung ist auf den Schutz der gesunden Allgemeinbevölkerung ausgerichtet und nicht auf einen ausreichenden Schutz hochgradig immungeschwächter Patienten. Die Bedeutung von Wasser als Quelle von invasiven Pilzinfektionen (zum Beispiel invasive Aspergillosen) wird kontrovers diskutiert [184, 185, 187, 188, 189, 19o]; diesbezüglich kann zurzeit noch keine Empfehlung abgeleitet werden.

Gut dokumentiert sind nosokomiale wasserassoziierte P. aeruginosa-, Legionella spp.-, Enterobacter cloacae-, Acine- tobacter spp.-, Serratia marcescens-, Burkholderia spp.- und Stenotrophomonas spp.Ausbrüche [179, 191, 192, 193, 194, 195, 196, 197]. Durch Einbeziehung vergleichender Untersuchungen von klinischen Isolaten von $P$. aeruginosa und von Wasserproben konnte die Bedeutung der Infektionsquelle Wasser eindeutig abgeklärt werden [198, 199, 200]. In bestimmten Einrichtungen mit kontaminierten Wasserinstallationssystemen können demnach bis zu 40\% der auf Intensivstationen auftretenden $P$. aeruginosa-Infektionen wasserassoziiert sein [201].

Immunsupprimierte Patienten können auf verschiedene Weise gegenüber Wasser-assoziierten Krankheitserregern exponiert sein:

- Trinken, Mundpflege, Mundspülung bei Mukositis,

- Zahnarztbesuch,

- Aspiration bei Schluckstörung,

- Einatmen kontaminierter Aerosole (zum Beispiel Legionellen),

- Körperwäsche, Baden, Reinigen von Kathetereintrittsstellen (zum Beispiel P. aeruginosa).

Das eigentliche Infektionsreservoir für die genannten fakultativ pathogenen $\mathrm{Mi}$ kroorganismen befindet sich in der Regel nicht im öffentlichen Wasserversorgungsnetz, sondern in der komplexen Trinkwasserinstallation von Gebäuden. Selten kommt es jedoch unter bestimmten ungünstigen Umständen vor, dass über das öffentliche Versorgungsnetz fakultativ pathogene Krankheitserreger (zum Beispiel Pseudomonas spp., Enterobacter spp., Cryptosporidien) in die Trinkwasserinstallation von Gebäuden eingeschwemmt werden.

Eine starke Vermehrung der genannten fakultativ-pathogenen Erreger findet zum Beispiel statt bei:

- Stagnation in der Trinkwasserinstallation oder in Entnahmestellen bei längerer Nichtbenutzung oder im Rahmen von Umbau- und Renovierungsmaßnahmen,

- zu niedriger Temperatur des zentralen Warmwasserspeichers,

- Biofilmbildung in Kunststoffleitungen, Kunststoffverbindungsstücken oder Perlatoren. 
Bei der Identifizierung der Herkunft beziehungsweise des Infektionsreservoirs in der Trinkwasserinstallation von Gebäuden wird zwischen einer systemischen Kontamination der Trinkwasserinstallation, einer teilzentralen Kontamination der Trinkwasserinstallation und einer Kontamination der Entnahmestelle (zum Beispiel Duschkopf, Strahlregler) unterschieden.

Die Kenntnis der zentralen Kontamination der Trinkwasserinstallation erhöht die Aufmerksamkeit der behandelnden Ärzte, wodurch die Diagnostik verbessert und damit die Detektionsraten von Legionellosen erhöht wurden [202, 203].

Mittelbar Wasser-assoziierte Infektionen können auftreten, wenn über das Wasser Medikamentenlösungen (zum Beispiel Saftzubereitungen), Antiseptika, Desinfektionsmittel, medizinisch-technische Geräte oder Reinigungsutensilien kontaminiert werden, was zu einer Weiterübertragung von Mikroorganismen auf den Patienten führen kann.

Eine Aussage, ab welcher Konzentration die genannten Erreger für immunsupprimierte Patienten krankheitsrelevant sind, ist nicht möglich. Daher muss durch gezielte Präventionsmaßnahmen einschließlich der Überprüfung des Trinkwasserinstallationssystems, die Wahrscheinlichkeit der Übertragung Wasserassoziierter Krankheitserreger auf den hochgradig immunsupprimierten $\mathrm{Pa}$ tienten gesenkt und der Gebrauch von Wasser ungesicherter mikrobiologischer Qualität vermieden werden.

Immunsupprimierte Patienten sind durch aus der öffentlichen Wasserversorgung eingeschwemmte weitere Krankheitserreger wie Parasiten (zum Beispiel Cryptosporidien), Viren (zum Beispiel Noroviren) stärker gefährdet als die gesunde Normalbevölkerung. Bei einem Trinkwasser-assoziierten Cryptosporidien-Ausbruch in Milwaukee, Wisconsin (1993), wurden 1\% aller betroffenen Patienten (zirka 4400 von 400.00o) hospitalisiert. Unter diesen machten mit 52\% Menschen mit Immunsuppression (exklusive der Patienten mit AIDS) den größten Anteil aus (mittlere Kosten des stationären Aufenthaltes U.S. \$5520, mittlere Liegedauer 7 Tage).
Parallel kam es zu einer dramatischen Zunahme der Todesfälle, bei denen die Cryptosporidien-Infektion unter den Todesursachen zumindest als signifikanter Kofaktor mit aufgeführt wurde. Die Mehrzahl der verstorbenen Patienten waren Patienten mit HIV-Infektion im Stadium AIDS [204, 205].

Vor diesem Hintergrund erscheint es angemessen, zukünftig mehr auf die Art der Trinkwasserversorgung immunsupprimierter Patienten zu achten.

Bei Wasser-assoziierten P. aerugino$s a$-Ausbrüchen auf Intensivstationen beziehungsweise auf hämatologisch-onkologischen Stationen mit kontaminierten Wasserinstallationen konnte durch endständige Sterilwasserfilter eine Beendigung des Ausbruches bzw. ein deutlicher Rückgang der Infektionen erzielt werden $[206,207]$, die auch andere wasserassoziierte Erreger sicher zurückhalten können. Experimentelle Untersuchungen bestätigen die Effizienz von endständigen Filtern, wenn sie sachgerecht eingesetzt werden $[208,209,210]$.

\subsubsection{Wasser zum Trinken anderer Herkunft als Leitungswasser}

Hierunter wird natürliches Mineralwasser, Quellwasser und Tafelwasser sowie sonstiges in zur Abgabe an den Verbraucher bestimmte Fertigpackungen abgefülltes Trinkwasser verstanden. Hierunter fällt auch Wasser aus sogenannten „Trinkbrunnen“, das heißt technischen Anlagen, die an das Kaltwassernetz der Trinkwasser-Hausinstallation angeschlossen werden und das Wasser durch Kühlung und Karbonisierung in seinen geschmacklichen Eigenschaften verfeinern, um es $\mathrm{Pa}$ tienten alternativ als Getränk zum Beispiel unter den Bezeichnungen „Wasser ohne Zusatz von Kohlensäure“ und „Wasser mit Zusatz von Kohlensäure“ anbieten zu können (siehe auch: Deutsche Gesellschaft für Krankenhaushygiene: Empfehlung zur Errichtung und Betrieb von Trinkbrunnen zum Anschluss an die Trinkwasserinstallation in Krankenhäusern, Reha-Kliniken, Altenpflegeheimen und vergleichbaren Einrichtungen) [208, 211].

Mineral- und Tafelwasser ebenso wie Wasser aus Trinkbrunnen werden nur auf ein begrenztes Spektrum von Mikro- organismen untersucht, ohne dass hierdurch zum Beispiel Campylobacter spp., Viren oder Parasiten erfasst sind. Unter bestimmten Umständen kann die bakteriologische Qualität von abgefülltem Mineralwasser beeinträchtigt sein, wie unter anderem Untersuchungen zu sogenannten nicht-tuberkulösen Mykobakterien zeigen $[212,213]$.

Untersuchungen von Trinkbrunnen in Krankenhäusern ergaben im Vergleich mit Mineralwasser statistisch signifikant häufiger den Nachweis von $P$. aeruginosa, Fäkalstreptokokken sowie Pilzen. Darüber hinaus ließen sich sowohl im Mineralwasser wie auch in Wässern von Trinkbrunnen in Krankenhäusern Legionellen nachweisen [208].

Campylobacter jejuni kann sich insbesondere bei niedrigen Temperaturen über mehrere Tage in abgepacktem natürlichem Mineralwasser halten [192]. Von Evans et al. [191] wurden epidemiologische Hinweise dafür gefunden, dass das Trinken von abgepacktem Wasser einen Risikofaktor für Campylobacter-Infektionen darstellt.

Eckmanns et al. [214] beschrieben einen nosokomialen $P$. aeruginosa-Ausbruch, der durch kontaminiertes abgepacktes „Stilles Wasser“ ausgelöst wurde. Dieses Wasser wurde zur Mundpflege verwendet.

Vor diesem Hintergrund ist die Frage keineswegs belanglos, welches Wasser hochgradig immunsupprimierten Patienten im Krankenhaus zum Trinken und zur Körperpflege zur Verfügung gestellt wird. Hier ergeben sich zusätzlich Aufgaben für das mikrobiologische Monitoring und die Notwendigkeit einer gezielten Prävention Wasser-assoziierter Infektionen in Hochrisikoeinheiten (siehe Kapitel 3).

\subsection{Luft}

Die invasive Aspergillose stellt eine der häufigsten und gravierendsten luftübertragenen Infektionen bei Patienten mit ausgeprägter Immunschwäche dar. Invasive Aspergillosen der Anastomosenregion zwischen Trachea und Transplantat sind eine bekannte Komplikation nach Lungen- und Herz-Lungen-Transplantationen [215]. Aspergillus spp. können in 
Form von Konidien durch raumlufttechnische Anlagen ohne ausreichende Luftfilterung in die tiefen Atemwege gelangen und über die Alveolen oder auch direkt über den Tracheobronchialbaum in die Blutgefäße eindringen [216, 217].

Außer dem aerogenen Übertragungsweg liegen Berichte über andere Übertragungswege vor, zum Beispiel Kontaktübertragung über die Kleidung bei Verbrennungspatienten, traumatische Inokulation und Inhalation von Aerosolen beim Duschen $[188,189]$. Es erfolgt keine Übertragung von Mensch zu Mensch [216].

Es besteht weitgehender Konsens, dass invasive Aspergillosen bei prädisponierten Patienten zu einem bedeutenden Anteil exogenen Ursprungs sind. Gut belegt ist das gehäufte Auftreten nosokomialer Aspergillus-Infektionen im Zusammenhang mit

- Abriss-, Bau- und Renovierungsarbeiten in Krankenhäusern und ihrer Umgebung [218, 219, 220, 221, 222] (cave: Abhängen von Zwischendecken),

- durch das Aufwirbeln von verrottendem Laub (zum Beispiel Hubschrauberlandeplatz, Motorengebläse bei Reinigungs-, Garten- und Landschaftsarbeiten) in der Stationsumgebung [223],

- durch vor dem Ausbruch noch nicht identifizierte Reservoire in der Abteilung [224],

- durch Klimaanlagen ohne adäquate Luftfilterung [216].

Auch eine nur kurz andauernde Exposition gegenüber hohen Konzentrationen von Aspergillus-Sporen in der Atemluft kann bei hochgradig immungeschwächten Patienten eine invasive Aspergillose nach sich ziehen $[225,226]$. Ausbruchsanalysen zeigen, dass es nicht möglich ist, einen ungefährlichen Grenzwert (zum Beispiel $<10 \mathrm{KBE} / \mathrm{m}^{3}$ ) anzugeben [227].

Die invasive Aspergillose (IA) ist (wie auch andere invasive Pilzinfektionen) für den Patienten ein akut lebensbedrohliches Ereignis. Nach einer 2001 publizierten Übersicht lag die Gesamtletalität der IA bei $58 \%$; sie erreichte $87 \%$ bei akut allogen stammzelltransplantierten Patienten und $88 \%$ bei Befall des zentralen Nervensystems [228]. Trotz Einsatz des liquorgängigen Antimykotikums Voriconazol, in $38 \%$ kombiniert mit neurochirurgischen Maßnahmen, betrug die Letalität nach einer retrospektiven Analyse von 81 Patienten mit ZNS-Aspergillose immer noch $69 \%$ [229].

Ein Fünftel aller infektionsbedingten Todesfälle bei Kindern mit akuter lymphatischer Leukämie gingen auf das Konto invasiver Pilzinfektionen [15]; pädiatrisch onkologische Patienten mit akuter myeloischer Leukämie gelten als Hochrisikogruppe [16]. 10\% aller NI in der prospektiven „Onkopaed Studie“ waren gesicherte oder wahrscheinliche invasive Aspergillosen; die Letalität betrug insgesamt $19 \%[119,230]$. Besonders anfällig für die Entwicklung einer invasiven Aspergillose sind Patienten in der Induktionstherapie bei akuten Leukämien oder bei myelodysplastischem Syndrom [231] und Patienten nach allogener Stammzelltransplantation [232, 233, 234].

Entscheidender Beweggrund für eine spezielle raumlufttechnische Ausstattung von stationären Behandlungseinheiten für Patienten mit hochgradiger Immunsuppression ist somit das Risiko von nosokomial aerogen erworbenen invasiven Pilzinfektionen [174, 235, 236, 237, 238, 239, 240, 241].

Nach Möglichkeit werden Patienten der Risikogruppe 3 mit dem höchsten Risiko für invasive Fadenpilzinfektionen auch jetzt schon in Behandlungseinheiten mit besonderer Klimatechnik untergebracht, in denen die Konzentration von Aspergillus-Sporen (gemessen mit einem geeigneten Gerät, zum Beispiel einem Anderson Sampler, mindestens $1000 \mathrm{Li}-$ ter [227]) unter $1 \mathrm{KBU}$ pro $\mathrm{m}^{3}$ Luft beträgt $[13,234,242,243]$. Dies gilt auch außerhalb von Ausbruchsituationen [244].

Es gilt als gesichert, dass die konsequente Unterbringung in Einheiten mit hocheffektiver (HEPA-)Luftfilterung gegenüber einer Behandlung auf normalen Pflegestationen die Inzidenz invasiver Aspergillosen reduziert [174, 220, 221, 245, 246, 247]. Die Kosten für die Ausstattung stationärer Einrichtungen mit solchen Anlagen und für deren Instanderhaltung führen dazu, dass ihre Notwendigkeit immer wieder angezweifelt wird. Dabei wird betont, dass es hierzu bislang keine aussagekräftigen prospektiv randomisierten, doppelblinden Studien gibt, sondern lediglich Fall-Kontroll-Studien und Interventionsstudien bei Ausbrüchen [232, 233, 234, 248, 249].

Doppelblinde prospektiv randomisierte Studien zu dieser Frage sind ethisch nicht vertretbar, weil in einer solchen Studie Patienten mit hohem Risiko für eine potenziell tödliche Infektion bewusst exponiert werden müssten.

Die verfügbare Evidenz reicht nach Auffassung der Kommission aus, Empfehlungen zur nichtmedikamentösen Prävention solcher Infektionen auszusprechen.

\section{Zusätzliche Hinweise [250]}

Zurzeit steht nur für einen kleinen Teil aller Patienten mit signifikant erhöhtem Risiko (Risikogruppe 2 und 3) eine protektive Isoliereinheit mit HEPA-filtrierter Luft zur Verfügung.

Die Atemwege der Patienten (und die Nasennebenhöhlen) können bei Aufnahme in den geschützten Bereich bereits Aspergillus-Sporen enthalten; dies gilt gerade auch für Patienten, die bereits eine invasive Aspergillose der Atemwege durchgemacht haben [251, 252].

Patienten, die ihre Isoliereinheit verlassen müssen (zum Beispiel zu diagnostischen Maßnahmen), benötigen einen effektiven Atemschutz außerhalb ihrer Isoliereinheiten [235, 253]. Der Nutzen von $\mathrm{FFP}_{2}$-Atemschutzmasken in diesem Kontext ist nicht bewiesen und überhaupt nur dann anzunehmen, wenn es sich um passgenau sitzende Masken handelt, die kontinuierlich getragen werden.

Die Frage „Wie können Patienten geschützt werden, die sich in ambulanter Behandlung befinden?" ist derzeit nicht geklärt.

Aus diesen Überlegungen ergeben sich - neben der Notwendigkeit einer in Zukunft besseren Ausstattung von stationären Behandlungseinheiten für Hochrisikopatienten - Indikationen für eine medikamentöse Prophylaxe invasiver Schimmelpilzinfektionen, die nicht Gegenstand dieser Empfehlung sind. 
Tab. 4 Infektionserreger, die bei Zoonosen isoliert werden

\section{Bakterien}

Bartonella henselae (Katzenkratzkrankheit,

Peliosis hepatis, bazilläre Angiomatose)

Campylobacter jejuni (Schweine, Kälber,

Tierfutter)

Capnocytophaga canimorsus (Hundebisse

und Kratzverletzungen)

Chlamydophila psittaci (Papageienkrankheit,

Psittakose)

Clostridium difficile (Hunde, Pferde et cetera)

Coxiella burnettii (Q-Fieber, Inhalation)

Enterohämorhagische E. coli (Kälber,

Schweine)

Leptospiren (Ratten, andere Nagetiere)

MRSA (Hunde, Pferde, Schweine)

Mycobacterium marinum (Aquarien)

Pasteurella multocida (Hundebisse)

Rhodococuus equi (Pneumonieerreger, Pferde et cetera)

Salmonella spp. (Schweine, Hühner, Kälber,

Reptilien, Schildkröten, Hunde, Katzen, Tier-

futter)

Streptobacillis moniliformis (Bissverletzungen,

Mäuse, Ratten)

Toxoplasma gondii (Katzen)

Yersinia enterocolitica (Schweine, Rinder,

Tierfutter)

Francisella tularensis (Tularämie, Kontakt zu

Wildhasen)

Parasiten

Cryptosporidium parvum, Cryptosporidium

hominis (Kälber, Lämmer, Hunde)

Giardia lamblia (Kälber, Lämmer), Toxoplasma

gondii (Katzen)

Pilze

Cryptococcus neoformans (Tauben)

Malassezia pachydermatis [426]

Sporothrix schenckii (Aquarien)

Viren

Lymphozytäre Choriomeningitis-Virus

(LCMV) (Mäuse, Meerschweinchen, Hamster)

\subsection{Umgebungsflächen, Gegenstände des täglichen Lebens}

Die Übertragung von Krankheitserregern erfolgt neben der oralen und inhalativen Aufnahme häufig durch direkten Kontakt mit kontaminierten Oberflächen. Die meisten Erreger nosokomialer Infektionen (Bakterien, Viren und Pilze) können in der unbelebten Umgebung des $\mathrm{Pa}$ tienten überdauern und außerhalb des menschlichen Organismus infektiös bleiben $[254,255,256]$.

Vielerorts werden für protektiv isolierte Patienten Notebooks (Laptop-Computer) mit Internetverbindung vorgehalten, um die Lebensqualität während der Iso- lierung zu verbessern. Zum Teil bringen die Patienten ihre eigenen Notebooks mit ins Krankenhaus. Hier besteht die Möglichkeit der Übertragung von Infektionserregern über Handkontaktflächen, vor allem, wenn Notebooks konsekutiv von verschiedenen Patienten genutzt werden $[257,258,259,260,261]$.

\subsection{Sanitärbereich}

Unter Einbeziehung von molekularen Typisierungsverfahren wurden Wasserhähne und Strahlrichter als Infektionsreservoire für $P$. aeruginosa beschrieben [262]. Auch elektronisch gesteuerte berührungslose Wasserarmaturen sind als mögliche Quelle für P. aeruginosa und Legionellen beschrieben worden [263]. Überläufe und Abflüsse von Waschbecken sind Infektionsreservoire für eine Vielzahl von Enterobacteriaceae und anderen gramnegativen Mikroorganismen. Beschrieben werden Ausbrüche durch E. cloacae, P. aeruginosa, A. baumannii und Serratia spp. $[141,166,264]$. Duschen beziehungsweise Duschköpfe sind in der Literatur mehrfach als Reservoire für Infektionserreger beschrieben worden $[265,266,267,268]$. Beim Spülvorgang der Toilette können kontaminierte Aerosole entstehen, die zu einer Weiterverbreitung von Krankheitserregern führen, wenn der Toilettendeckel nicht geschlossen wurde [269, 270].

\subsection{Tierkontakte}

Haus- und Nutztiere können für Menschen in Belastungssituationen eine wichtige emotionale Stütze sein. Bei Patienten mit Immunschwäche ist abzuwägen, welche Risken durch Tierkontakte (natürlich außerhalb des Krankenhauses) entstehen können [41, 271]. Neben Biss- und Kratzverletzungen sind vom Tier auf den Menschen übertragbare Infektionen (Zoonosen; Auswahl in $\bullet$ Tab. 4) ein zu beachtendes Risiko [272, 273].

Ein besonders hohes Risiko geht dabei von Jungtieren aus, die selbst erst zahlreiche Infektionen durchmachen, ohne dabei immer Symptome einer Erkrankung zu zeigen. Sehr junge Tiere zeigen zudem oft noch kein gefestigtes Verhalten, sodass nicht nur höhere Infektionsraten, sondern auch ein höheres Kontami- nationspotenzial für das häusliche Umfeld das Risiko der Übertragung steigert [274]. Zoonosen durch darmpathogene Erreger wie Salmonellen, Campylobacter spp. und Yersinien verursachen bei Immunsupprimierten deutlich häufiger Bakteriämien (bis zu 70\%) und sekundäre septische $\mathrm{Ab}$ siedlungen [275].

Weitere beschriebene Übertragungswege hängen mit der Versorgung von Haustieren zusammen. Risiken entstehen zum Beispiel durch Aerosolisierung von Erregern (Cryptococcus spp.) aus dem Kot beim Säubern von Käfigen [276, 277], beim Reinigen von Aquarien (Mycobacterium marinum) [273] und durch Zubereitung von Frischfutter (zum Beispiel Salmonellen, Campylobacter spp., Listerien, Schimmelpilze, Toxoplasmen) [273, 275, 278, 279, 280, 281, 282]. Empfehlungen zur Auswahl geeigneter Tiere können daher das Zoonoserisiko senken [274].

Von Tier zu Mensch übertragbare Infektionskrankheiten verursachen ein komplexes Spektrum von Erkrankungen [273], die bei immunsupprimierten $\mathrm{Pa}$ tienten auch atypisch verlaufen können [275]. Das Behandlungsteam muss daher wissen, ob der Patient in seinem häuslichen Umfeld regelmäßig Kontakt zu bestimmten Tieren hat, um die Patienten gezielt über geeignete Präventionsmaßnahmen aufklären zu können.

\section{Prävention}

\subsection{Schulung der Patienten und ihrer Angehörigen}

Patienten und Angehörige (sowie in begrenztem Umfang auch Besucher, siehe Hinweise zur Besucherregelung) müssen schon in den ersten Tagen nach der Diagnosestellung anhand konkreter Beispiele über Infektionsrisiken und über die erforderlichen Präventionsmaßnahmen informiert werden.

Die konkrete Durchführung der Händedesinfektion sowie die Pflege von Haut und Schleimhaut sind hier besonders hervorzuheben. Unterstützend sollten Merkblätter eingesetzt werden, die gegebenenfalls in die Muttersprache des Patienten übersetzt werden müssen.

Die Patienten müssen lernen, Fieber als ein Alarmsymptom zu interpretieren, 
das während der Phase der Granulozytopenie immer eine sofortige Vorstellung in der onkologischen Abteilung und eine antibakterielle Therapie erforderlich macht. Die Informationsvermittlung muss dem Lebensalter, den intellektuellen Möglichkeiten, dem Sprachverständnis und der Risikoperzeption des Patienten angepasst erfolgen. Widersprüchliche Aussagen in nerhalb des Behandlungsteams müssen unbedingt vermieden werden.

Die frühestmöglich beginnende Schulung von Patienten, Angehörigen und Besuchern in Bezug auf die konsequente Umsetzung von Standardhygienemaßnahmen und die Vermeidung spezieller Expositionen wird empfohlen (Kat IB).

\subsection{Anforderungen an die Besucherregelung (Kat IB)}

Auf die besondere Bedeutung und die korrekte Durchführung der Händedesinfektion sind die Angehörigen und jeder Besucher so früh wie möglich hinzuweisen (auch: Ablegen von Schmuck und Uhren, die sich an Fingern, Händen und Unterarmen befinden).

Die schriftlich vom Behandlungsteam festgelegte Besucherregelung sollte erläutern, dass von bestimmten Erkrankungen, die sich zum Zeitpunkt des Besuches möglicherweise noch in Inkubation befinden, besondere Risiken für die Patienten ausgehen und wie wichtig der vollständige und gegebenenfalls geboosterte Impfschutz der Angehörigen (Kinder nach STIKO-Empfehlung) für den Patienten sein kann (Herdenimmunität) [133, 283, 284, 285, 286, 287, 288, 289].

Angehörige/Besucher mit Zeichen einer akuten Infektion (zum Beispiel Fieber, Diarrhö, Atemwegsinfektion mit Husten und Fließschnupfen, unklares Exanthem, Konjunktivitis) sollten von einem Besuch ausgeschlossen werden.

Je offener die Kommunikation zwischen Behandlungsteam und Angehörigen über diese Thematik ist, desto eher werden die Kontaktpersonen sich vorab erkundigen, ob ein Besuch vor dem Hintergrund einer möglichen Ansteckung angemessen ist oder nicht.

Bei Anzeichen einer Atemwegsinfektion im Sinne eines leichten Infekts der oberen Luftwege und bei Herpes labialis müs- sen Besucher zusätzlich zur sorgfältigen Händedesinfektion einen Mund-NasenSchutz (MNS) tragen [121]. Auch Kinder sollten ihrem Alter angemessen in die hygienische Händedesinfektion eingewiesen werden, die gegebenenfalls von den Angehörigen beziehungsweise vom Pflegepersonal beaufsichtigt wird.

Besucherkinder müssen sich in der Nähe der Eltern aufhalten und werden von den Eltern (nicht vom Pflegepersonal) beaufsichtigt. Ein orientierendes „klinisches Screening “ aller Kinder vor Betreten der Station wird vielerorts vereinbart.

Wenn die Eltern wirklich verstanden haben (bei sprachlichen Barrieren ist eine muttersprachliche Übersetzung unbedingt notwendig), wie sie sich verhalten müssen, und gelernt haben, das Behandlungsteam bei offenen Fragen vorab zu konsultieren, ist ein solches Screening außerhalb der Risikogruppe 3 nicht erforderlich.

- Der Ausschluss von klinisch gesunden Besuchern jeden Lebensalters, bei denen es keine Hinweise auf eine kontagiöse Erkrankung in Inkubation gibt, ist aus Gründen der Infektionsprävention außerhalb der Risikogruppe 3 nicht gerechtfertigt und sollte unterbleiben, weil dieses Vorgehen zu einer zusätzlichen Einschränkung der Lebensqualität von Patienten mit Krebserkrankungen führt.

- Alle Besucher sollten schon vor dem ersten Kontakt zum Patienten in die Händedesinfektion eingewiesen werden und sich vor jedem Kontakt zum Patienten die Hände desinfizieren (Kat IA).

- Die Angehörigen des Patienten sollten zusätzlich über spezielle Infektionsrisiken in einem Merkblatt aufgeklärt werden (Kat IB).

- Für das Tragen von Besucherkitteln oder einer speziellen Bereichskleidung für Besucher außerhalb der Risikogruppe 3 gibt es derzeit keinen Beleg für einen infektionspräventiven Nutzen (Kat III).

- Besucher mit nicht-fieberhaften Infektionen der oberen Luftwege („Erkältung“) oder mit Herpes labialis müssen zusätzlich zur sorgfältigen Händedesinfektion einen MundNasen-Schutz anlegen (Kat II).

\subsection{Immunprophylaxe}

Die aktive Immunisierung immunsupprimierter Patienten ist Gegenstand einer eigenen Empfehlung der STIKO [290]. Sowohl beim Patienten selbst als auch bei den Angehörigen ist in Abhängigkeit vom Ausmaß der Immunsuppression auf eine vollständige Immunisierung nach den Empfehlungen der STIKO zu achten.

Besonders wichtig ist der vollständige Impfschutz nach STIKO-Empfehlung auch bei medizinischem Personal, das in engem Kontakt zu immunsupprimierten Patienten tätig ist.

\subsection{Standardhygienemaßnahmen}

Bei der Behandlung von hochgradig immunsupprimierten Patienten besteht die unbedingte Notwendigkeit, Standardhygienemaßnahmen (siehe Definition) konsequent umzusetzen. Dies gelingt nicht, wenn es in einer Abteilung zu viele unterschiedliche Vorgehensweisen gibt, die nach Gutdünken der gerade zuständigen Mitarbeiter zum Einsatz kommen. Daher sollte sich das Behandlungsteam in Absprache mit dem Hygienefachpersonal auf bestimmte, einheitliche Vorgehensweisen einigen, die für alle (auch für Ärzte, Oberärzte und Chefärzte, Konsiliarärzte, Physiotherapeuten und so weiter) verbindlich sind.

- Das gesamte Behandlungsteam muss in Bezug auf die Inhalte der Empfehlungen der KRINKO zur Händehygiene [31] sorgfältig geschult sein und diese konsequent umsetzen (Kat IA).

- Die Einweisung neuer Mitarbeiter, der Patienten sowie der Angehörigen und Besucher in die Bedeutung und Praxis der Händehygiene wird empfohlen. Weiterhin wird die mindestens einmal jährlich stattfindende Schulung des gesamten Teams zur Händedesinfektion und die Überprüfung der Compliance empfohlen (Kat IA).

- Auf Stationen, auf denen immunsupprimierte Patienten behandelt werden, müssen in ausreichender Zahl patientennahe Spender zur Händedesinfektion mit Mitteln mit geeignetem Wirkungsspektrum verfügbar sein (Kat IB). 
- Geeignete Schutzkleidung (Schürzen, Kittel) soll ausschließlich patientenbezogen zur Eindämmung bestimmter übertragbarer Infektionserreger und generell bei der Pflege von Patienten mit Diarrhö oder großflächigen Wunden getragen werden (Kat IB).

- Es ist nicht erforderlich, dass Personal oder Besucher beim Betreten der Station zusätzlich zur Händedesinfektion einen Schutzkittel anlegen (Kat IB).

- Für Stationen, auf denen Patienten der Risikogruppe 2 und 3 behandelt werden, wird dem medizinischen Personal, das in die Behandlung und Pflege der Patienten unmittelbar involviert ist, das Tragen von Bereichskleidung empfohlen, die vom Arbeitgeber sachgerecht aufbereitet wird (Kat II).

- Zusätzlich ist bei Patienten, die zur Risikogruppe 3 gehören und daher protektiv isoliert werden, der Einsatz keimarmer patientenbezogener Schutzkittel zu empfehlen (Kat II).

- Es gibt derzeit keine Evidenz für den infektionspräventiven Nutzen eines MNS (Kat III) außer zur Prävention von Tröpfcheninfektionen (Kat IB).

- Ein MNS wird (außerhalb der protektiven Isolierung in Risikogruppe 3) nur gezielt zur Prävention von Tröpfcheninfektionen eingesetzt (sowohl bei engem Kontakt zu kontagiösen Patienten als auch bei Mitarbeitern mit Infekten der oberen Luftwege oder Herpes labialis) (Kat IB).

- Patienten aus Risikogruppe 2 und 3 , die außerhalb der Station innerhalb des Krankenhauses oder im freien Klinikgelände Bereiche mit erhöhtem Risiko einer Aspergillus-Exposition passieren müssen, kann eine $\mathrm{FFP}_{2}$ Atemschutzmaske mit Ausatemventil angeboten werden; ein eindeutiger Vorteil ist jedoch nicht belegt [291] (Kat III).

- Mitarbeiterinnen und Mitarbeiter, die selbst an einer potenziell infektiösen akuten Erkrankung leiden (zum Beispiel Fieber, Atemwegsinfektion mit Fließschnupfen oder häufigem Husten, Infektion der Haut, insbesondere im Bereich der Hände, unklares Exanthem, Diarrhö) oder bekanntermaßen mit MRSA besiedelt sind, dürfen nicht in der Pflege von Patienten mit Immunschwäche eingesetzt werden (Kat IB).

\subsection{Reinigung und Desinfektion}

Hierzu wird auf die KRINKO-Empfehlung zu den „Anforderungen an die Hygiene bei der Reinigung und Desinfektion von Flächen“ verwiesen [38].

- Die Umsetzung der Anforderung der oben angegebenen KRINKO-Empfehlung ist in der Praxis nur möglich, wenn der gesamte Ablauf (unabhängig vom Thema Krankenhauszertifizierung) einem strukturierten Qualitätsmanagement unterliegt, in dessen Entwicklung das Hygienefachpersonal und das Behandlungsteam eingebunden werden (Kat IB).

- Um den besonders hohen Anforderungen dieser Abteilungen genügen zu können, muss vom Hygienefachpersonal geschultes Reinigungspersonal mit angemessener Stundenzahl zur Verfügung stehen, das spezielle Instruktionen des Behandlungsteams sowohl verstehen als auch umsetzen kann (Kat IB).

\subsection{Anteil und Ausstattung von Zimmern zur Isolierung}

- Aufgrund des insgesamt deutlich erhöhten Bedarfs an Isolierzimmern müssen auf einer Station, auf der Patienten der Risikogruppen 2 und 3 behandelt werden, mindestens $40 \%$ (besser 50\%) der Zimmer zur Isolierung (als Einzelzimmer nutzbares Zimmer mit eigenem Bad und Toilette mit entsprechenden Händedesinfektionsspendern und einem ausreichend groß dimensionierten Eingangsbereich, in dem Kittel, Handschuhe und MNS angelegt und vor Verlassen des Zimmers entsorgt werden können) genutzt werden können [292] (Kat IB).

\subsubsection{Protektive Isolierung}

- Granuolozytopenische Patienten der Risikogruppe 1 und 2 können bei sorgfältiger Beachtung der Standardhygienemaßnahmen in einem Zweibettzimmer mit eigenem Sanitär- bereich untergebracht werden [293] (Kat II).

- Da in der pädiatrischen Onkologie sehr häufig aus medizinischen Gründen Mütter oder Väter (allgemein: Begleitpersonen) mit aufgenommen werden müssen, sind die Krankenzimmer dort so zu dimensionieren, dass neben dem Bett des Patienten ein Klappbett aufgestellt werden kann, ohne dass die Pflege des Kindes (vor allem im Nachtdienst) hierdurch unverhältnismäßig erschwert wird oder zusätzliche Infektionsrisiken entstehen.

- Patienten der Risikogruppe 3 müssen in einem als Einzelzimmer nutzbaren Zimmer mit eigenem Sanitärbereich isoliert werden (zu den Anforderungen an die Raumluft siehe Abschnitt 3.9) (Kat IB).

\subsubsection{Isolierung bei Besiedlung oder Infektion mit kontagiösen Erregern}

- Patienten, die mit kontagiösen Infektionserregern infiziert sind oder diese asymptomatisch langfristig ausscheiden, werden in einem als Einzelzimmer nutzbaren Zimmer nach Barrierestandards isoliert, die sich aus dem Übertragungsweg des jeweiligen Erregers ergeben (Kat IB).

- Es ist aus krankenhaushygienischer Sicht zulässig, Patienten der Risikogruppe 1 und 2, die eine Infektion durch den gleichen Erreger aufweisen, zu kohortieren. Hier ist jedoch in der Risikogruppe 2 eine Abwägung des Einzelfalls durch die behandelnden Onkologen erforderlich (Kat II).

- In Abteilungen, die auf die Behandlung von Patienten mit Immunschwäche spezialisiert sind, sollte ein Zimmer verfügbar sein, das durch einen Schleusenbereich vom Rest der Station abgegrenzt ist und durch eine entsprechende raumlufttechnische Ausstattung (negativer Druck der Schleuse sowohl zum Patientenzimmer als auch zum Flur hin, Ableitung der Luft nach außen oder Filterung) die Isolierung von Patienten mit aerogen übertragbaren Infektionskrankheiten (zum Beispiel Varizellen, Masern, Tuberkulose) zulässt (Kat II). 


\begin{tabular}{|c|c|c|}
\hline $\begin{array}{l}\text { Mögliche Quellen Nahrungs- } \\
\text { mittel-assoziierter Infektionen }\end{array}$ & Nicht empfohlen & Empfohlen \\
\hline Fleisch inklusive Geflügel, Fisch & Roh oder nicht ausreichend erhitzt & Ausreichend erhitzt ${ }^{\mathrm{a}}$ (Fleisch im Kern weiß oder braun gebraten, Saft klar) \\
\hline Eier und Eiprodukte & Roh oder nicht ausreichend erhitzt & Pasteurisierte Eiprodukte, ausreichend gekocht (mindestens 8 Minuten) \\
\hline Milchprodukte wie Quark, Käse & $\begin{array}{l}\text { Produkte aus nicht pasteurisierter } \\
\text { Milch (Rohmilchprodukte) }\end{array}$ & Pasteurisierte oder ultrahoch-erhitzte Produkte \\
\hline Salat & Salatbar, frei zugänglich & Salat, der sorgfältig gewaschen und frisch zubereitet wurde ${ }^{b}$ \\
\hline Wasser/Eis & $\begin{array}{l}\text { Leitungswasser ungefiltert oder } \\
\text { nicht ausreichend erhitzt }\end{array}$ & $\begin{array}{l}\text { Mikrobiologisch kontrolliertes Mineralwasser in Flaschen (mit oder ohne Koh- } \\
\text { lensäure), Wasser nach 0,2 } \mu \text { m Filtration, ausreichend gekochter Tee (1 Minute } \\
\text { sprudelnd kochen) }\end{array}$ \\
\hline Getrocknete Gewürze, Pfeffer & & Gekocht/gebraten ${ }^{c}$ \\
\hline Früchte und Gemüse & & Gewaschen und geschält \\
\hline Nüsse & & Nur erhitzte, vakuumverpackte, geschälte Nüsse, schnell aufbrauchen \\
\hline Müsli & Großpackung für alle Patienten & $\begin{array}{l}\text { Kleine patientenbezogene Gebinde, maximal } 1 \text { Woche nutzen. In Risikogruppe } 2 \\
\text { und } 3 \text { autoklavierte Einzelportionen }\end{array}$ \\
\hline
\end{tabular}

Kein Patient darf aufgrund der Besiedlung oder Infektion mit einem kontagiösen Erreger eine qualitativ schlechtere medizinische Überwachung oder Behandlung erhalten. Dem Risiko einer reaktiven Depression oder eines Hospitalismus (vor allem bei Kindern) muss in diesem Kontext durch geeignete Maßnahmen begegnet werden, die außerhalb des Zuständigkeitsbereiches dieser Empfehlung in der Verantwortung des Behandlungsteams liegen.

\subsection{Lebensmittel}

Prinzipiell muss unterschieden werden zwischen

- der Krankenhausküche, für die besondere Anforderungen (gesetzliche Regelungen und Kontrollen) nach dem HACCP-Konzept gelten. Die Versorgung mit Lebensmitteln aus der Krankenhausküche ist somit nicht Gegenstand dieser Empfehlung.

- der Lagerung und Zubereitung von Lebensmitteln in einer Stationsküche mit Zugang für Patienten und Angehörige (pädiatrische Onkologie: „Elternküche"). Da die hier relevanten Empfehlungen auch für ambulante Behandlungsphasen zu Hause gelten, finden sich weitere detaillierte Hinweise im Kapitel 5.

- Wenn die Stationsküche (oder eine separate Küche im Stationsumfeld) auch von Patienten oder Angehörigen genutzt wird, muss hierfür vom Hygienefachpersonal und vom Behandlungsteam ein gemeinsames, hygieneorientiertes Organisationskonzept erstellt werden (Kat II).

- Für die Lagerung und Verabreichung von Sondenkost (Magensonde, Jejunalsonde, perkutane endoskopische Gastrostomie) und Formulanahrung (Säuglinge) wird die Erstellung eines schriftlich fixierten Hygienestandards empfohlen (Kat IB).

- Die Sicherheit von Probiotika bei immunsupprimierten Patienten wird kontrovers diskutiert (zum Beispiel wurden Bakteriämien durch Lactobacillus spp. oder Fungämien durch Saccharomyces spp. berichtet) [294, 295, 296, 297, 298, 299, 300, 301, 302, 303, 304, 305, 306, 307, 308]. Von der Verabreichung probiotischer Lebensmittel an immunsupprimierte Patienten wird abgeraten, solange keine ausreichenden Studien zur Sicherheit verfügbar sind (Kat IB) (• Tab. 5).

\subsection{Baulich-funktionelle Maßnahmen zur Gewährleistung des protektiven Umfeldes}

- Stationen und Spezialambulanzen, in denen Patienten mit Immunschwäche behandelt werden, sollten keine Durchgangsstationen/-bereiche zu anderen Stationen oder Ambulanzen sein, sondern baulich-funktionell von diesen getrennt liegen (Kat IB).
- Alle Oberflächen inklusive des Fußbodens müssen leicht $\mathrm{zu}$ reinigen und zu desinfizieren sein (Kat IB).

- Polstermöbel, Teppichböden und Topfblumen sind als Einrichtung ungeeignet [309] (Kat IB).

- Sanitärräume mit Waschbecken, Dusche und Toilette sollten in ausreichender Zahl vorhanden sein (in Risikogruppe 2 möglichst ein Sanitärraum für zwei Patienten, in Risikogruppe 3 ein Sanitärraum pro Patient) (Kat IB).

- Waschbecken sollen so konstruiert sein, dass sie freihändig bedient werden können, der Wasserstrahl nicht in den Ablauf zielt und kein Überlauf vorhanden ist (Kat II).

- Waschbecken sollten gegebenenfalls durch einen Spritzschutz so abgeschirmt werden, dass es nicht zu einer Kontamination der Umgebung durch Spritzwasser kommen kann (dies gilt insbesondere für Reinbereiche und Eingriffsräume) (Kat II).

- Sanitärräume müssen ausreichend beund entlüftet und desinfizierend gereinigt werden, damit sie nicht zum Reservoir für Schimmelpilze werden (Kat IB).

- In der Nähe von Abteilungen, die hochgradig immunsupprimierte Patienten behandeln, dürfen keine klinikeigenen Kompostierungsanlagen und keine Anlagen zur Müllverarbeitung liegen, da sie massenhaft 
Pilzsporen emittieren können [310] (Kat IB).

- In Risikogruppe 3 erfolgt eine desinfizierende Reinigung (Krankenhauswäsche) von Kopfkissen und Bettdecken nach jedem Patientenwechsel [309] (Kat IB).

- Matratzen beziehungsweise der Schonbezug müssen bei jedem Patientenwechsel desinfiziert werden (Kat IB).

\subsection{Anforderungen an die Raumluft}

- Patienten mit schwerer oder sehr schwerer Immunsuppression (Risikogruppe 2 oder 3 ) sollen während der stationären Therapie in Räumlichkeiten mit HEPA-gefilterter Luft (Filterklasse H13) zur Vermeidung von invasiven Aspergillosen/Fadenpilzinfektionen behandelt werden, die nach dem allgemein anerkannten Stand der Technik ausgelegt sind [247] (Kat IB).

- Wenn die Raumluft im angrenzenden Stationsflur nicht ebenfalls HEPAgefiltert (Filterklasse $\mathrm{H}_{13}$ ) ist, sollte das Zimmer zur protektiven Isolierung mit Schleuse und Überdruckbelüftung ausgestattet sein (Kat II).

- Ob ein Laminar Air Flow/eine turbulenzarme Verdrängungsströmung in diesem Kontext einen Vorteil bietet, ist eine ungelöste Frage (Kat III). Die HEPA-Filtration der Luft ist vorrangig (Kat IB).

- Es erscheint sinnvoll, bei Neubauten oder einer Kernsanierung nicht nur die Krankenzimmer, sondern ganze Stationen oder Stationsbereiche mit HEPA-gefilterter Luft zu versorgen, da offensichtlich auch kürzere intensive Expositionsepisoden ein relevantes Risiko bergen (Aufenthaltsraum, diagnostische Maßnahmen im Eingriffsraum außerhalb des Isolierzimmers und andere) und dann die soziale Isolierung der Patienten geringer ist (Kat II).

- In jedem Fall muss eine regelmäßige Wartung und Kontrolle der raumlufttechnischen Anlagen sichergestellt werden; die mikrobiologischen Kontrollen (vor allem die Bewertung der Ergebnisse) sollen in der Verant- wortung der Krankenhaushygieniker liegen (Kat IB).

- Sofern eine zentrale raumlufttechnische Anlage mit endständiger HEPA-Filtration nicht vorhanden ist, können vor allem auch zur Vermeidung einer Exposition durch Bau- und Renovierungsarbeiten dezentrale mobile oder fest installierte HEPA-Filtrationsgeräte in den Patientenräumen eingesetzt werden. Auch mit diesen Geräten kann bei entsprechender Anordnung im Isolierzimmer ein kontrollierter Überdruck erzeugt werden [216, 221, 311] (Kat II).

- Bei Verlassen des Zimmers können Patienten der Risikogruppe 2 oder 3 dicht anliegende partikelfiltrierende Atemschutzmasken (FFP 2 oder 3 mit Ausatemventil) verwenden [291, 312] (Kat III).

- Raumluftbefeuchter oder andere technische Geräte, die potenziell kontaminierte Aerosole emittieren, dürfen nicht verwendet werden (Kat IB).

\subsection{Anforderungen an die Wasserversorgung}

- Die mikrobiologische Qualität des Wassers in onkologischen Abteilungen, die immunsupprimierte Patienten behandeln, muss den Empfehlungen des Umweltbundesamtes nach Anhörung der Trinkwasserkommission entsprechen $[141,150,313,314$, 315] (Kat IB) und sollte sowohl dem Hygienefachpersonal als auch dem Behandlungsteam bekannt sein und bewertet werden (Kat IB).

- Art, Umfang und Häufigkeit der Wasseruntersuchungen übriger Wasserentnahmestellen auf der Station (unter anderem auf Legionellen, $P$. aeruginosa und gegebenenfalls andere nicht fermentierende Bakterien) sind in einem Wasser-Sicherheitsplan festzulegen; die Ergebnisse werden vom Hygienefachpersonal dokumentiert und vom Krankenhaushygieniker bewertet (Kat IB).

- Insbesondere bei Oberflächenwasserversorgung (Flusswasser und Talsperren) muss bei Grenzwertüberschreitung und Hinweisen auf eine Kontamination (entsprechend $₫ 9$ der
TrinkwV 2001) eine unverzügliche Information des zuständigen Krankenhaushygienikers beziehungsweise der für die Krankenhaushygiene Verantwortlichen seitens des Wasserversorgers in Abstimmung mit dem Gesundheitsamt sichergestellt werden (Kat. IV).

- Es muss sichergestellt werden, dass immunsupprimierte Patienten bei einer Kontamination des öffentlichen Wasserversorgungsnetzes mit Krankheitserregern zeitnah in den lokalen Medien (oder über die behandelnden Ärzte) entsprechend informiert und gegebenenfalls auf mögliche eigene Schutzmaßnahmen hingewiesen werden (entsprechend $\$ 9$ der TrinkwV 2001) (Kat. IV).

- Bei Verwendung von endständigen o,2 $\mu \mathrm{m}$-Filtern kann die Untersuchungsfrequenz reduziert werden. Allerdings ist schon bei der Installation die Möglichkeit einer Kontamination der äußeren Filteroberfläche zu bedenken (zum Beispiel der Wasserstrahl geht direkt in den Siphon, zu geringer Abstand zwischen dem Becken und dem Filterauslass) (Kat IB).

- Sofern die Einhaltung der Empfehlungen des Umweltbundesamtes nicht gewährleistet werden kann, sollte zur Pflege von Haut und Schleimhaut während der Phasen der hochgradigen Immunsuppression (Risikogruppe 2 und 3) nur steriles oder sterilfiltriertes Wasser verwendet werden (Kat. IB). Hierzu wird, sofern kein anderes geeignetes Verfahren bereitsteht, der Einsatz endständiger Bakterienfilter empfohlen $[141,167,210,316]$ (Kat IB). Dabei sollte durch einen ausreichenden Abstand zwischen der Armatur und dem Becken und durch Schulung des Personals (auch der Reinigungskräfte) sowie der Patienten eine Kontamination des Filters von außen vermieden werden.

- Für die (Wasser-)Spülung von Wunden darf nur sterile $\mathrm{NaCl}$-/RingerLösung oder 0,2 $\mu \mathrm{m}$ gefiltertes Wasser verwendet werden (Kat II). Die bislang verfügbaren Studien hierzu haben aus Sicherheitsgründen keine Patienten mit hochgradiger 
Immunsuppression eingeschlossen, sodass die publizierten Daten nicht zur Beurteilung der Zulässigkeit einer Wundspülung mit Trinkwasser bei Immunsupprimierten herangezogen werden können [317].

- Für Saftzubereitungen von Medikamenten und Inhalationslösungen dürfen nur sterile oder sterilfiltrierte Flüssigkeiten verwendet werden (Kat IA).

- Kaffee- und Teeautomaten erhitzen das Wasser möglicherweise nicht ausreichend; daher sollte bevorzugt Tee und Kaffee mit sprudelnd kochendem Wasser aufgebrüht werden (Kat IB).

- Das am besten abgesicherte Verfahren zur Abtötung aller bekannten potenziellen Krankheitserreger (mit Ausnahme von Sporenbildnern) ist die Verwendung von abgekochtem Trinkwasser (mindestens bis zum Sprudeln kochen) und die Aufbewahrung in thermisch desinfizierten Gefäßen mit Deckel (Kat II).

- Da das Abkochen des Wassers einen erheblichen Energieverbrauch erzeugt und es zu Verbrühungsunfällen kommen kann, sollte alternativ in Absprache mit dem Hygienefachpersonal die Entnahme in thermisch desinfizierte Gefäße mit Deckel aus einer gut kontrollierten Zapfstelle mit endständiger 0,2 $\mu \mathrm{m}$ Filtration erwogen werden (Kat II).

- Der Wechsel des abgekochten oder sterilfiltrierten Wassers, das zur Mundspülung verwendet wird, sollte einmal pro Schicht (alle 8 Stunden) erfolgen (Kat II).

- Tee sollte stets mit sprudelnd kochendem Wasser aufgegossen werden und ist zur Mundpflege bei Patienten der Risikogruppe 2 und 3 sowie als Getränk in der Risikogruppe 3 nicht geeignet (Kat IB).

- Wenn Trinkbrunnen beziehungsweise hauseigene Karbonisierungsanlagen verwendet werden, müssen sie den oben genannten Empfehlungen des Umweltbundesamtes entsprechen. Dies ist durch regelmäßige Untersuchung zu verifizieren (Kat IB).

- Mineralwasser, das den Patienten in diesen Bereichen angeboten wird, un- terliegt der hygienisch-mikrobiologischen Chargenkontrolle durch den Hersteller. Das zuständige Hygienefachpersonal sollte dennoch in regelmäßigen Abständen (zum Beispiel zweimal jährlich) Stichprobenkontrollen bei Mineralwasser für immunsupprimierte Patienten durchführen. Geöffnete Mineralwasserflaschen sollten nicht länger als einen Tag gekühlt nach Anbruch aufbewahrt werden (Kat II).

\subsection{Anforderungen an den Sanitärbereich}

Siehe hierzu auch die Hinweise im Abschnitt baulich-funktionelle Maßnahmen (3.8).

- Bei Neubauplanung von Krankenhausstationen sollten elektronisch gesteuerte „kontaktfreie “ Wasserauslässe vermieden werden $[318,319]$. Eine hygienisch einwandfreie Wasserentnahme kann auch durch Fuß- oder Kniebedienungen oder ausreichend lange Schwenkhebel sichergestellt werden (Kat IB).

- Alle sanitären Anlagen müssen in den Hygieneplan der Station aufgenommen und zumindest täglich wischdesinfiziert werden (Kat IB).

- Die Verwendung von Duschvorhängen ist zu vermeiden, da diese zu einem Reservoir für Schimmelpilze und biofilmbildende Bakterien werden können und sich nur sehr aufwendig desinfizierend reinigen lassen (Kat II).

\subsection{Anforderungen an die Hygiene bei Umbaumaßnahmen und Abrissarbeiten}

- Ausnahmslos alle Umbaumaßnahmen, Renovierungsarbeiten und Abrissarbeiten im Umfeld von Stationen, auf denen hochgradig immunsupprimierte Patienten behandelt werden, sind bereits in der Planungsphase mit dem zuständigen Hygienefachpersonal abzustimmen (Kat IB).

- Auch die ärztliche Direktion der entsprechenden Abteilung ist mit ausreichendem zeitlichem Vorlauf zu informieren (Kat IB).
- Bei größeren Projekten, von denen wahrscheinlich eine erhebliche Exposition der immunsupprimierten $\mathrm{Pa}$ tienten ausgeht, muss eine multidisziplinäre Präventionsgruppe unter der Koordination des Krankenhaushygienikers gebildet werden, die Festlegungen zu den erforderlichen Schutzmaßnahmen trifft und die Bautätigkeit aus krankenhaushygienischer Sicht überwacht (Kat IB).

- Gegebenenfalls kann es erforderlich werden, die entsprechende Station ganz aus dem Gefahrenbereich in ein anderes entferntes Gebäude zu verlegen, bis die Arbeiten abgeschlossen sind oder, falls dies nicht möglich ist, die Station zu schließen (Kat II).

- Die Station muss von den Bauarbeiten sicher abgetrennt werden; bei entsprechender Lage ist häufig eine Abtrennung mithilfe einer staubdichten Leichtbauwand möglich. Die einwandfreie Abdichtung kann mithilfe eines Partikelzählers leicht überprüft werden; die Messergebnisse sollten dokumentiert werden (Kat IB).

- Mit den ausführenden Firmen und den unbedingt zu involvierenden Fachplanern sollte ausdrücklich vereinbart werden, dass die Einhaltung der Präventionsrichtlinien des Klinikums auch strikt von den Beschäftigten des ausführenden Unternehmens zu beachten und Gegenstand des Bauauftrags sind (Kat IB).

- Insbesondere muss auch die Möglichkeit eines Baustopps bei Verstößen gegen die Schutzmaßnahmen vertraglich abgesichert sein; gerade in diesem Punkt ist eine eindeutige Definition der entsprechenden Kompetenzen und der Verantwortlichkeit zwingend notwendig (Kat IB).

- Patientenversorgungsbereiche, die durch Baumaßnahmen in erhöhtem Maße staubexponiert sind, müssen mindestens arbeitstäglich feucht gereinigt werden (Kat $I B)$.

\subsection{Prävention der nosokomialen Harnwegsinfektion}

Hier wird auf die entsprechende Empfehlung der KRINKO verwiesen [320]. 


\subsection{Prävention der nosokomialen Wundinfektion}

Hier wird auf die entsprechende Empfehlung der KRINKO verwiesen [321].

\subsection{Prävention der nosokomialen Sepsis}

Neben der Empfehlung der KRINKO zur Prävention Gefäßkatheter-assoziierter Infektionen [32] haben die internistischen $[49,92]$ und die pädiatrisch-onkologischen [94] Fachgesellschaften detaillierte Empfehlungen zur Prävention Katheter-assoziierter Blutstrominfektionen publiziert, auf die an dieser Stelle verwiesen wird.

\subsection{Prävention der nosokomialen Gastrointestinalinfektion}

- Aus krankenhaushygienischer Perspektive ist es erforderlich, dass bei immunsupprimierten Patienten mit nosokomialer Diarrhö eine erweiterte Erregerdiagnostik erfolgt, deren Einzelheiten mit den zuständigen Mikrobiologen und dem Hygienefachpersonal festgelegt werden sollten (Kat IB).

- Die Dauer der Isolierung wird bei hochgradig immunsupprimierten Patienten aufgrund der möglicherweise erheblich verlängerten Ausscheidungsperiode durch Kontrolluntersuchungen bestimmt; in Abhängigkeit vom nachgewiesenen Erreger sind die erregerspezifischen Barrieremaßnahmen zu beachten und mit dem Hygienefachpersonal abzustimmen [322, 323, 324, 325, 326, 327] (Kat IB).

\subsection{Prävention von Zoonosen}

Für Patienten, die protektiv isoliert werden, sind Tierkontakte auszuschließen [41]. Weitere Hinweise zur Prävention von Zoonosen finden sich in Kapitel 5.

\section{Surveillance}

\subsection{Besonderheiten in der Surveillance von nosokomialen Infektionen bei Immunschwäche}

Die Falldefinitionen und somit auch die Surveillance nosokomialer Infektionen (NI) nach $\$ 23$ IfSG $[29,328]$ sind bei immunsupprimierten Patienten unter einer intensiven Therapie erschwert. Bei mehr als der Hälfte aller Fieberepisoden, die bei Patienten mit Granulozytopenie beobachtet werden, bleibt die Ursache unklar. Klinische Infektionszeichen können fehlen, und Fieber ist oft das einzige Symptom.

Die in bestimmten Situationen übliche antibiotische Prophylaxe $[6,329,330]$ sowie die empirische Vorbehandlung mit Antibiotika senken den Anteil positiver Blutkulturen. Unerwünschte Wirkungen der Therapie können klinische „Infektionszeichen" vortäuschen [331]. Die Synthese laborchemischer Entzündungsmarker kann durch die antineoplastische Therapie unterdrückt werden. Erhöhte laborchemische Entzündungszeichen können zudem durch die Grunderkrankung oder die Chemotherapie-induzierte Mukositis verursacht werden. Bildgebende Verfahren können während der Granulozytopenie falsch-negative Resultate liefern [237, 239, 332, 333]. Das spezielle Spektrum fakultativ pathogener, opportunistischer Erreger, deren Auftreten mit Art und Ausmaß der Immunschwäche korreliert, stellt besondere Anforderungen an die mikrobiologische Diagnostik. Invasive diagnostische Methoden wie diagnostische Punktionen oder spezielle Endoskopien sind bei Patienten mit hochgradiger Immunsuppression mit einem erhöhten Risiko für Komplikationen assoziiert [334, 335].

Verschiedene Surveillance-Studien von NI nach Stammzelltransplantation beziehen die Anzahl der Ereignisse nicht auf Patiententage, sondern auf Granulozytopenietage im Sinne einer gezielten, risikoadaptierten Erfassung [336, 337, 338, 339]. Dieser Ansatz fokussiert die nur begrenzt vorhandenen Ressourcen auf ein umschriebenes Zeitfenster, in dem vor allem bakterielle, device-assoziierte Infektionen und Pneumonien vorkommen.

Außerhalb des SCT-Settings sind 5075\% aller Patienten zum Zeitpunkt der
NI granulozytopenisch [11, 339, 340], und nahezu alle schweren CVAD-assoziierten Septikämien mit septischem Schock oder Multiorganversagen treten bei granulozytopenischen Patienten auf. Andererseits gibt es erregerspezifische nosokomiale Ausbrüche [37, 117, 341, 342, 343, 344] oder NI, die durch systematische Fehler im Hygienemanagement entstehen [23, 168, 171, 177, 18o, 181, 224, 345, 346, 347, 348, 349]. Beide sind nicht auf Patienten mit Granulozytopenie begrenzt. CVAD-assoziierte Bakteriämien treten auch bei nicht granulozytopenischen Patienten auf [91, 350, $351,352,353$ ] und sollten im Sinne von $\$ 23$ IfSG $[29,328]$ insbesondere dann als NI erfasst, dokumentiert und bewertet werden, wenn der Katheter als Infektionsquelle gesichert wurde.

Die von einer Clostridium difficile-assoziierten Erkrankung betroffenen Patienten [337] werden zu gleichen Teilen vor oder nach der Rekonvaleszenz der Leukozytenzahl symptomatisch [334, 354, 355, 356, 357, 358]; bei einer Beschränkung auf die Phase der Granulozytopenie würden etwa 50\% aller Episoden nicht erfasst.

Das Auftreten oder die Häufung von Infektionen durch bestimmte nosokomiale Infektionserreger wie $P$. aeruginosa, Legionellen, Aspergillus spp., MRSA, VRE und ESBL-bildende gramnegative Bakterien hat krankenhaushygienisch eine erhebliche Relevanz.

In der pädiatrischen Onkologie ist außerhalb der akuten Phase der Stammzelltransplantation die Inzidenzdichte von NI pro 1000 Patiententage niedriger, quantitativ treten jedoch die meisten NI bei $\mathrm{Pa}$ tienten unter einer konventionellen Chemotherapie auf [340, 359, 360, 361, 362].

\subsection{Katheter-assoziierte Infektionen}

Die infektionsepidemiologische Definition für Katheter-assoziierte Infektionen $[47,92,337,338,339,340,363,364,365,366]$ sichert keinesfalls den CVAD als Quelle der klinischen Symptomatik oder der positiven Blutkultur [49, 50, 92, 367]. Die meisten CVAD-assoziierten Infektionen werden erfolgreich empirisch in situ (über den Katheter) behandelt, sodass die Katheterspitze nicht für die Diagnostik zur Verfügung steht [368]. 


\subsection{Empfehlungen zur Surveillance}

- Onkologische Behandlungszentren müssen eine prospektive Surveillance nosokomialer Infektionen nach den Vorgaben des IfSG [29] und den entsprechenden Erläuterungen des RKI [30] durchführen (Kat IV).

- Die Surveillance sollte mit einem geeigneten Modul erfolgen, das an die Besonderheiten der Patientenpopulation adaptiert ist (Kat IB).

- Eine auf die Behandlungsphasen mit Granulozytopenie beschränkte Surveillance ist als Mindestvoraussetzung zu sehen (Kat IB).

- Nosokomiale Infektionen durch Legionella pneumophila, Clostridium difficile sowie wahrscheinliche und gesicherte invasive Pilzinfektionen sollen (ebenso wie NI durch Erreger mit speziellen Resistenzen und Multiresistenzen wie MRSA, VRE und ESBL-bildende gramnegative Erreger) auch bei Patienten systematisch erfasst werden, die nicht granulozytopenisch sind (Kat IB; Aufzeichnungspflicht für multiresistente Erreger nach $\$ 23$ IfSG, Kat IV).

- Die Surveillance soll in enger Zusammenarbeit zwischen dem Hygienefachpersonal (Krankenhaushygieniker, Hygienefachkräfte) und den verantwortlichen Ärzten durchgeführt werden. Über die dokumentierten nosokomialen Infektionen und die Bedeutung der im Kontext von NI isolierten Erreger muss zur Validierung vor der Meldung ein Konsens zwischen dem Hygienefachpersonal und den behandelnden Ärzten angestrebt werden (Kat IB).

- Onkologischen Behandlungszentren soll entsprechend ausgebildetes Hygienefachpersonal für die Surveillance zugeteilt werden (Kat IB).

- Prospektive multizentrische Surveillance-Studien mit geeigneten Modulen (zum Beispiel ONKO-KISS, Oncoped) sollen dazu genutzt werden, Referenzdaten für den Vergleich zwischen verschiedenen Zentren zu generieren. Dies ermöglicht den teilnehmenden Zentren die Identifizierung von Problembereichen (Kat IB).
- Die Surveillance ist kein Selbstzweck und führt alleine nicht zur Verringerung nosokomialer Infektionen. Daher sollte das Behandlungsteam onkologischer Zentren die Ergebnisse in enger Zusammenarbeit mit dem zuständigen Krankenhaushygieniker und dem Hygienefachpersonal in einem kontinuierlichen Diskussionsprozess zur Verbesserung des krankenhaushygienischen und infektionspräventiven Gesamtkonzepts der Abteilung einsetzen (Kat IB).

\subsection{Surveillance von invasiven Aspergillosen}

In der klinischen Praxis ist es außerordentlich schwierig, die klinischen und radiologischen Befunde eines fiebernden granulozytopenischen Patienten einer invasiven Pilzinfektion zuzuordnen. Die verfügbaren klinisch anwendbaren Methoden der Diagnostik weisen keine ausreichende Sensitivität und Spezifität auf. Ein erheblicher Anteil aller mit systemischen Antimykotika behandelten Patienten hat lediglich eine „mögliche“ invasive Pilzinfektion und erhält eine empirische oder präemptive Behandlung.

Hieraus ergibt sich für das Hygienefachpersonal und das Behandlungsteam die schwierig zu beantwortende Frage, welche Parameter zur Surveillance von invasiven Aspergillosen sinnvoll genutzt werden können.

- Eine mögliche, aber aufwendige Option der Surveillance invasiver Aspergillosen ist die Erfassung aller Ereignisse, die den internationalen Konsensuskriterien einer „wahrscheinlichen“ oder "gesicherten invasiven Aspergillose" entsprechen, als nosokomiale Pneumonie pro 1000 stationäre Patiententage [369] (Kat II).

- Derzeit ist es nicht möglich, einheitliche Empfehlungen auszusprechen, ob und wann Luftkeimmessungen auf Stationen mit Risikopatienten durchgeführt werden sollten (Kat III). Dies obliegt der Entscheidung und Verantwortung des Krankenhaushygienikers, insbesondere anlässlich ungewöhnlicher Häufungen von vermuteten Fadenpilzpneumonien [37] (Kat IB).

\subsection{Mikrobiologisches Screening von immunsupprimierten Patienten}

Der Nutzen einer routinemäßigen Abnahme mikrobiologischer Kulturen von Patient (Haut, Schleimhaut, Blut, Stuhl, Urin, Rachenspülwasser) oder Umgebung ohne akuten Anlass (zum Beispiel Infektionsverdacht, Ausbruchsuntersuchung) ist außerhalb der Risikogruppe 3 nicht belegt [370, 371, 372, 373, 374].

Infektions-assoziierte Isolate haben eine höhere klinische Relevanz [375], was die abteilungsspezifische Festlegung zur empirischen Therapie bei Fieber und Granulozytopenie angeht $[8,9,49,63,64,364$, $368,376,377]$.

- Keine routinemäßigen mikrobiologischen Kulturen von Patient und Umgebung ohne Infektions- oder Ausbruchsverdacht (Kat IB) (ausgenommen solche, die durch Gesetze und Verordnungen zur Qualitätssicherung vorgeschrieben sind) (Kat IV).

- Onkologische Patienten mit invasiven Kathetern, langer Granulozytopeniedauer und höhergradiger $\mathrm{Mu}$ kositis oder auch Patienten, die in der Anamnese wiederholt mit Antibiotika (insbesondere mit Cephalosporinen der Gruppe III und Fluorochinolonen $[378,379,380,381])$ behandelt oder größeren operativen Eingriffen unterzogen wurden, haben ein erhöhtes Risiko, mit multiresistenten Erregern besiedelt zu sein $[382,383]$. Daher kann auch ohne einen Ausbruchsverdacht im Einzelfall ein Aufnahme-Screening auf MRSA [36, 384], VRE oder ESBL-Bildner [385] indiziert sein. Hierüber sollten sich die zuständigen Kliniker, Krankenhaushygieniker und Mikrobiologen intern verständigen $($ Kat $I B)$.

Eine spezielle Situation kann sich ergeben, wenn Patienten eine medikamentöse antimikrobielle Prophylaxe erhalten [386]. Zum Beispiel kann die evidenzbasierte Prophylaxe mit Fluconazol nach allogener Stammzelltransplantation $[6,387]$ zu einer Selektion Fluconazol-resistenter Candida spp. (C. krusei, C. glabrata) führen $[388,389]$. Hierzu wird auf die Emp- 
Tab. 6 Empfehlungen zur Nahrungsmittelhygiene im häuslichen Umfeld (für die Zubereitung von Nahrungsmitteln durch die Patienten beziehungsweise durch Angehörige/ Begleitpersonen)

\section{Einkauf:}

- Nur Lebensmittel in unbeschädigten Verpackungen einkaufen

- Ablaufdatum kontrollieren

- Gekühlte Lebensmittel zuletzt auswählen und in geeigneter Kühltasche transportieren

- Rohes Fleisch und rohen Fisch in separater Plastiktüte transportieren

Lagerung von Lebensmitteln:

- Kühl lagern (Kühlschrank mit "sauberen" und "nicht sauberen" Fächern)

- Frisches Fleisch und Fisch innerhalb von zwei Tagen zubereiten

- Eingelegtes/gepökeltes Fleisch in 5 Tagen zubereiten

- Tiefkühlkost bei minus $18^{\circ} \mathrm{C}$ lagern

- Falls die Kühlung versehentlich unterbrochen wurde (aufgetaute Nahrungsmittel), Tiefkühlkost verwerfen

- Tiefkühlgemüse sofort nach dem Auftauen zubereiten.

- Fleisch oder Fisch in einem abgedeckten Gefäß im Kühlschrank auftauen

- Geöffnete Tiefkühlpackungen am gleichen Tag verbrauchen

- Nach Ablauf des Mindesthaltbarkeitsdatums Nahrungsmittel verwerfen

- Kühlschrank regelmäßig (mindestens alle 2 Wochen) reinigen.

Zubereitung:

- Händewaschen mit Seife, ab Risikogruppe 2: Händedesinfektion

- Früchte und Gemüse waschen und schälen („,putzen“)

- Angestoßenes oder verfärbtes Obst verwerfen

- Nicht direkt aus einer Flasche oder Tüte trinken

- Kreuzkontamination zwischen unsauberen und sauberen Lebensmitteln vermeiden

- Küchenutensilien in der Spülmaschine bei $60^{\circ} \mathrm{C}$ aufbereiten

- Küchenhandtücher und Wischlappen täglich erneuern und bei mindestens $60^{\circ} \mathrm{C}$ in der

Waschmaschine waschen.

- Geflügel sollte wegen der hohen Kontaminationsrate des Geflügelfleisches mit Salmonellen und Campylobacter spp. nicht vom Immunsupprimierten selbst zubereitet werden

- Das Auftauwasser (oft kontaminiert: Salmonellen, Campylobacter spp.) muss sicher aufgefangen und entsorgt werden

Sicheres Kochen:

- Eier fest kochen (mindestens 8 Minuten)

- Fleisch und Fisch komplett durchgaren oder -braten

Sicheres Servieren:

- Speisen heiß servieren, kalte Speisen kühlen, bis sie serviert werden

- Fertig zubereitete Speisen weniger als $2 \mathrm{~h}$ abgedeckt lagern, ggf. erneut erhitzen

Restaurantbesuch:

- Nur ausreichend erhitzte Speisen auswählen

- Nicht von einer Salatbar essen

- Keinen Frischkäse aus unpasteurisierter Milch oder andere Rohmilchprodukte essen

- Die Speisen nicht mit Pfeffer oder nicht autoklavierten Gewürzen nachwürzen

fehlungen der Fachgesellschaften verwiesen $[238,333,387]$.

\subsection{Ausbruchs-Management}

Hier wird auf die entsprechende Empfehlung der KRINKO verwiesen [390].

\section{Infektionsrisiken im häuslichen Umfeld}

Die in diesem Kapitel gegebenen Hinweise von Experten der Infektionsprävention bei hochgradig immunsupprimierten $\mathrm{Pa}$ tienten können zur Gestaltung von Materialien zur Information und Schulung von Patienten und ihren Angehörigen genutzt werden. Dies dient insbesondere dazu, den Patienten und seine engen Kontaktpersonen zur Erkennung dieser Risiken zu befähigen. Sie sind nicht mit den üblichen Evidenzkategorien versehen, weil der häusliche Behandlungsbereich nicht in die Kompetenz der KRINKO-Empfehlungen fällt.

\subsection{Lebensmittel (siehe hierzu auch Tabelle 5 in der Empfehlung)}

- Prinzipiell sollte Fleisch vor dem Verzehr ausreichend lange gebraten oder gekocht werden (Kerntemperatur $>70^{\circ} \mathrm{C}$ ), um ggf. darin enthaltene
Krankheitserreger sicher abzutöten [191].

- Auf den Verzehr von rohem Fleisch, zum Beispiel in Form von „Mettbrötchen", Räucherware (Wurst, Lachs und andere geräucherte Fischsorten) oder nicht durchgebratenen Steaks, sollte ganz verzichtet werden.

- Milch und Obstsäfte sollten pasteurisiert sein, einmal geöffnet stets im Kühlschrank gelagert und innerhalb von 24 Stunden nach dem Öffnen verbraucht werden.

- Während der intensiven Therapie und bei lang anhaltender Lymphozytopenie (Mangel an $\mathrm{CD}_{4}$-positiven

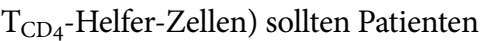
unbedingt auf den Verzehr von Rohmilchprodukten verzichten.

- Zum Teil befinden sich Rohmilchprodukte im Handel, die nicht ohne ein sorgfältiges Studium des Kleingedruckten auf der Packung als solche erkennbar sind. Dies gilt auch für offen konfektionierte Käsesorten (gegebenenfalls unbedingt nachfragen).

- Gegen den Verzehr von gewaschenem und geschältem/geputztem Obst und Gemüse gibt es keine Einwände („Peel it, cook it, boil it or leave it.").

- Wenn in der Phase der ochgradigen Immunsuppression Beeren (Erdbeeren, Himbeeren, Stachelbeeren, Kirschen et cetera) verzehrt werden, sollten diese vorher gewaschen und gekocht werden (Mus beziehungsweise Grütze).

- Saucen und Dressings aus offenen Mehrportionsabpackungen (offene Flaschen) sollten vermieden werden (abgepackte Einzelportionen verwenden) (• Tab. 6).

\subsection{Vorbeugung von lebensbedrohlichen Schimmelpilzinfektionen}

Blumen und Topfpflanzen (auch Hydrokulturen und andere Nährmedien) sind in fast jedem Haushalt anzutreffen. Mögliche Infektionsrisiken stellen zum einen Pilzsporen (Aspergillus spp.) zum Beispiel in der Topferde dar, die eingeatmet werden können, zum anderen Bakterien (zum Beispiel Pseudomonas spp.) im 
Blumenwasser, die bevorzugt über kontaminierte Hände weiterverbreitet werden [391]. Grundsätzlich ist bei hochgradig Immunsupprimierten ein Verzicht auf Pflanzen im Innenraumbereich $\mathrm{zu}$ empfehlen, auch wenn dies nicht wissenschaftlich gesichert ist. Zumindest sollten aber folgende Präventionsmaßnahmen berücksichtigt werden:

- gründliches Händewaschen nach Kontakt mit Blumen oder Pflanzen,

- keine Pflanzen im Küchenbereich oder in der Nähe von Speisen,

- welk gewordene Blumen und Pflanzen sofort entsorgen (nicht vom Patienten selbst),

- keine Zimmerpflanzen im Schlafbereich.

Der Abfallentsorgung innerhalb des häuslichen Bereiches ist besondere Aufmerksamkeit zu widmen. Beim Befüllen der Biotonne kann es zu einer starken Exposition gegenüber Pilzsporen (insbesondere Aspergillus fumigatus) kommen [392]. Insekten (zum Beispiel Fliegen, Wespen), die durch organische Abfälle angelockt werden, können als Vektoren von Krankheitserregern auftreten.

Die Standzeit der Abfälle in der Wohnung sollte auf 24 Stunden limitiert sein. Dies gilt in besonderer Weise für organische Abfälle. Abfallbehälter sollten mit einem Deckel verschlossen werden, und Bioabfälle sollten nicht in der Wohnung stehen, sondern im Freien an einem möglichst kühlen, schattigen Platz [393]. Das Öffnen und das Schließen der Biotonne darf auf keinen Fall vom immunsupprimierten Patienten selbst durchgeführt werden. Nach jeder Berührung mit Abfall muss eine sorgfältige Händehygiene erfolgen.

Kellerräume sind häufig schlecht durchlüftet, kühl und feucht, wodurch das Wachstum von Schimmelpilzen begünstigt wird. Auf den Oberflächen kommt es zur Ansammlung von Staubschichten, die bei Bewegung aufgewirbelt werden. Gleiches gilt für schlecht isolierte Räume oder bei Baumängeln. Patienten mit hochgradiger Immunsuppression (ab Risikogruppe 1) sollten Kellerräume und andere feuchte Räumlichkeiten sowie Räume mit manifestem Schimmelpilzwachstum unbedingt meiden.
Bauliche Mängel, die als Ursache einer Schimmelpilzbelastung der Wohnraumluft infrage kommen, müssen saniert werden. Gegebenenfalls kann es, auf entsprechenden Hinweis des Patienten hin, erforderlich werden, die Wohnung zu inspizieren, bevor der hochgradig immungeschwächte Patient erstmals nach Hause entlassen wird.

Gartenarbeit hat einen hohen Erholungswert. Der schwer immunsupprimierte Patient sollte jedoch beachten, dass bei der Gartenarbeit zwangsläufig direkter Hautkontakt mit organischem Material und mit einer Vielzahl von Mikroorganismen (einschließlich Pilzsporen, Clostridium tetani und Clostridium perfringens) erfolgt. Durch dornige Sträucher und Gebüsche sind leicht Verletzungen der intakten Haut mit dem Risiko einer Erregerinokulation möglich. Beim Rasenmähen wird eine nicht unbeträchtliche Menge von organischem Material aerosolisiert. Auch bei Kompostierungsarbeiten kommt es zu einer starken Pilzbelastung (Aspergillus-Arten) der Luft [394].

Das Ausbringen von Rindenmulch (organisch angedauten Materialien) kann zu extrem hoher Exposition gegenüber Aspergillus-Sporen führen. Das Risiko bei Umgang mit Rindenmulch ist hoch; es wurde sogar ein Todesfall bei einem nicht immunsupprimierten Arbeiter beschrieben [395].

Grundsätzlich ist daher während der hochgradigen Immunsuppression ein Verzicht auf Gartenarbeit zu empfehlen. Lässt sich dies nicht umsetzen, sollten folgende Vorsichtsmaßnahmen beachtet werden:

$$
\begin{aligned}
& \text { Tragen geeigneter Kleidung und } \\
& \text { Handschuhe, die vor Verletzungen } \\
& \text { schützen, } \\
& \text { - bei staub- beziehungsweise aerosol- } \\
& \text { bildenden Tätigkeiten Tragen einer } \\
& \text { dicht anliegenden Atemschutzmaske } \\
& \text { (FFP2), } \\
& \text { nach Beendigung der Gartenar- } \\
& \text { beit gründliche Händehygiene und } \\
& \text { Händepflege, } \\
& \text { auch oberflächliche Verletzungen } \\
& \text { sofort mit einem geeigneten } \\
& \text { Antiseptikum behandeln. }
\end{aligned}
$$

Handwerkliches Arbeiten an Haus oder Wohnung kann mit einer erheblichen Ex- position gegenüber Baustaub, Schmutz und Schutt einhergehen. Häufig werden solche Tätigkeiten in schlecht durchlüfteten Räumen ausgeführt. Mauerwerk kann, insbesondere wenn es feucht ist, stark mit Pilzen und Pilzsporen kontaminiert sein [396]. Auch bei der Holzbearbeitung (zum Beispiel Sägen) kann es zu einer Exposition gegenüber Pilzen kommen [397]. Auf der Oberfläche von Hölzern wurde eine Vielzahl von Schimmelpilzen gefunden, wie zum Beispiel Aspergillus fumigatus, Aspergillus niger, Trichoderma viride und Rhizopus spp. Aus Spanplatten wurden mehr als 30 Schimmelpilzarten isoliert [398] und auch auf Tropenhölzern können sich besonders gefährliche tropische Pilze befinden (zum Beispiel Erreger der Blastomykose) [399]. Wird Holz im Freien gelagert und damit Feuchtigkeit (zum Beispiel in Form von Niederschlägen) ausgesetzt, so ist die Gefahr einer Besiedlung durch Schimmelpilze besonders groß [398].

Aufgrund des hohen Infektionsrisikos muss dem immunsupprimierten $\mathrm{Pa}$ tienten von allen Staub produzierenden handwerklichen Tätigkeiten abgeraten werden. Das Tragen eines geeigneten dicht anliegenden Atemschutzes ( $\left.\mathrm{FFP}_{2}\right)$ minimiert zwar das Risiko, ist aber nur bedingt als Alternative zu empfehlen, da er während der mechanischen Tätigkeit leicht verrutschen kann beziehungsweise oft falsch angelegt wird. Die einmalige Inhalation einer hohen Anzahl von Pilzsporen kann eine Infektion nach sich ziehen. Dieses Risiko muss bei derartigen Arbeiten angenommen werden.

\subsection{Infektiöse Erkrankungen im häuslichen Umfeld}

Von akuten (symptomatischen) Infektionserkrankungen (zum Beispiel Diarrhö, fieberhafte Atemwegsinfektionen) bei Mitbewohnern resultiert ein zusätzliches Infektionsrisiko, das umso höher ist, je enger die Bewohner zusammenleben. Familienmitglieder oder Mitbewohner sollten über die möglichen Übertragungswege der Erkrankung informiert sein [40o].

Alle Haushaltsmitglieder sollten Standardhygienemaßnahmen besonders konsequent befolgen [401]. Hierzu empfiehlt es sich, ein Aufklärungsgespräch durch 
Hygienefachpersonal und erforderlichenfalls eine krankenhaushygienische Begehung des häuslichen Umfeldes durch Hygienefachpersonal vornehmen zu lassen mit dem Ziel, Infektionsreservoire und risiken zu erkennen und gezielte Vorschläge für individuell bezogene Hygienemaßnahmen zu geben.

Bei gastrointestinalen Infektionen reicht das Händewaschen als alleinige Schutzmaßnahme nicht aus. Hier ist bei Patienten mit gravierender Immunschwäche die hygienische Händedesinfektion für Patient und Angehörige obligat. Auch eine Desinfektion der Toilettenbrille nach der Nutzung durch einen erkrankten Mitbewohner kann im Einzelfall erforderlich sein. Daher ist in gut begründeten Fällen der Einsatz von Hände- und Flächendesinfektionsmitteln auch zu Hause medizinisch indiziert.

Wenn das Kind eines immunsupprimierten Elternteils akut erkrankt ist, sollte möglichst eine andere Person die Pflege des Kindes übernehmen. Bei respiratorischen Infektionen anderer Personen sollten die Patienten auf ausreichende Distanz achten und die erkrankten Mitbewohner geeignete Schutzmaßnahmen ergreifen (Einmaltaschentücher, beim Husten Mund und Nase bedecken, räumliche Distanz, Händedesinfektion, MNS).

\subsection{Prävention von Infektionen durch Tierkontakte}

- Aus präventiven und differenzialdiagnostischen Erwägungen sollte dem Behandlungsteam auf jeden Fall bekannt sein, ob der Patient in seinem häuslichen Umfeld regelmäßig in direkten oder indirekten Kontakt zu bestimmten Tieren kommt.

- Haus- und Nutztiere, die in Kontakt zu immungeschwächten Patienten stehen, sollten tierärztlich überwacht, regelmäßig entwurmt und bei Symptomen einer Infektion (zum Beispiel Diarrhö, Ornithose) tierärztlich untersucht werden (Erregerdiagnostik auf Cryptosporidien, Salmonellen, Campylobacter spp., Chlamydia psittaci).

- Neue Haustiere sollten erst beim Tierarzt vorgestellt werden, bevor der erste Kontakt zum Patienten stattfindet.
- Neue Haustiere nicht jünger als sechs Monate (Katzen zwölf Monate).

- Impfungen für Haustiere nach veterinärmedizinischen Schemata zu empfehlen (keine Gefahr für immunsupprimierten Patienten).

- Zu vermeiden sind (direkte und indirekte) Kontakte zu Wildtieren (Mäuse, Ratten, Vögel, Hasen, Igel), Reptilien (Geckos, Schlangen, Schildkröten), Kälbern, Fohlen, Lämmern, Schafherden.

- Niemals Wildtiere „zum Spaß“ jagen oder in die Enge treiben.

- Niemals kranke Wildtiere „zur Pflege“ aufnehmen.

- Niemals Tierkadaver ohne Schutzhandschuhe berühren.

- Haushunde keine Wildmäuse fressen lassen (E. granulosus/E. multilocularis); gegebenenfalls monatlich mit Praziquantel entwurmen.

- Tiere während der Phase der intensiven Therapie nicht in Badeseen oder Flüssen baden lassen (vor allem nicht nach Regengüssen).

- Tierkontakte bei immungeschwächten Kleinkindern müssen immer beaufsichtigt werden.

- Streichelzoos sollten von immunsupprimierten Patienten gemieden werden.

- Sorgfältiges Händewaschen (oder Händedesinfektion) nach direktem Tierkontakt.

- Nicht vom Haustier ablecken lassen (insbesondere keine Wunden!), das Tier nicht küssen.

- Das Saubermachen von Katzentoilette, Vogelkäfig, Kaninchenstall, Aquarium et cetera darf nicht durch den Patienten erfolgen.

- Die Katzentoilette mindestens alle zwei Tage reinigen (Desinfektion mit heißem Wasser ist möglich).

- Katzen- oder Hundedecken sollten einmal pro Woche bei mindestens $60^{\circ} \mathrm{C}$ gewaschen werden.

- Vogelkäfig täglich reinigen.

- Patienten vom Taubenschlag fernhalten; keine Speicher betreten, in denen Tauben nisten.

- Katzen hochgradig immungeschwächter Patienten sollten im Haus gehalten werden.
- Kontrolle von Haustieren auf Ektoparasiten (Flöhe, Zecken), gegebenenfalls Therapie.

- Keine „wilden Spiele“ mit erhöhtem Risiko von Kratz- oder Bisswunden.

- Auch oberflächliche Kratzwunden sofort mit einem geeigneten Präparat antiseptisch behandeln.

- Bei Bissverletzung antiseptisch behandeln, steril abdecken und sofort in der Klinik vorstellen (plus tierärztliche Untersuchung des Haustiers).

- Eine Übertragung von Krankheitserregern durch Tierfutter muss vermieden werden (nicht in der Küche füttern oder Futter zubereiten, sorgfältige Händehygiene).

- Haustiere vom Essenstisch fernhalten.

- Haustieren dürfen kein ungekochtes Fleisch, keine Schlachtabfälle und keine rohen Eier angeboten werden.

- Haustiere sollten Wasser von Trinkwasserqualität zu trinken bekommen. - Bei Auftreten von MRSA sollten ggf. Hauskatzen, Hunde und Schweine als potenzielle Träger mit berücksichtigt werden $[402,403]$.

\subsection{Sonstige Hinweise zu häufig gestellten Fragen}

Patienten der Risikogruppe 1 während der Granulozytopenie und alle Patienten ab Risikogruppe 2 sollten in ambulanten Behandlungsphasen nicht in öffentlichen Schwimmbädern [404], Kleinbadeteichen oder in Badeseen baden.

Hot Whirl Pools sind grundsätzlich wegen der erhöhten Gefährdung (vor allem durch Legionellen und Pseudomonaden) sowohl im öffentlichen wie privaten Bereich zu meiden.

Um die Lebensqualität und die soziale Integration der Patienten nicht zu gefährden, sind soziale Kontakte mit Freunden und Bekannten in den ambulanten Phasen der Behandlung auch bei Patienten der Risikogruppe 2 möglich und sinnvoll. Die nicht erkrankten Kontaktpersonen sollten analog zur Besucherregelung im stationären Bereich über die Infektionsrisiken aufseiten des Patienten informiert sein und sich entsprechend verhalten.

Kinder und Jugendliche der Risikogruppe 1 dürfen durchaus die Schule besuchen, wenn keine anderen Gründe da- 
gegen sprechen. Die Klassenleiter und die Mitschüler sollten - das Einverständnis der Patienten beziehungsweise der Eltern vorausgesetzt - von entsprechenden Mitarbeitern des Behandlungsteams aktiv über die Erkrankung des Kindes informiert werden.

Bei Auftreten von Varizellen oder anderen hochkontagiösen Infektionskrankheiten in der Schule (Masern, Ringelröteln) müssen die behandelnden Ärzte über die Eltern umgehend informiert werden, da gegebenenfalls eine entsprechende Prophylaxe eingeleitet werden muss.

Auf die Händehygiene ist auch in den ambulanten Behandlungsphasen sorgfältig zu achten; das Händeschütteln sollten die Patienten ganz vermeiden.

Kino- oder Theaterbesuche (beziehungsweise die Teilnahme an anderen sozialen „Events“ mit vielen Personen) sind in der Risikogruppe 1 möglich, ab Risikogruppe 2 nicht (oder nur unter konsequenter Anwendung zusätzlicher Schutzmaßnahmen, zum Beispiel eines MNS zum Schutz vor Tröpfcheninfektionen) zu empfehlen.

Immunsupprimierte Patienten dürfen während der intensiven Therapie (ab Risikogruppe 2) keine öffentlichen Verkehrsmittel oder Shuttle-Busse in Kliniken benutzen. In der Regel wird hierüber eine Sondervereinbarung mit der zuständigen Krankenkasse geschlossen, sodass die höheren Fahrtkosten nicht zulasten der Patienten gehen.

Die Empfehlungen wurden ehrenamtlich und ohne Einflussnahme kommerzieller Interessengruppen im Auftrag der Kommission für Krankenhaushygiene und Infektionsprävention bearbeitet von M. Exner (Leiter der Arbeitsgruppe), Bonn; G. Maschmeyer, Potsdam; B. Christiansen, Kiel; S. Engelhart, Bonn; B. Hornei, Köln; N. Wischnewski, Berlin; A. Simon, Bonn.

\section{Literatur}

1. Berner R, Sauter S, Duffner U et al (1998) Bacteremic episodes in pediatric oncologic patients, especially caused by the Streptococcus viridans group. Klin Padiatr 210:256-260

2. Pizzo PA, Rubin M, Freifeld A, Walsh TJ (1991) The child with cancer and infection. I. Empiric therapy for fever and neutropenia, and preventive strategies. J Pediatr 119:679-694
3. Chanock S (1993) Evolving risk factors for infectious complications of cancer therapy. Hematol Oncol Clin North Am 7:771-793

4. Chanock SJ, Pizzo PA (1995) Infection prevention strategies for children with cancer and AIDS: contrasting dilemmas. J Hosp Infect (30 Suppl):197-208

5. Chanock SJ, Pizzo PA (1997) Infectious complications of patients undergoing therapy for acute leukemia: current status and future prospects. Semin Oncol 24:132-140

6. Maschmeyer G, Kern WV, Deutsche Gesellschaft für Hämatologie und Onkologie (2004) Infektionen bei hämatologischen und onkologischen Patienten. DGHO Homepage (http://www.dgho. de)

7. Crawford J, Dale DC, Lyman GH (2004) Chemotherapy-induced neutropenia: risks, consequences, and new directions for its management. Cancer 100:228-237

8. Buchheidt D, Bohme A, Cornely OA et al (2003) Diagnosis and treatment of documented infections in neutropenic patients - recommendations of the Infectious Diseases Working Party (AGIHO) of the German Society of Hematology and Oncology (DGHO). Ann Hematol 82(Suppl 2):S127-S132

9. Link H, Bohme A, Cornely OA et al (2003) Antimicrobial therapy of unexplained fever in neutropenic patients - guidelines of the Infectious Diseases Working Party (AGIHO) of the German Society of Hematology and Oncology (DG$\mathrm{HO}$ ), study group interventional therapy of unexplained fever, Arbeitsgemeinschaft Supportivmaßnahmen in der Onkologie (ASO) Deutsche Krebsgesellschaft (DKG-German Cancer Society). Ann Hematol 82(Suppl 2):S105-S117

10. Cosgrove S, Perl TM (2004) Ch. 60, Infection control and prevention in hematopoetic stem cell transplant patients. In: Mayhall C (ed) Hospital epidemiology and infection control. Lippincott Williams \& Wilkins, Philadelphia Baltimore New York, pp 1011-1070

11. Gaur A (2004) Ch. 58, Nosocomial infections in patients with neoplastic diseases. In: Mayhall C (ed) Hospital epidemiology and infection control. Lippincott Williams \& Wilkins, Philadelphia Baltimore New York, pp 969-984

12. Singh N (2004) Ch. 59, Nosocomial infections in solid organ transplant recipients. In: Mayhall C (ed) Hospital epidemiology and infection control. Lippincott Williams \& Wilkins, Philadelphia Baltimore New York, pp 985-1009

13. Centers for Disease Control and Prevention (2000) Guidelines for preventing opportunistic infections among hematopoietic stem cell transplant recipients. MMWR Recomm Rep 49:1-125, CE121-127

14. Slota M, Green M, Farley A et al (2001) The role of gown and glove isolation and strict handwashing in the reduction of nosocomial infection in children with solid organ transplantation. Crit Care Med 29:405-412

15. Grigull L, Beier R, Schrauder A et al (2003) Invasive fungal infections are responsible for onefifth of the infectious deaths in children with ALL. Mycoses 46:441-446

16. Lehrnbecher T, Varwig D, Kaiser J et al (2004) Infectious complications in pediatric acute myeloid leukemia: analysis of the prospective multiinstitutional clinical trial AML-BFM 93. Leukemia 18:72-77
17. Rousseau A, Morcos M, Amrouche L et al (2004) Lethal pulmonary hemorrhage caused by a fulminant Stenotrophomonas maltophilia respiratory infection in an acute myeloid leukemia patient. Leuk Lymphoma 45:1293-1296

18. Slats AM, Egeler RM, van der Does-van den Berg A et al (2005) Causes of death - other than progressive leukaemia - in childhood acute lymphoblastic (ALL) and myeloid leukemia (AML): the Dutch Childhood Oncology Group experience. Leukemia 19:537-544

19. Gaur AH, Flynn PM, Shenep JL (2004) Optimum management of pediatric patients with fever and neutropenia. Indian J Pediatr 71:825-835

20. Vento S, Cainelli F (2003) Infections in patients with cancer undergoing chemotherapy: aetiology, prevention, and treatment. Lancet Oncol 4:595-604

21. Lehrnbecher T, Foster C, Vazquez N et al (1997) Therapy-induced alterations in host defense in children receiving therapy for cancer. J Pediatr Hematol Oncol 19:399-417

22. Lehrnbecher T, Laws $H$ (2005) Infektionen in der pädiatrischen Hämatologie und Onkologie. Klin Padiatr 217(Suppl1):3-8

23. Nourse C, Byrne C, Murphy H et al (2000) Eradication of vancomycin resistant Enterococcus faecium from a paediatric oncology unit and prevalence of colonization in hospitalized and community-based children. Epidemiol Infect 124:5359

24. Nourse C, Murphy H, Byrne C et al (1998) Control of a nosocomial outbreak of vancomycin resistant Enterococcus faecium in a paediatric oncology unit: risk factors for colonisation. Eur J Pediatr 157:20-27

25. Smith TL, Pullen GT, Crouse V et al (2002) Bloodstream infections in pediatric oncology outpatients: a new healthcare systems challenge. Infect Control Hosp Epidemiol 23:239-243

26. Gaynes R (2002) Health care-associated bloodstream infections: a change in thinking. Ann Intern Med 137:850-851

27. Friedman ND, Kaye KS, Stout JE et al (2002) Health care-associated bloodstream infections in adults: a reason to change the accepted definition of community-acquired infections. Ann Intern Med 137:791-797

28. Carratala J, Garcia-Vidal C (2008) What is healthcare-associated pneumonia and how is it managed? Curr Opin Infect Dis 21:168-173

29. (n a) (2000) Infektionsschutzgesetz. Gesetz zur Verhütung und Bekämpfung von Infektionskrankheiten beim Menschen (Infektionsschutzgesetz - IfSG). Bundesgesetzblatt 1:1045-1077

30. Kommission für Krankenhaushygiene und Infektionsprävention beim Robert Koch-Institut (2001) Mitteilungen der Kommission für Krankenhaushygiene und Infektionsprävention zur Surveillance (Erfassung und Bewertung) von nosokomialen Infektionen (Umsetzung §23 IfSG). Bundesgesundheitsbl Gesundheitsforsch Gesundheitsschutz 44:523-536

31. Kommission für Krankenhaushygiene und Infektionsprävention (2000) Händehygiene - Mitteilung der Kommission für Krankenhaushygiene und Infektionsprävention am Robert Koch-Institut. Bundesgesundheitsbl Gesundheitsforsch Gesundheitsschutz 43:230-233 
32. Kommission für Krankenhaushygiene und Infektionsprävention (2002) Prävention Gefäßkatheter-assoziierter Infektionen - Empfehlung der Kommission für Krankenhaushygiene und Infektionsprävention am Robert Koch-Institut. Bundesgesundheitsbl Gesundheitsforsch Gesundheitsschutz 25:907-924

33. Kommission für Krankenhaushygiene und Infektionsprävention (2000) Prävention der nosokomialen Pneumonie. Mitteilung der Kommission für Krankenhaushygiene und Infektionsprävention am Robert Koch-Institut. Bundesgesundheitsbl Gesundheitsforsch Gesundheitsschutz 43:302-309

34. Kommission für Krankenhaushygiene und Infektionsprävention am Robert Koch-Institut (1999) Empfehlungen zur Prävention und Kontrolle Katheter-assoziierter Harnwegsinfektionen. Bundesgesundheitbl Gesundheitsforsch Gesundheitsschutz 42:806-809

35. Kommission für Krankenhaushygiene und Infektionsprävention am Robert Koch-Institut (2000) Anforderungen der Hygiene bei Operationen und anderen invasiven Eingriffen. Bundesgesundheitsbl Gesundheitsforsch Gesundheitsschutz 43:644-648

36. Kommission für Krankenhaushygiene und Infektionsprävention am Robert Koch-Institut (1999) Empfehlung zur Prävention und Kontrolle von Methicillin-resistenten Staphylococcus aureusStämmen (MRSA) in Krankenhäusern und anderen medizinischen Einrichtungen - Mitteilung der Kommission für Krankenhaushygiene und Infektionsprävention am RKI. Bundesgesundheitsbl Gesundheitsforsch Gesundheitsschutz 42:954-958

37. Kommission für Krankenhaushygiene und Infektionsprävention (2002) Ausbruchsmanagement und strukturiertes Vorgehen bei gehäuftem Auftreten nosokomialer Infektionen. Empfehlung der Kommission für Krankenhaushygiene und Infektionsprävention am Robert Koch-Institut. Bundesgesundheitsbl Gesundheitsforsch Gesundheitsschutz 45:180-186

38. Kommission für Krankenhaushygiene und Infektionsprävention (2004) Anforderung an die Hygiene bei der Reinigung und Desinfektion von Flächen. Empfehlung der Kommission für Krankenhaushygiene und Infektionsprävention am Robert Koch-Institut. Bundesgesundheitsbl Gesundheitsforsch Gesundheitsschutz 47:51-61

39. Kommission für Krankenhaushygiene und Infektionsprävention am Robert Koch-Institut (2006) Infektionsprävention in der Zahnheilkunde Anforderungen an die Hygiene. Mitteilung der Kommission für Krankenhaushygiene und Infektionsprävention am Robert Koch-Institut. Bundesgesundheitsbl Gesundheitsforsch Gesundheitsschutz 49:375-394

40. Exner M, Just HM (2009) Personnel and organizational prerequisites for prevention and control of nosocomial infections. Bundesgesundheitsbl Gesundheitsforsch Gesundheitsschutz 52:889890

41. Risi GF, Tomascak V (1998) Prevention of infection in the immunocompromised host. Am J Infect Control 26:594-604

42. Simon A, Ammann RA, Bode U et al (2008) Nosocomial infections in pediatric cancer patients: results of a prospective surveillance study from 7 university hospitals in Germany and Switzerland. BMC Infect Dis E-Pub May 23:70
43. Hachem R, Raad I (2002) Prevention and management of long-term catheter related infections in cancer patients. Cancer Invest 20:11051113

44. Mirro J Jr, Rao BN, Kumar M et al (1990) A comparison of placement techniques and complications of externalized catheters and implantable port use in children with cancer. J Pediatr Surg 25:120-124

45. Morrison VA, Peterson BA, Bloomfield CD (1990) Nosocomial septicemia in the cancer patient: the influence of central venous access devices, neutropenia, and type of malignancy. Med Pediatr Oncol 18:209-216

46. Raad I (1998) Intravascular-catheter-related infections. Lancet 351:893-898

47. Urrea M, Rives S, Cruz O et al (2004) Nosocomial infections among pediatric hematology/oncology patients: results of a prospective incidence study. Am J Infect Control 32:205-208

48. Hoff J van, Berg AT, Seashore JH (1990) The effect of right atrial catheters on infectious complications of chemotherapy in children. J Clin Oncol 8:1255-1262

49. Fatkenheuer $G$, Buchheidt D, Cornely OA et al (2003) Central venous catheter (CVC)-related infections in neutropenic patients - guidelines of the Infectious Diseases Working Party (AGIHO) of the German Society of Hematology and Oncology (DGHO). Ann Hematol 82(Suppl 2):S149S157

50. Fatkenheuer G, Cornely O, Seifert H (2002) Clinical management of catheter-related infections. Clin Microbiol Infect 8:545-550

51. Mermel LA, Farr BM, Sherertz RJ et al (2001) Guidelines for the management of intravascular catheter-related infections. J Intraven Nurs 24:180205

52. Jarvis WR (2002) The evolving world of healthcare-associated bloodstream infection surveillance and prevention: is your system as good as you think? Infect Control Hosp Epidemiol 23:236238

53. Jarvis WR (2004) Controlling healthcare-associated infections: the role of infection control and antimicrobial use practices. Semin Pediatr Infect Dis 15:30-40

54. McCarthy A, Rao JS, Byrne M et al (1998) Central venous catheter infections treated with teicoplanin. Eur J Haematol (Suppl 62):15-17

55. Farr BM, Salgado CD, Karchmer TB, Sherertz RJ (2001) Can antibiotic-resistant nosocomial infections be controlled? Lancet Infect Dis 1:38-45

56. Gaynes R, Edwards R, National Nosocomial Surveillance System (2005) Overview of nosocomial infections caused by gram-negative bacilli. Clin Infect Dis 41:848-854

57. Bodey G, Buckley M, Sathe Y, Freireich EJ (1966) Quantitative relationships between circulating leukocytes and infection in patients with acute leukemia. Ann Intern Med 64:328-340

58. Torres HA, Bodey GP, Rolston KV et al (2003) Infections in patients with aplastic anemia: experience at a tertiary care cancer center. Cancer 98:86-93

59. Catenacci DV, Schiller GJ (2005) Myelodysplasic syndromes: a comprehensive review. Blood Rev 19:301-319

60. Dallorso S, Manzitti C, Dodero P et al (2003) Uneventful outcome of unrelated hematopoietic stem cell transplantation in a patient with leukemic transformation of Kostmann syndrome and long-lasting invasive pulmonary mycosis. Eur J Haematol 70:322-325
61. Donadieu J, Leblanc T, Bader Meunier B et al (2005) Analysis of risk factors for myelodysplasias, leukemias and death from infection among patients with congenital neutropenia. Experience of the French severe chronic neutropenia study group. Haematologica 90:45-53

62. Ferry C, Ouachee M, Leblanc T et al (2005) Hematopoietic stem cell transplantation in severe congenital neutropenia: experience of the French SCN register. Bone Marrow Transplant 35:45-50

63. Maschmeyer $G$, Beinert T, Buchheidt $D$ et al (2003) Diagnosis and antimicrobial therapy of pulmonary infiltrates in febrile neutropenic patients - guidelines of the Infectious Diseases Working Party (AGIHO) of the German Society of Hematology and Oncology (DGHO). Ann Hematol 82(Suppl 2):S118-S126

64. Maschmeyer $\mathrm{G}$, Beinert T, Buchheidt D et al (2009) Diagnosis and antimicrobial therapy of lung infiltrates in febrile neutropenic patients: guidelines of the Infectious Diseases Working Party of the German Society of Haematology and Oncology. Eur J Cancer 45:2462-2472

65. Kontoyiannis DP, Bodey GP (2002) Invasive aspergillosis in 2002: an update. Eur J Clin Microbiol Infect Dis 21:161-172

66. Kontoyiannis DP, Lionakis MS, Lewis RE et al (2005) Zygomycosis in a tertiary-care cancer center in the era of Aspergillus-active antifungal therapy: a case-control observational study of 27 recent cases. J Infect Dis 191:1350-1360

67. Kontoyiannis DP, Torres HA, Chagua $\mathrm{M}$ et al (2004) Trichosporonosis in a tertiary care cancer center: risk factors, changing spectrum and determinants of outcome. Scand J Infect Dis 36:564-569

68. Kontoyiannis DP, Vaziri I, Hanna HA et al (2001) Risk factors for candida tropicalis fungemia in patients with cancer. Clin Infect Dis 33:16761681

69. Lex C, Korholz D, Kohlmuller B et al (2001) Infectious complications in children with acute lymphoblastic leukemia and T-cell lymphoma - a rationale for tailored supportive care. Support Care Cancer 9:514-521

70. Lehrnbecher T (2001) Intravenous immunoglobulins in the prevention of infection in children with hematologic-oncologic diseases. Klin Padiatr 213(Suppl 1):A103-A105

71. American Academy of Pediatrics, Committee on Infectious Diseases (2000) American academy of pediatrics. Committee on Infectious Diseases. Policy statement: recommendations for the prevention of pneumococcal infections, including the use of pneumococcal conjugate vaccine (Prevnar), pneumococcal polysaccharide vaccine, and antibiotic prophylaxis. Pediatrics 106:362366

72. Davidson RN, Wall RA (2001) Prevention and management of infections in patients without a spleen. Clin Microbiol Infect 7:657-660

73. Montalembert M de, Lenoir G (2004) Antibiotic prevention of pneumococcal infections in asplenic hosts: admission of insufficiency. Ann Hematol 83:18-21

74. Hasse B, Moll C, Oehy K et al (2005) Anti-infectious prophylaxis after splenectomy: current practice in an eastern region of Switzerland. Swiss Med Wkly 135:291-296

75. Bow EJ (1998) Infection risk and cancer chemotherapy: the impact of the chemotherapeutic regimen in patients with lymphoma and solid tissue malignancies. J Antimicrob Chemother 41(Suppl D):1-5 
76. Cornely OA, Ullmann AJ, Karthaus M (2004) Opportunistic infections after treatment with monoclonal antibodies. Wien Med Wochenschr 154:209-217

77. Dai MS, Chao TY, Kao WY et al (2004) Delayed hepatitis $B$ virus reactivation after cessation of preemptive lamivudine in lymphoma patients treated with rituximab plus CHOP. Ann Hematol 83:769-774

78. Endo T, Sakai T, Fujimoto K et al (2001) A possible role for lamivudine as prophylaxis against hepatitis $B$ reactivation in carriers of hepatitis $B$ who undergo chemotherapy and autologous peripheral blood stem cell transplantation for non-Hodgkin's lymphoma. Bone Marrow Transplant 27:433-436

79. Lin PC, Poh SB, Lee MY et al (2005) Fatal fulminant hepatitis $B$ after withdrawal of prophylactic lamivudine in hematopoietic stem cell transplantation patients. Int J Hematol 81:349-351

80. Pelizzari AM, Motta M, Cariani E et al (2004) Frequency of hepatitis $B$ virus mutant in asymptomatic hepatitis $B$ virus carriers receiving prophylactic lamivudine during chemotherapy for hematologic malignancies. Hematol J 5:325-328

81. Rossi G (2003) Prophylaxis with lamivudine of hepatitis $\mathrm{B}$ virus reactivation in chronic $\mathrm{HbsAg}$ carriers with hemato-oncological neoplasias treated with chemotherapy. Leuk Lymphoma 44:759-766

82. Rossi G, Pelizzari A, Motta M, Puoti M (2001) Primary prophylaxis with lamivudine of hepatitis $B$ virus reactivation in chronic $\mathrm{HbsAg}$ carriers with lymphoid malignancies treated with chemotherapy. Br J Haematol 115:58-62

83. Yeo W, Chan PK, Ho WM et al (2004) Lamivudine for the prevention of hepatitis $B$ virus reactivation in hepatitis B s-antigen seropositive cancer patients undergoing cytotoxic chemotherapy. J Clin Oncol 22:927-934

84. Akiyama H, Yoshinaga H, Tanaka T et al (1997) Effects of cyclosporin A on hepatitis $C$ virus infection in bone marrow transplant patients. Bone Marrow Transplantation Team. Bone Marrow Transplant 20:993-995

85. Widell A, Christensson B, Wiebe T et al (1999) Epidemiologic and molecular investigation of outbreaks of hepatitis $C$ virus infection on a pediatric oncology service. Ann Intern Med 130:130-134

86. Rieske K, Domula M, Liebert UG et al (1998) Clinical aspects and epidemiology of hepatitis $C$ in immunosuppressed children with mostly oncologic diseases. Klin Padiatr 210:274-278

87. Styczynski J, Wysocki M, Koltan S, Kurylak A (2001) Epidemiologic aspects and preventive strategy of hepatitis $B$ and $C$ viral infections in children with cancer. Pediatr Infect Dis J 20:1042-1049

88. Knoll A, Helmig M, Peters O, Jilg W (2001) Hepatitis $C$ virus transmission in a pediatric oncology ward: analysis of an outbreak and review of the literature. Lab Invest 81:251-262

89. Weinstock DM, Rogers M, Eagan J et al (2002) Nosocomial central venous catheter infections among patients with different types of cancer. Infect Control Hosp Epidemiol 23:234-235

90. Weisman LE (2004) Coagulase-negative staphylococcal disease: emerging therapies for the neonatal and pediatric patient. Curr Opin Infect Dis 17:237-241
91. Viscoli C, Castagnola E, Giacchino M et al (1999) Bloodstream infections in children with cancer: a multicentre surveillance study of the Italian Association of Paediatric Haematology and Oncology. Supportive therapy group-infectious diseases section. Eur J Cancer 35:770-774

92. Wolf $\mathrm{HH}$, Leithauser $\mathrm{M}$, Maschmeyer $\mathrm{G}$ et al (2008) Central venous catheter-related infections in hematology and oncology: Guidelines of the Infectious Diseases Working Party (AGIHO) of the German Society of Hematology and Oncology (DGHO). Ann Hematol 87:863-876

93. Simon A, Ammann RA, Wiszniewsky G et al (2008) Taurolidine-citrate lock solution (TauroLock $^{\mathrm{TM}}$ ) significantly reduces CVAD-associated Gram positive infections in paediatric cancer patients. BMC Infectious Diseases 8:102

94. Simon A, Beutel K, Hasan C, Bode U (2005) Evidence-based recommendation for the management of long-term central venous access devices in pediatric patients. German Society of Pediatric Hematology and Oncology (GPOH) Bonn

95. Simon A, Bode U, Beutel K (2006) Diagnosis and treatment of catheter-related infections in paediatric oncology: an update. Clin Microbiol Infect 12:606-620

96. O'Grady NP, Alexander M, Dellinger EP et al (2002) Guidelines for the prevention of intravascular catheter-related infections. The hospital infection control practices advisory committee, center for disese control and prevention, u.s. Pediatrics 110:e51

97. Raad I (2000) Management of intravascular catheter-related infections. J Antimicrob Chemother 45:267-270

98. Sitges-Serra A, Girvent M (1999) Catheter-related bloodstream infections. World J Surg 23:589595

99. Blot F, Nitenberg G, Brun-Buisson C (2000) New tools in diagnosing catheter-related infections. Support Care Cancer 8:287-292

100. Bouza E, Burillo A, Munoz P (2002) Catheter-related infections: diagnosis and intravascular treatment. Clin Microbiol Infect 8:265-274

101. Longuet P, Douard MC, Arlet G et al (2001) Venous access port-related bacteremia in patients with acquired immunodeficiency syndrome or cancer: the reservoir as a diagnostic and therapeutic tool. Clin Infect Dis 32:1776-1783

102. Lacey S, Want SV (1991) Pseudomonas pickettii infections in a paediatric oncology unit. J Hosp Infect 17:45-51

103. Marroni M, Pasticci MB, Pantosti A et al (2003) Outbreak of infusion-related septicemia by Ralstonia pickettii in the oncology department. Tumori 89:575-576

104. Pegues DA, Carson LA, Anderson RL et al (1993) Outbreak of Pseudomonas cepacia bacteremia in oncology patients. Clin Infect Dis 16:407-411

105. Attar A, Messing B (2001) Evidence-based prevention of catheter infection during parenteral nutrition. Curr Opin Clin Nutr Metab Care 4:211218

106. Ball PA (2003) Intravenous in-line filters: filtering the evidence. Curr Opin Clin Nutr Metab Care 6:319-325

107. Christensen ML, Hancock ML, Gattuso J et al (1993) Parenteral nutrition associated with increased infection rate in children with cancer. Cancer 72:2732-2738
108. Hodge D, Puntis JW (2002) Diagnosis, prevention, and management of catheter related bloodstream infection during long term parenteral nutrition. Arch Dis Child Fetal Neonatal Ed 87: F21-F24

109. Lenssen $\mathrm{P}$, Bruemmer BA, Bowden RA et al (1998) Intravenous lipid dose and incidence of bacteremia and fungemia in patients undergoing bone marrow transplantation. Am J Clin Nutr 67:927-933

110. Moukarzel AA, Haddad I, Ament ME et al (1994) 230 patient years of experience with home longterm parenteral nutrition in childhood: natural history and life of central venous catheters. J Pediatr Surg 29:1323-1327

111. Pollack PF, Kadden M, Byrne WJ et al (1981) 100 patient years' experience with the Broviac silastic catheter for central venous nutrition. JPEN J Parenter Enteral Nutr 5:32-36

112. Puntis JW, Holden CE, Smallman S et al (1991) Staff training: a key factor in reducing intravascular catheter sepsis. Arch Dis Child 66:335-337

113. Moreira BM, Leobons MB, Pellegrino FL et al (2005) Ralstonia pickettii and Burkholderia cepacia complex bloodstream infections related to infusion of contaminated water for injection. J Hosp Infect 60:51-55

114. Bahles S, Schnitzler N (2000) Infektionsschutzgesetz - Kommentar und Vorschriftensammlung. Kohlhammer, Stuttgart Berlin Köln

115. Gastmeier P, Stamm-Balderjahn S, Hansen S et al (2005) How outbreaks can contribute to prevention of nosocomial infection: analysis of 1,022 outbreaks. Infect Control Hosp Epidemiol 26:357-361

116. Pusch D, Oh DY, Wolf S et al (2005) Detection of enteric viruses and bacterial indicators in German environmental waters. Arch Virol 150:929947

117. Simon A, Schildgen $O$, Maria Eis-Hubinger $A$ et al (2006) Norovirus outbreak in a pediatric oncology unit. Scand J Gastroenterol 41:693-699

118. Rayani A, Bode U, Habas E et al (2007) Rotavirus infections in paediatric oncology patients: a matched-pairs analysis. Scand J Gastroenterol 42:81-87

119. Simon A, Bode U, Fleischhack $G$, Kramer M (2005) Surveillance of nosocomial infections in pediatric cancer patients. Am J Infect Control 33:611

120. Simon A, Khurana K, Wilkesmann A et al (2006) Nosocomial respiratory syncytial virus infection: impact of prospective surveillance and targeted infection control. Int J Hyg Environ Health 209:317-324

121. Hall CB (2000) Nosocomial respiratory syncytial virus infections: the "Cold War" has not ended. Clin Infect Dis 31:590-596

122. Eisen D, Essell J, Broun ER (1997) Oral cavity complications of bone marrow transplantation. Semin Cutan Med Surg 16:265-272

123. Barker GJ (1999) Current practices in the oral management of the patient undergoing chemotherapy or bone marrow transplantation. Support Care Cancer 7:17-20

124. Solomon CS, Shaikh AB, Arendorf TM (1995) An efficacious oral health care protocol for immunocompromised patients. Spec Care Dentist 15:228-233

125. Philpott-Howard J (1996) Prevention of fungal infections in hematology patients. Infect Control Hosp Epidemiol 17:545-551 
126. Patel R, Paya CV (1997) Infections in solid-organ transplant recipients. Clin Microbiol Rev 10:86124

127. Hicks KL, Chemaly RF, Kontoyiannis DP (2003) Common community respiratory viruses in patients with cancer: more than just ${ }_{\text {"common }}$ colds". Cancer 97:2576-2587

128. Couch RB, Englund JA, Whimbey E (1997) Respiratory viral infections in immunocompetent and immunocompromised persons. Am J Med 102:2-9; discussion 25-26

129. Hirsch HH, Steffen I, Francioli P, Widmer AF (2006) Respiratory syncytial virus infections: measures in immunocompromised patients. Schweiz Rundsch Med Prax 95:61-66

130. Burke JP (2003) Infection control - a problem for patient safety. N Engl J Med 348:651-656

131. Pittet $D$ (2000) Improving compliance with hand hygiene in hospitals. Infect Control Hosp Epidemiol 21:381-386

132. Harbarth S, Sudre P, Dharan S et al (1999) Outbreak of Enterobacter cloacae related to understaffing, overcrowding, and poor hygiene practices. Infect Control Hosp Epidemiol 20:598-603

133. Boulay BR, Murray CJ, Ptak J et al (2006) An outbreak of pertussis in a hematology-oncology care unit: implications for adult vaccination policy. Infect Control Hosp Epidemiol 27:92-95

134. Nair D, Gupta N, Kabra S et al (1999) Salmonella senftenberg: a new pathogen in the burns ward. Burns 25:723-727

135. Blok HE, Troelstra A, Kamp-Hopmans TE et al (2003) Role of healthcare workers in outbreaks of methicillin-resistant Staphylococcus aureus: a 10-year evaluation from a Dutch university hospital. Infect Control Hosp Epidemiol 24:679-685

136. Chuman Y, Takata T, Sameshima H et al (2003) Campylobacter fetus bacteremia in a patient with adult T cell leukemia. Clin Infect Dis 36:1497-1498

137. Monno R, Rendina M, Ceci G et al (2004) Campylobacter fetus bacteremia in an immunocompromised patient: case report and review of the literature. New Microbiol 27:281-285

138. Monselise A, Blickstein D, Ostfeld I et al (2004) A case of cellulitis complicating Campylobacter jejuni subspecies jejuni bacteremia and review of the literature. Eur J Clin Microbiol Infect Dis 23:718-721

139. Shehabi AA, Abu-Al-Soud W, Mahafzah A et al (2004) Investigation of Burkholderia cepacia nosocomial outbreak with high fatality in patients suffering from diseases other than cystic fibrosis. Scand J Infect Dis 36:174-178

140. Remington J, Schimpff SC (1981) Please don't eat the salads. N Engl J Med 304:433-435

141. Exner M, Kramer A, Lajoie L et al (2005) Prevention and control of health care-associated waterborne infections in health care facilities. Am J Infect Control 33:S26-S40

142. Wiesmayr S, Tabarelli W, Stelzmueller I et al (2005) Listeria meningitis in transplant recipients. Wien Klin Wochenschr 117:229-233

143. Rivero GA, Torres HA, Rolston KV, Kontoyiannis DP (2003) Listeria monocytogenes infection in patients with cancer. Diagn Microbiol Infect Dis 47:393-398

144. Mora J, White M, Dunkel IJ (1998) Listeriosis in pediatric oncology patients. Cancer 83:817-820

145. Ponticelli C, Campise MR (2005) Neurological complications in kidney transplant recipients. J Nephrol 18:521-528
146. Willems RJ, Top J, Santen M van et al (2005) Global spread of vancomycin-resistant Enterococcus faecium from distinct nosocomial genetic complex. Emerg Infect Dis 11:821-828

147. Moellering RC Jr (1998) Vancomycin-resistant enterococci. Clin Infect Dis 26:1196-1199

148. Bouakline A, Lacroix C, Roux N et al (2000) Fungal contamination of food in hematology units. J Clin Microbiol 38:4272-4273

149. Eccles NK, Scott GM (1992) Aspergillus in pepper. Lancet 339:618

150. Wilson C, Dettenkofer M, Jonas D, Daschner FD (2004) Pathogen growth in herbal teas used in clinical settings: a possible source of nosocomial infection? Am J Infect Control 32:117-119

151. Hauer T, Jonas D, Dettenkofer M, Daschner FD (1999) Tea as a source of Acinetobacter baumannii ventilator-associated pneumonia? Infect Control Hosp Epidemiol 20:594

152. Schmid I, Albert M, Stachel D, Simon A (2008) Nahrungsmittelrestriktionen zur Infektionsprävention bei Kindern mit Krebserkrankung: Was ist gesichert und was ist sinnvoll? Hygiene \& Medizin 33:16-24

153. Todd J, Schmidt M, Christain J, Williams R (1999) The low-bacteria diet for immunocompromised patients. Reasonable prudence or clinical superstition? Cancer Pract 7:205-207

154. Dols CL, Bowers JM, Copfer AE (2001) Preventing food- and water-borne illnesses. Am J Nurs 101:24AA-24HH

155. Smith LH, Besser SG (2000) Dietary restrictions for patients with neutropenia: a survey of institutional practices. Oncol Nurs Forum 27:515520

156. Lau SK, Woo PC, Leung KW, Yuen KY (2002) Emergence of cotrimoxazole- and quinolone-resistant Campylobacter infections in bone marrow transplant recipients. Eur J Clin Microbiol Infect Dis 21:127-129

157. Nassauer A (2006) Anforderungen an die Hygiene bei der Lebensmittelversorgung und ihre Qualität - Hinweise und Kommentierung. Epid Bull 29:228-229

158. French MR, Levy-Milne R, Zibrik D (2001) A survey of the use of low microbial diets in pediatric bone marrow transplant programs. J Am Diet Assoc 101:1194-1198

159. Mank A, Lelie $H$ van der (2003) Is there still an indication for nursing patients with prolonged neutropenia in protective isolation? An evidence-based nursing and medical study of 4 years experience for nursing patients with neutropenia without isolation. Eur J Oncol Nurs 7:17-23

160. Dadd G, McMinn P, Monterosso L (2003) Protective isolation in hemopoietic stem cell transplants: a review of the literature and single institution experience. J Pediatr Oncol Nurs 20:293300

161. Fenelon $L$ (1998) Strategies for prevention of infection in short-duration neutropenia. Infect Control Hosp Epidemiol 19:590-592

162. Fenelon LE (1995) Protective isolation: who needs it? J Hosp Infect (Suppl 30):218-222

163. Moody K, Charlson ME, Finlay J (2002) The neutropenic diet: what's the evidence? J Pediatr Hematol Oncol 24:717-721

164. Pizzo PA, Purvis DS, Waters C (1982) Microbiologic evaluation of food items. J Am Diet Assoc 81:272-279

165. Rose JB (1997) Environmental ecology of Cryptosporidium and public health implications. Annu Rev Public Health 18:135-161
166. Leclerc H, Schwartzbrod L, Dei-Cas E (2002) Microbial agents associated with waterborne diseases. Crit Rev Microbiol 28:371-409

167. Hall J, Hodgson G, Kerr KG (2004) Provision of safe potable water for immunocompromised patients in hospital. J Hosp Infect 58:155-158

168. Engelhart S, Krizek L, Glasmacher A et al (2002) Pseudomonas aeruginosa outbreak in a haematology-oncology unit associated with contaminated surface cleaning equipment. J Hosp Infect 52:93-98

169. Wilkinson FH, Kerr KG (1998) Bottled water as a source of multi-resistant Stenotrophomonas and Pseudomonas species for neutropenic patients. Eur J Cancer Care (Engl) 7:12-14

170. Bert F, Maubec E, Bruneau B et al (1998) Multi-resistant Pseudomonas aeruginosa outbreak associated with contaminated tap water in a neurosurgery intensive care unit. J Hosp Infect 39:5362

171. Buttery JP, Alabaster SJ, Heine RG et al (1998) Multiresistant Pseudomonas aeruginosa outbreak in a pediatric oncology ward related to bath toys. Pediatr Infect Dis J 17:509-513

172. Muscarella LF (2004) Contribution of tap water and environmental surfaces to nosocomial transmission of antibiotic-resistant Pseudomonas aeruginosa. Infect Control Hosp Epidemiol 25:342-345

173. Oren I, Zuckerman T, Avivi I et al (2002) Nosocomial outbreak of Legionella pneumophila serogroup 3 pneumonia in a new bone marrow transplant unit: evaluation, treatment and control. Bone Marrow Transplant 30:175-179

174. Tablan OC, Anderson LJ, Besser R et al (2004) Guidelines for preventing health-care-associated pneumonia, 2003: recommendations of CDC and the Healthcare Infection Control Practices Advisory Committee. MMWR Recomm Rep 53:136

175. Greenberg D, Chiou CC, Famigilleti R et al (2006) Problem pathogens: paediatric legionellosis implications for improved diagnosis. Lancet Infect Dis 6:529-535

176. O'Neill $E$, Humphreys $H$ (2005) Surveillance of hospital water and primary prevention of nosocomial legionellosis: what is the evidence? J Hosp Infect 59:273-279

177. Kappstein I, Grundmann H, Hauer T, Niemeyer C (2000) Aerators as a reservoir of Acinetobacter junii: an outbreak of bacteraemia in paediatric oncology patients. J Hosp Infect 44:27-30

178. Nasser RM, Rahi AC, Haddad MF et al (2004) Outbreak of Burkholderia cepacia bacteremia traced to contaminated hospital water used for dilution of an alcohol skin antiseptic. Infect Control Hosp Epidemiol 25:231-239

179. Perola $O$, Nousiainen $T$, Suomalainen $S$ et al (2002) Recurrent Sphingomonas paucimobilis bacteraemia associated with a multi-bacterial water-borne epidemic among neutropenic patients. J Hosp Infect 50:196-201

180. Sakhnini E, Weissmann A, Oren I (2002) Fulminant Stenotrophomonas maltophilia soft tissue infection in immunocompromised patients: an outbreak transmitted via tap water. Am J Med Sci 323:269-272

181. Kline S, Cameron S, Streifel A et al (2004) An outbreak of bacteremias associated with Mycobacterium mucogenicum in a hospital water supply. Infect Control Hosp Epidemiol 25:10421049 
182. Kauppinen J, Nousiainen $T$, Jantunen E et al (1999) Hospital water supply as a source of disseminated Mycobacterium fortuitum infection in a leukemia patient. Infect Control Hosp Epidemiol 20:343-345

183. Conger NG, O'Connell RJ, Laurel VL et al (2004) Mycobacterium simae outbreak associated with a hospital water supply. Infect Control Hosp Epidemiol 25:1050-1055

184. Exner M, Gornik V (2004) Parasitic zoonoses transmitted by drinking water. Giardiasis and cryptosporidiosis. Bundesgesundheitsbl Gesundheitsforsch Gesundheitsschutz 47:698-704

185. Hajjeh RA, Warnock DW (2001) Counterpoint: invasive aspergillosis and the environment - rethinking our approach to prevention. Clin Infect Dis 33:1549-1552

186. Anaissie EJ, Costa SF (2001) Nosocomial aspergillosis is waterborne. Clin Infect Dis 33:1546-1548

187. Anaissie EJ, Kuchar RT, Rex JH et al (2001) Fusariosis associated with pathogenic fusarium species colonization of a hospital water system: a new paradigm for the epidemiology of opportunistic mold infections. Clin Infect Dis 33:18711878

188. Anaissie EJ, Stratton SL, Dignani MC et al (2002) Cleaning patient shower facilities: a novel approach to reducing patient exposure to aerosolized Aspergillus species and other opportunistic molds. Clin Infect Dis 35:E86-E88

189. Anaissie EJ, Stratton SL, Dignani MC et al (2003) Pathogenic molds (including Aspergillus species) in hospital water distribution systems: a 3year prospective study and clinical implications for patients with hematologic malignancies. Blood 101:2542-2546

190. Anaissie EJ, Stratton SL, Dignani MC et al (2002) Pathogenic Aspergillus species recovered from a hospital water system: a 3-year prospective study. Clin Infect Dis 34:780-789

191. Evans MR, Ribeiro CD, Salmon RL (2003) Hazards of healthy living: bottled water and salad vegetables as risk factors for Campylobacter infection. Emerg Infect Dis 9:1219-1225

192. Tatchou-Nyamsi-Konig JA, Moreau A, Federighi M, Block JC (2007) Behaviour of Campylobacter jejuni in experimentally contaminated bottled natural mineral water. J Appl Microbiol 103:280288

193. Centers for Disease Control and Prevention Cryptosporidiosis. http://www.cdc.gov/crypto/

194. Aumeran C, Paillard C, Robin F et al (2007) Pseudomonas aeruginosa and Pseudomonas putida outbreak associated with contaminated water outlets in an oncohaematology paediatric unit. J Hosp Infect 65:47-53

195. Ferroni A, Nguyen L, Pron B et al (1998) Outbreak of nosocomial urinary tract infections due to Pseudomonas aeruginosa in a paediatric surgical unit associated with tap-water contamination. J Hosp Infect 39:301-307

196. Horcajada JP, Martinez JA, Alcon A et al (2006) Acquisition of multidrug-resistant serratia marcescens by critically III patients who consumed tap water during receipt of oral medication. Infect Control Hosp Epidemiol 27:774-777

197. Verweij PE, Meis JF, Christmann V et al (1998) Nosocomial outbreak of colonization and infection with Stenotrophomonas maltophilia in preterm infants associated with contaminated tap water. Epidemiol Infect 120:251-256
198. Rogues AM, Boulestreau H, Lasheras A et al (2007) Contribution of tap water to patient colonisation with Pseudomonas aeruginosa in a medical intensive care unit. J Hosp Infect 67:72-78

199. Trautmann M, Lepper PM, Haller M (2005) Ecology of Pseudomonas aeruginosa in the intensive care unit and the evolving role of water outlets as a reservoir of the organism. Am J Infect Control 33:S41-S49

200. Valles J, Mariscal D, Cortes P et al (2004) Patterns of colonization by Pseudomonas aeruginosa in intubated patients: a 3-year prospective study of 1,607 isolates using pulsed-field gel electrophoresis with implications for prevention of ventilator-associated pneumonia. Intensive Care Med 30:1768-1775

201. Reuter S, Sigge A, Wiedeck H, Trautmann M (2002) Analysis of transmission pathways of Pseudomonas aeruginosa between patients and tap water outlets. Crit Care Med 30:22222228

202. Stout JE, Muder RR, Mietzner S et al (2007) Role of environmental surveillance in determining the risk of hospital-acquired legionellosis: a national surveillance study with clinical correlations. Infect Control Hosp Epidemiol 28:818-824

203. Sabria M, Modol JM, Garcia-Nunez M et al (2004) Environmental cultures and hospital-acquired Legionnaires' disease: a 5-year prospective study in 20 hospitals in Catalonia, Spain. Infect Control Hosp Epidemiol 25:1072-1076

204. Corso PS, Kramer MH, Blair KA et al (2003) Cost of illness in the 1993 waterborne Cryptosporidium outbreak, Milwaukee, Wisconsin. Emerg Infect Dis 9:426-431

205. Hoxie NJ, Davis JP, Vergeront JM et al (1997) Cryptosporidiosis-associated mortality following a massive waterborne outbreak in Milwaukee, Wisconsin. Am J Public Health 87:20322035

206. Trautmann M, Bauer C, Schumann C et al (2006) Common RAPD pattern of Pseudomonas aeruginosa from patients and tap water in a medical intensive care unit. Int J Hyg Environ Health 209:325-331

207. Vianelli N, Giannini MB, Quarti C et al (2006) Resolution of a Pseudomonas aeruginosa outbreak in a hematology unit with the use of disposable sterile water filters. Haematologica 91:983-985

208. Rechenburg A, Engelhart S, Exner M (2001) Spring water in hospitals - an alternative drinking water concerns with processed mineral water? Dtsch Med Wochenschr 126:50

209. Vonberg RP, Eckmanns T, Bruderek J et al (2005) Use of terminal tap water filter systems for prevention of nosocomial legionellosis. J Hosp Infect 60:159-162

210. Vonberg RP, Rotermund-Rauchenberger D, Gastmeier P (2005) Reusable terminal tap water filters for nosocomial legionellosis prevention. Ann Hematol 84:403-405

211. Adler S, Eikenberg M, Daschner F (2007) Drinking water in hospitals: water coolers vs. drinking water systems vs. mineral water in bottles. Dtsch Med Wochenschr 132:281-284

212. Papadopoulou A, MacDonald A, Williams MD et al (1997) Enteral nutrition after bone marrow transplantation. Arch Dis Child 77:131-136

213. Zamberlan da Silva ME, Santana RG, Guilhermetti $\mathrm{M}$ et al (2008) Comparison of the bacteriological quality of tap water and bottled mineral water. Int J Hyg Environ Health 211:504-509
214. Eckmanns T, Oppert M, Martin M et al (2008) An outbreak of hospital-acquired Pseudomonas aeruginosa infection caused by contaminated bottled water in intensive care units. Clin Microbiol Infect 14:454-458

215. Monforte V, Roman A, Gavalda J et al (2001) Nebulized amphotericin B prophylaxis for Aspergillus infection in lung transplantation: study of risk factors. J Heart Lung Transplant 20:12741281

216. Manuel RJ, Kibbler CC (1998) The epidemiology and prevention of invasive aspergillosis. J Hosp Infect 39:95-109

217. Perdelli F, Cristina ML, Sartini M et al (2006) Fungal contamination in hospital environments. Infect Control Hosp Epidemiol 27:44-47

218. Burwen DR, Lasker BA, Rao $\mathrm{N}$ et al (2001) Invasive aspergillosis outbreak on a hematologyoncology ward. Infect Control Hosp Epidemiol 22:45-48

219. Iwen PC, Davis JC, Reed EC et al (1994) Airborne fungal spore monitoring in a protective environment during hospital construction, and correlation with an outbreak of invasive aspergillosis. Infect Control Hosp Epidemiol 15:303-306

220. Loo VG, Bertrand C, Dixon C et al (1996) Control of construction-associated nosocomial aspergillosis in an antiquated hematology unit. Infect Control Hosp Epidemiol 17:360-364

221. Barnes RA, Rogers TR (1989) Control of an outbreak of nosocomial aspergillosis by laminar airflow isolation. J Hosp Infect 14:89-94

222. Thio CL, Smith D, Merz WG et al (2000) Refinements of environmental assessment during an outbreak investigation of invasive aspergillosis in a leukemia and bone marrow transplant unit. Infect Control Hosp Epidemiol 21:18-23

223. Engelhart S, Hanfland J, Glasmacher A et al (2003) Impact of portable air filtration units on exposure of haematology-oncology patients to airborne Aspergillus fumigatus spores under field conditions. J Hosp Infect 54:300-304

224. Anderson K, Morris G, Kennedy H et al (1996) Aspergillosis in immunocompromised paediatric patients: associations with building hygiene, design, and indoor air. Thorax 51:256-261

225. Rhame FS, Streifel AJ, Kersey JH Jr, McGlave PB (1984) Extrinsic risk factors for pneumonia in the patient at high risk of infection. Am J Med 76:4252

226. ( $\mathrm{n}$ a) Centers for Diseases Control and Prevention, Infectious Disease Society of America, American Society of Blood and Marrow Transplantation (2000) Guidelines for preventing opportunistic infections among hematopoietic stem cell transplant recipients. MMWR Recomm Rep 49:1125, CE121-127

227. Vonberg RP, Gastmeier P (2006) Nosocomial aspergillosis in outbreak settings. J Hosp Infect 63:246-254

228. Lin SJ, Schranz J, Teutsch SM (2001) Aspergillosis case-fatality rate: systematic review of the literature. Clin Infect Dis 32:358-366

229. Schwartz S, Ruhnke M, Ribaud P et al (2005) Improved outcome in central nervous system aspergillosis, using voriconazole treatment. Blood 106:2641-2645

230. Simon A, Ammann RA, Bode U et al (2008) Healthcare-associated infections in pediatric cancer patients: results of a prospective surveillance study from university hospitals in Germany and Switzerland. BMC Infect Dis 8:70 
231. Muhlemann K, Wenger C, Zenhausern R, Tauber MG (2005) Risk factors for invasive aspergillosis in neutropenic patients with hematologic malignancies. Leukemia 19:545-550

232. Oren I, Goldstein N (2002) Invasive pulmonary aspergillosis. Curr Opin Pulm Med 8:195-200

233. Oren I, Haddad N, Finkelstein R, Rowe JM (2001) Invasive pulmonary aspergillosis in neutropenic patients during hospital construction: before and after chemoprophylaxis and institution of HEPA filters. Am J Hematol 66:257-262

234. Passweg JR, Rowlings PA, Atkinson KA et al (1998) Influence of protective isolation on outcome of allogeneic bone marrow transplantation for leukemia. Bone Marrow Transplant 21:1231-1238

235. Marr KA, Carter RA, Boeckh M et al (2002) Invasive aspergillosis in allogeneic stem cell transplant recipients: changes in epidemiology and risk factors. Blood 100:4358-4366

236. Marr KA, Carter RA, Crippa F et al (2002) Epidemiology and outcome of mould infections in hematopoietic stem cell transplant recipients. Clin Infect Dis 34:909-917

237. Groll AH, Kurz M, Schneider W et al (1999) Fiveyear-survey of invasive aspergillosis in a paediatric cancer centre. Epidemiology, management and long-term survival. Mycoses 42:431-442

238. Groll AH, Ritter J, Muller FM (2001) Prevention of fungal infections in children and adolescents with cancer. Klin Padiatr 213(Suppl 1):A50-A68

239. Herbrecht $R$, Natarajan-Amé $S$, Letscher-Bru $V$, Canuet M (2004) Invasive pulmonary aspergillosis. Semin Respir Crit Care Med 25:191-202

240. Bille J, Marchetti O, Calandra T (2005) Changing face of health-care associated fungal infections. Curr Opin Infect Dis 18:314-319

241. Iwen PC, Reed EC, Armitage JO et al (1993) Nosocomial invasive aspergillosis in lymphoma patients treated with bone marrow or peripheral stem cell transplants. Infect Control Hosp Epidemiol 14:131-139

242. Sherertz RJ, Belani A, Kramer BS et al (1987) Impact of air filtration on nosocomial Aspergillus infections. Unique risk of bone marrow transplant recipients. Am J Med 83:709-718

243. Leenders $A C$, Belkum $A$ van, Behrendt $M$ et al (1999) Density and molecular epidemiology of Aspergillus in air and relationship to outbreaks of Aspergillus infection. J Clin Microbiol 37:17521757

244. Alberti C, Bouakline A, Ribaud P et al (2001) Relationship between environmental fungal contamination and the incidence of invasive aspergillosis in haematology patients. J Hosp Infect 48:198-206

245. Cornet M, Levy V, Fleury L et al (1999) Efficacy of prevention by high-efficiency particulate air filtration or laminar airflow against Aspergillus airborne contamination during hospital renovation. Infect Control Hosp Epidemiol 20:508-513

246. Streifel AJ (2002) In with the good air. Infect Control Hosp Epidemiol 23:488-490

247. Eckmanns T, Ruden H, Gastmeier P (2006) The influence of high-efficiency particulate air filtration on mortality and fungal infection among highly immunosuppressed patients: a systematic review. J Infect Dis 193:1408-1418

248. Hahn T, Cummings KM, Michalek AM et al (2002) Efficacy of high-efficiency particulate air filtration in preventing aspergillosis in immunocompromised patients with hematologic malignancies. Infect Control Hosp Epidemiol 23:525-531
249. Humphreys H (2004) Positive-pressure isolation and the prevention of invasive aspergillosis. What is the evidence? J Hosp Infect 56:93-100; quiz 163

250. Hayes-Lattin B, Leis JF, Maziarz RT (2005) Isolation in the allogeneic transplant environment: how protective is it? Bone Marrow Transplant 36:373-381

251. Nosari A, Oreste P, Cairoli R et al (2001) Invasive aspergillosis in haematological malignancies: clinical findings and management for intensive chemotherapy completion. Am J Hematol 68:231-236

252. Sipsas NV, Kontoyiannis DP (2006) Clinical issues regarding relapsing aspergillosis and the efficacy of secondary antifungal prophylaxis in patients with hematological malignancies. Clin Infect Dis 42:1584-1591

253. Benjamin DK Jr, Miller WC, Bayliff S et al (2002) Infections diagnosed in the first year after pediatric stem cell transplantation. Pediatr Infect Dis J 21:227-234

254. Kramer A, Schwebke I, Kampf G (2006) How long do nosocomial pathogens persist on inanimate surfaces? A systematic review. BMC Infect Dis $6: 130$

255. Hota B (2004) Contamination, disinfection, and cross-colonization: are hospital surfaces reservoirs for nosocomial infection? Clin Infect Dis 39:1182-1189

256. Muto CA, Jernigan JA, Ostrowsky BE et al (2003) SHEA guideline for preventing nosocomial transmission of multidrug-resistant strains of Staphylococcus aureus and enterococcus. Infect Control Hosp Epidemiol 24:362-386

257. Neely AN (2000) A survey of gram-negative bacteria survival on hospital fabrics and plastics. J Burn Care Rehabil 21:523-527

258. Neely AN, Maley MP (2000) Survival of enterococci and staphylococci on hospital fabrics and plastic. J Clin Microbiol 38:724-726

259. Neely AN, Maley MP (2001) Dealing with contaminated computer keyboards and microbial survival. Am J Infect Control 29:131-132

260. Neely AN, Sittig DF (2002) Basic microbiologic and infection control information to reduce the potential transmission of pathogens to patients via computer hardware. J Am Med Inform Assoc 9:500-508

261. Engelhart E, Fischnaller E, Simon A et al (2008) Mikrobielle Kontamination von Computerbedienungsoberflächen (Tastatur, Maus) in einem Universitätsklinikum unter Alltagsbedingungen Hygiene \& Medizin 33:504-507

262. Blanc DS, Nahimana I, Petignat C et al (2004) Faucets as a reservoir of endemic Pseudomonas aeruginosa colonization/infections in intensive care units. Intensive Care Med 30:1964-1968

263. Halabi M, Wiesholzer-Pittl M, Schoberl J, Mittermayer $\mathrm{H}$ (2001) Non-touch fittings in hospitals: a possible source of Pseudomonas aeruginosa and Legionella spp. J Hosp Infect 49:117-121

264. Hota S, Hirji Z, Stockton K et al (2009) Outbreak of multidrug-resistant Pseudomonas aeruginosa colonization and infection secondary to imperfect intensive care unit room design. Infect Control Hosp Epidemiol 30:25-33

265. Arnouts PJ, Ramael MR, Ysebaert DK et al (1991) Legionella pneumophila peritonitis in a kidney transplant patient. Scand J Infect Dis 23:119122
266. Gahrn-Hansen B, Uldum SA, Schmidt J et al (1995) Nosocomial Legionella pneumophila infection in a nephrology department. Ugeskr Laeger 157:590-594

267. Kusnetsov J, Torvinen E, Perola O et al (2003) CoIonization of hospital water systems by legionellae, mycobacteria and other heterotrophic bacteria potentially hazardous to risk group patients. Apmis 111:546-556

268. Sax H, Dharan S, Pittet D (2002) Legionnaires' disease in a renal transplant recipient: nosocomial or home-grown? Transplantation 74:890-892

269. Gerba CP, Wallis C, Melnick JL (1975) Microbiological hazards of household toilets: droplet production and the fate of residual organisms. Appl Microbiol 30:229-237

270. Barker J, Bloomfield SF (2000) Survival of Salmonella in bathrooms and toilets in domestic homes following salmonellosis. J Appl Microbiol 89:137-144

271. Hemsworth S, Pizer B (2006) Pet ownership in immunocompromised children - a review of the literature and survey of existing guidelines. Eur J Oncol Nurs 10:117-127

272. Plaut M, Zimmerman EM, Goldstein RA (1996) Health hazards to humans associated with domestic pets. Annu Rev Public Health 17:221-245

273. Krauss H, WA, Appel M, Enders B et al (2004) Zoonosen. Deutscher Ärzteverlag, Köln

274. Clare A, Dykewicz H, Jonathan F (2000) Kaplan in collaboration with the Guidelines Working Group Members from CDC tIDSoA, and the American Dociety of Blood and Marrow Transplantation. Guidelines für preventing opportunistic infections among hematopoietic stem cell transplant recipients - recommendations of CDC, the Infectious Disease Society of America and the American Society of Blood and Marrow Transplantation. MMWR 49:1-128

275. Kotton CN (2007) Zoonoses in solid-organ and hematopoietic stem cell transplant recipients. Clin Infect Dis 44:857-866

276. Nosanchuk JD, Shoham S, Fries BC et al (2000) Evidence of zoonotic transmission of Cryptococcus neoformans from a pet cockatoo to an immunocompromised patient. Ann Intern Med 132:205-208

277. Shrestha RK, Stoller JK, Honari G et al (2004) Pneumonia due to Cryptococcus neoformans in a patient receiving infliximab: possible zoonotic transmission from a pet cockatiel. Respir Care 49:606-608

278. Juckett $G$ (1997) Pets and parasites. Am Fam Physician 56:1763-1774, 1777-1778

279. Marcus LC, Marcus E (1998) Nosocomial zoonoses. N Engl J Med 338:757-759

280. Robertson ID, Irwin PJ, Lymbery AJ, Thompson RC (2000) The role of companion animals in the emergence of parasitic zoonoses. Int J Parasitol 30:1369-1377

281. Goldstein EJ (1991) Household pets and human infections. Infect Dis Clin North Am 5:117-130

282. Tan JS (1997) Human zoonotic infections transmitted by dogs and cats. Arch Intern Med 157:1933-1943

283. Krause PJ, Gross PA, Barrett TL et al (1994) Quality standard for assurance of measles immunity among health care workers. The Infectious Diseases Society of America. Infect Control Hosp Epidemiol 15:193-199

284. Uckay I, Sax H, Hugonnet S et al (2005) Consequences of an unsufficient range of immunity in „pediatric" infectious diseases - example with measles. Ther Umsch 62:679-684 
285. Poland GA, Tosh P, Jacobson RM (2005) Requiring influenza vaccination for health care workers: seven truths we must accept. Vaccine 23:2251-2255

286. Russell ML, Henderson EA (2003) The measurement of influenza vaccine coverage among health care workers. Am J Infect Control 31:457461

287. McIntosh ED (2005) Paediatric infections: prevention of transmission and disease-implications for adults. Vaccine 23:2087-2089

288. Tennenberg AM, Brassard JE, Van Lieu J, Dru$\sin$ LM (1997) Varicella vaccination for healthcare workers at a university hospital: an analysis of costs and benefits. Infect Control Hosp Epidemiol 18:405-411

289. Weber DJ, Rutala WA, Hamilton H (1996) Prevention and control of varicella-zoster infections in healthcare facilities. Infect Control Hosp Epidemiol 17:694-705

290. Ständige Impfkommission (STIKO) am Robert Koch-Institut (2005) Hinweise zu Impfungen bei Patienten mit Immundefizienz. Epidemiol Bull 39:1-2

291. Maschmeyer G, Neuburger S, Fritz L et al (2009) A prospective, randomised study on the use of well-fitting masks for prevention of invasive aspergillosis in high-risk patients. Ann Oncol 20:1560-1564

292. Langley JM, Hanakowski M, Bortolussi R (1994) Demand for isolation beds in a pediatric hospital. Am J Infect Control 22:207-211

293. Pottecher B, Herbrecht R, Blanc-Vincent MP et al (2000) Standards, Options and Recommendations (SOR) for the surveillance and the prevention of cross infections in oncology. Federation Nationale des Centres de Lutte Contre le Cancer. Bull Cancer 87:557-591

294. Salminen MK, Rautelin H, Tynkkynen S et al (2006) Lactobacillus bacteremia, species identification, and antimicrobial susceptibility of 85 blood isolates. Clin Infect Dis 42:e35-e44

295. Land MH, Rouster-Stevens K, Woods CR et al (2005) Lactobacillus sepsis associated with probiotic therapy. Pediatrics 115:178-181

296. Kunz AN, Fairchok MP, Noel JM (2005) Lactobacillus sepsis associated with probiotic therapy. Pediatrics 116:517; author reply 517-518

297. Cannon JP, Lee TA, Bolanos JT, Danziger LH (2005) Pathogenic relevance of Lactobacillus: a retrospective review of over 200 cases. Eur J Clin Microbiol Infect Dis 24:31-40

298. Arpi M, Vancanneyt M, Swings J, Leisner JJ (2003) Six cases of Lactobacillus bacteraemia: identification of organisms and antibiotic susceptibility and therapy. Scand J Infect Dis 35:404-408

299. Carretto E, Barbarini D, Marzani FC et al (2001) Catheter-related bacteremia due to Lactobacillus rhamnosus in a single-lung transplant recipient. Scand J Infect Dis 33:780-782

300. Schlegel L, Lemerle S, Geslin P (1998) Lactobacillus species as opportunistic pathogens in immunocompromised patients. Eur J Clin Microbiol Infect Dis 17:887-888

301. Cooper CD, Vincent A, Greene JN et al (1998) Lactobacillus bacteremia in febrile neutropenic patients in a cancer hospital. Clin Infect Dis 26:1247-1248

302. Munoz $P$, Bouza E, Cuenca-Estrella M et al (2005) Saccharomyces cerevisiae fungemia: an emerging infectious disease. Clin Infect Dis 40:1625-1634
303. Herbrecht R, Nivoix Y (2005) Saccharomyces cerevisiae fungemia: an adverse effect of Saccharomyces boulardii probiotic administration. Clin Infect Dis 40:1635-1637

304. Enache-Angoulvant A, Hennequin C (2005) Invasive Saccharomyces infection: a comprehensive review. Clin Infect Dis 41:1559-1568

305. Cassone M, Serra P, Mondello F et al (2003) Outbreak of Saccharomyces cerevisiae subtype boulardii fungemia in patients neighboring those treated with a probiotic preparation of the organism. J Clin Microbiol 41:5340-5343

306. Cesaro S, Chinello P, Rossi L, Zanesco L (2000) Saccharomyces cerevisiae fungemia in a neutropenic patient treated with Saccharomyces boulardii. Support Care Cancer 8:504-505

307. Fiore NF, Conway JH, West KW, Kleiman MB (1998) Saccharomyces cerevisiae infections in children. Pediatr Infect Dis J 17:1177-1179

308. Olver WJ, James SA, Lennard A et al (2002) Nosocomial transmission of Saccharomyces cerevisiae in bone marrow transplant patients. J Hosp Infect 52:268-272

309. Woodcock AA, Steel N, Moore CB et al (2006) Fungal contamination of bedding. Allergy 61:140-142

310. Göttlich E, Engesser K, Bardtke D (1994) Emission von Pilzsporen in Müllverarbeitungsanlagen. Forum Städte-Hygiene 45:321-325

311. Mahieu LM, De Dooy JJ, Laer Van FA et al (2000) A prospective study on factors influencing aspergillus spore load in the air during renovation works in a neonatal intensive care unit. J Hosp Infect 45:191-197

312. Raad I, Hanna H, Osting CH et al (2002) Masking of neutropenic patients on transport from hospital rooms is associated with a decrease in nosocomial aspergillosis during construction. Infect Control Hosp Epidemiol 23:41-43

313. ( $\mathrm{n}$ a) (2006) Hausinstallationen, aus denen Wasser für die Öffentlichkeit bereit gestellt wird, als potenzielles Infektionsreservoir mit besonderer Berücksichtigung von Einrichtungen zur medizinischen Versorgung - Kenntnisstand, Prävention und Kontrolle - Ergebnisse einer Expertenanhörung am 31.03.2004 im Universitätsklinikum Bonn. Bundesgesundheitsbl Gesundheitsforsch Gesundheitsschutz 49:681-686

314. (n a) (2006) Hygienisch-mikrobiologische Untersuchung im Kaltwasser von Wasserversorgungsanlagen nach $\S 3$ Nr. 2 Buchstabe c TrinkwV 2001, aus denen Wasser für die Öffentlichkeit im Sinne des § 18 Abs. 1 TrinkwV 2001 bereitgestellt wird. Empfehlung des Umweltbundesamtes nach Anhörung der Trinkwasserkommission des Bundesministeriums für Gesundheit. Bundesgesundheitsbl Gesundheitsforsch Gesundheitsschutz 49:693-696

315. (n a) (2006) Periodische Untersuchung auf Legionellen in zentralen Erwärmungsanlagen der Hausinstallation nach $\S 3 \mathrm{Nr}$. 2 Buchstabe c TrinkwV 2001, aus denen Wasser für die Öffentlichkeit bereit gestellt wird. Empfehlung des Umweltbundesamtes nach Anhörung der Trinkwasserkommission des Bundesministeriums für Gesundheit. Bundesgesundheitsbl Gesundheitsforsch Gesundheitsschutz 49:697-700

316. Ortolano GA, Russell RL, Angelbeck JA et al (2004) Contamination control in nursing with filtration. Part 1: filters applied to intravenous fluids and point-of-use hospital water. J Infus Nurs 27:89-103
317. Fernandez R, Griffiths R (2008) Water for wound cleansing. Cochrane Database Syst Rev: CD003861

318. Chaberny IF, Gastmeier P (2004) Should electronic faucets be recommended in hospitals? Infect Control Hosp Epidemiol 25:997-1000

319. Hargreaves J, Shireley L, Hansen S et al (2001) Bacterial contamination associated with electronic faucets: a new risk for healthcare facilities. Infect Control Hosp Epidemiol 22:202-205

320. Kommission für Krankenhaushygiene und Infektionsprävention (1999) Prävention und Kontrolle Katheter-assoziierter Harnwegsinfektionen am Robert Koch-Institut. Bundesgesundheitsbl Gesundheitsforsch Gesundheitsschutz 42:806-809

321. Kommission für Krankenhaushygiene und Infektionsprävention (2007) Prävention postoperativer Infektionen im Operationsgebiet. Empfehlungen der Kommission für Krankenhaushygiene und Infektionsprävention am Robert KochInstitut. Bundesgesundheitsbl Gesundheitsforsch Gesundheitsschutz 50:377-393

322. Chadwick PR, Beards G, Brown D et al (2000) Management of hospital outbreaks of gastro-enteritis due to small roundstructured viruses. J Hosp Infect 45:1-10

323. Plößer P (2007) Clostridium difficile: Nachweis von Ribotyp 027 in Deutschschland - Clostridium difficile im Überblick - Hygienemaßnahmen. Hyg Med 32:403-405

324. Robert Koch-Institut (2007) Norovirus Infektionen: Deutliche Zunahme von Gastroenteritiden. Epidemiol Bull 48:428

325. Robert Koch-Institut (2007) RKI-Ratgeber Infektionskrankheiten „Rotaviren“ - Merkblätter für Ärzte:"Aktualisierung vom Juni 2007". Epid Bull 10:77-79

326. Robert Koch-Institut (2008) Clostridium difficile: Zum Stand der Meldungen schwer verlaufender Infektionen in Deutschland. Epidemiol Bull 15:117-118

327. Schneider T, Eckmanns T, Ignatius R et al (2007) Clostridium-difficile-assoziierte Diarrhö. Dtsch Ärztebl 104:1588-1594

328. Robert Koch-Institut Berlin (2000) Surveillance nosokomialer Infektionen sowie die Erfassung von Erregern mit speziellen Resistenzen und Multiresistenzen ( $\$ 6$ Abs. 3 und $\S 23$ Abs. 1 und 2 in Verbindung mit $\S 4$ Abs. 2 Nr. 2 b IfSG). Rechtliche Voraussetzungen und Umsetzungsempfehlungen. Bundesgesundheitsbl Gesundheitsforsch Gesundheitsschutz 43:887-890

329. Auletta JJ, O'Riordan MA, Nieder ML (1999) Infections in children with cancer: a continued need for the comprehensive physical examination. J Pediatr Hematol Oncol 21:501-508

330. Simon A, Fleischhack G, Marklein G, Ritter J (2001) Antimicrobial prophylaxis of bacterial infections in pediatric oncology patients. Klin Padiatr 213(Suppl 1):A22-A37

331. Gorschluter M, Marklein G, Hofling K et al (2002) Abdominal infections in patients with acute leukaemia: a prospective study applying ultrasonography and microbiology. Br J Haematol 117:351-358

332. Bohme A, Ruhnke M, Buchheidt D et al (2003) Treatment of fungal infections in hematology and oncology - guidelines of the Infectious $\mathrm{Di}$ seases Working Party (AGIHO) of the German Society of Hematology and Oncology (DGHO). Ann Hematol 82(Suppl 2):S133-S140 
333. Groll AH, Ritter J (2005) Diagnosis and management of fungal infections and pneumocystis pneumonitis in pediatric cancer patients. Klin Padiatr 217(Suppl 1):37-66

334. Gorschluter M, Glasmacher A, Hahn C et al (2001) Clostridium difficile infection in patients with neutropenia. Clin Infect Dis 33:786-791

335. Neville K, Renbarger J, Dreyer Z (2002) Pneumonia in the immunocompromised pediatric cancer patient. Semin Respir Infect 17:21-32

336. Carlisle PS, Gucalp R, Wiernik PH (1993) Nosocomial infections in neutropenic cancer patients. Infect Control Hosp Epidemiol 14:320-324

337. Dettenkofer M, Ebner W, Bertz H et al (2003) Surveillance of nosocomial infections in adult recipients of allogeneic and autologous bone marrow and peripheral blood stem-cell transplantation. Bone Marrow Transplant 31:795-801

338. Dettenkofer M, Wenzler-Röttele S, Babikir R et al and the Hospital Infection Surveillance System for Patients with Hematologic/Oncologic Malignancies Study Group (2005) Surveillance of nosocomial sepsis and pneumonia in patients with a bone marrow or peripheral blood stem cell transplant: a multicener project. Clin Infect Dis 40:926-931

339. Engelhart S, Glasmacher A, Exner M, Kramer MH (2002) Surveillance for nosocomial infections and fever of unknown origin among adult hematology-oncology patients. Infect Control Hosp Epidemiol 23:244-248

340. Simon A, Fleischhack G, Hasan C et al (2000) Surveillance for nosocomial and central line-related infections among pediatric hematology-oncology patients. Infect Control Hosp Epidemiol 21:592-596

341. Rogers M, Weinstock DM, Eagan J et al (2000) Rotavirus outbreak on a pediatric oncology floor: possible association with toys. Am J Infect Control 28:378-380

342. Kavaliotis J, Loukou I, Trachana M et al (1998) Outbreak of varicella in a pediatric oncology unit. Med Pediatr Oncol 31:166-169

343. Moschovi MA, Theodoridou M, Papaevangelou V et al (2002) Outbreak of enteroviral infection in a pediatric hematology-oncology unit. Clin Infect Dis 34:1269-1272

344. Anonymus (2005) Management of a tuberculosis exposure in an oncology hospital. Can Commun Dis Rep 31:149-156

345. Labarca JA, Leber AL, Kern VL et al (2000) Outbreak of Stenotrophomonas maltophilia bacteremia in allogenic bone marrow transplant patients: role of severe neutropenia and mucositis. Clin Infect Dis 30:195-197

346. Barchiesi F, Caggiano G, Falconi Di Francesco L et al (2004) Outbreak of fungemia due to Candida parapsilosis in a pediatric oncology unit. Diagn Microbiol Infect Dis 49:269-271

347. Levin AS, Costa SF, Mussi NS et al (1998) Candida parapsilosis fungemia associated with implantable and semi-implantable central venous catheters and the hands of healthcare workers. Diagn Microbiol Infect Dis 30:243-249

348. McAllister TA, Lucas CE, Mocan H et al (1989) Serratia marcescens outbreak in a paediatric oncology unit traced to contaminated chlorhexidine. Scott Med J 34:525-528

349. Stephenson JR, Heard SR, Richards MA, Tabaqchali S (1985) Gastrointestinal colonization and septicaemia with Pseudomonas aeruginosa due to contaminated thymol mouthwash in immunocompromised patients. J Hosp Infect 6:369-378
350. Aledo A, Heller G, Ren L et al (1998) Septicemia and septic shock in pediatric patients: 140 consecutive cases on a pediatric hematology-oncology service. J Pediatr Hematol Oncol 20:215221

351. Gorelick MH, Owen WC, Seibel NL, Reaman GH (1991) Lack of association between neutropenia and the incidence of bacteremia associated with indwelling central venous catheters in febrile pediatric cancer patients. Pediatr Infect Dis $J$ 10:506-510

352. Rahiala J, Perkkio M, Riikonen P (1998) Infections occurring during the courses of anticancer chemotherapy in children with ALL: a retrospective analysis of 59 patients. Pediatr Hematol Oncol 15:165-174

353. Salzer W, Steinberg SM, Liewehr DJ et al (2003) Evaluation and treatment of fever in the nonneutropenic child with cancer. J Pediatr Hematol Oncol 25:606-612

354. Gerding DN (2004) Clindamycin, cephalosporins, fluoroquinolones, and Clostridium difficileassociated diarrhea: this is an antimicrobial resistance problem. Clin Infect Dis 38:646-648

355. Gerding DN, Johnson S, Peterson LR et al (1995) Clostridium difficile-associated diarrhea and colitis. Infect Control Hosp Epidemiol 16:459-477

356. Hanna H, Raad I, Gonzalez V et al (2000) Control of nosocomial Clostridium difficile transmission in bone marrow transplant patients. Infect Control Hosp Epidemiol 21:226-228

357. Johnson S, Gerding DN (1998) Clostridium difficile-associated diarrhea. Clin Infect Dis 26:10271034; quiz 1035-1036

358. Paterson DL (2004) „Collateral damage" from cephalosporin or quinolone antibiotic therapy. Clin Infect Dis (Suppl 38) 4:S341-S345

359. Simon A (2004) Prävention invasiver Aspergillosen bei hochgradig Immunsupprimierten onkologischen Patienten. Krankenhaushygiene und Infektionsverhütung 26:157-163

360. Simon A, Fleischhack $G$ (2001) Surveillance for nosocomial infections in pediatric hematology/oncology patients. Klin Padiatr 213(Suppl 1): A106-A113

361. Simon A, Fleischhack G (2001) Non-pharmacologic strategies to prevent and control infectious complications in pediatric hematology/oncology patients. Klin Padiatr 213(Suppl 1)1:A9-A21

362. Simon A, Hasan C (2003) Infektionen in der pädiatrischen Onkologie. Kinder- und Jugendmedizin 3:227-239

363. Simon A, Beutel K, Hasan A, Bode U (2008) Evidence-based recommendation for the management of long-term central venous access devices in pediatric patients. German Society of Pediatric Hematology and Oncology (GPOH), Bonn

364. Laws HJ, Ammann RA, Lehrnbecher T (2005) Diagnostic procedures and management of fever in pediatric cancer patients. Klin Padiatr 217:9-16

365. Schuster FR, Laws HJ (2005) Infectious complications in the child undergoing hematopoietic stem cell transplantation. Klin Padiatr 217(Suppl 1):143-149

366. Laws HJ, Kobbe G, Dilloo D et al (2005) Surveillance of nosocomial infections in paediatric recipients of bone marrow or peripheral blood stem cell transplantation during neutropenia, compared with adult recipients. J Hosp Infect 62:8088
367. Seifert H, Cornely O, Seggewiss K et al (2003) Bloodstream infection in neutropenic cancer patients related to short-term nontunnelled catheters determined by quantitative blood cultures, differential time to positivity, and molecular epidemiological typing with pulsed-field gel electrophoresis. J Clin Microbiol 41:118-123

368. Beutel K, Simon A (2005) Diagnostic and management of central venous line infections in pediatric cancer patients. Klin Padiatr 217:91100

369. De Pauw B, Walsh TJ, Donnelly JP et al (2008) Revised definitions of invasive fungal disease from the European Organization for Research and Treatment of Cancer/Invasive Fungal Infections Cooperative Group and the National Institute of Allergy and Infectious Diseases Mycoses Study Group (EORTC/MSG) Consensus Group. Clin Infect Dis 46:1813-1821

370. Elishoov H, Or R, Strauss N, Engelhard D (1998) Nosocomial colonization, septicemia, and Hickman/Broviac catheter-related infections in bone marrow transplant recipients. A 5-year prospective study. Medicine (Baltimore) 77:83-101

371. Cohen ML, Murphy MT, Counts GW et al (1983) Prediction by surveillance cultures of bacteremia among neutropenic patients treated in a protective environment. J Infect Dis 147:789793

372. Daw MA, Munnelly P, McCann SR et al (1988) Value of surveillance cultures in the management of neutropenic patients. Eur J Clin Microbiol Infect Dis 7:742-747

373. Jong PJ de, Jong MD de, Kuijper EJ, Lelie H van der (1993) The value of surveillance cultures in neutropenic patients receiving selective intestinal decontamination. Scand J Infect Dis 25:107113

374. Feld R (1997) The role of surveillance cultures in patients likely to develop chemotherapy-induced mucositis. Support Care Cancer 5:371-375

375. GlupczynskiY (2001) Usefulness of bacteriological surveillance cultures for monitoring infection in hospitalized patients: a critical reappraisal. Acta Clin Belg 56:38-45

376. Lehrnbecher T, Laws HJ (2005) Infectious complications in pediatric cancer patients. Klin Padiatr 217:3-8

377. Simon A, Beutel K, Marklein G, Fleischhack G (2005) Bacterial infections in pediatric cancer patients. Klin Padiatr 217:17-36

378. Weber SG, Gold HS, Hooper DC et al (2003) Fluoroquinolones and the risk for methicillin-resistant Staphylococcus aureus in hospitalized patients. Emerg Infect Dis 9:1415-1422

379. Evans ME, Titlow WB (1998) Levofloxacin selects fluoroquinolone-resistant methicillin-resistant Staphylococcus aureus less frequently than ciprofloxacin. J Antimicrob Chemother 41:285288

380. Graffunder EM, Venezia RA (2002) Risk factors associated with nosocomial methicillin-resistant Staphylococcus aureus (MRSA) infection including previous use of antimicrobials. J Antimicrob Chemother 49:999-1005

381. Venezia RA, Domaracki BE, Evans AM et al (2001) Selection of high-level oxacillin resistance in heteroresistant Staphylococcus aureus by fluoroquinolone exposure. J Antimicrob Chemother 48:375-381

382. Schmidt-Hieber M, Blau IW, Schwartz S et al (2007) Intensified strategies to control vancomycin-resistant enterococci in immunocompromised patients. Int J Hematol 86:158-162 
383. Worth LJ, Thursky KA, Seymour JF, Slavin MA (2007) Vancomycin-resistant Enterococcus faecium infection in patients with hematologic malignancy: patients with acute myeloid leukemia are at high-risk. Eur J Haematol 79:226-233

384. Kommission für Krankenhaushygiene und Infektionsprävention (2004) Kommentar zu den Empfehlungen zur Prävention von Methicillin-resistenten Staphylococcus aureus Stämmen in Krankenhäusern und anderen medizinschen Einrichtungen. Epid Bull 46:396

385. Paterson DL, Bonomo RA (2005) Extended-spectrum beta-lactamases: a clinical update. Clin Microbiol Rev 18:657-686

386. Falagas ME, Vardakas KZ, Samonis G (2008) Decreasing the incidence and impact of infections in neutropenic patients: evidence from metaanalyses of randomized controlled trials. Curr Med Res Opin 24:215-235

387. Kruger WH, Bohlius J, Cornely OA et al (2005) Antimicrobial prophylaxis in allogeneic bone marrow transplantation. Guidelines of the Infectious Diseases Working Party (AGIHO) of the German Society of Haematology and Oncology. Ann Oncol 16:1381-1390

388. Chryssanthou E, Cherif H, Petrini B et al (2004) Surveillance of triazole susceptibility of colonizing yeasts in patients with haematological malignancies. Scand J Infect Dis 36:855-859

389. Ellis ME, Qadri SM, Spence D et al (1994) The effect of fluconazole as prophylaxis for neutropenic patients on the isolation of Candida spp. from surveillance cultures. J Antimicrob Chemother 33:1223-1228

390. Kommission für Krankenhaushygiene und Infektionsprävention (2002) Empfehlungen zum Vorgehen bei gehäuftem Auftreten von nosokomialer Infektion. Empfehlungen der Kommission für Krankenhaushygiene und Infektionsprävention am Robert Koch-Institut. Bundesgesundheitsbl Gesundheitsforsch Gesundheitsschutz 45:180-186

391. Kates SG, McGinley KJ, Larson EL, Leyden JJ (1991) Indigenous multiresistant bacteria from flowers in hospital and nonhospital environments. Am J Infect Control 19:156-161

392. Mathys W, Klus K, Rehms H (1996) Erfahrungen mit dem Einsatz von Biotonnen mit Biofiltern hinsichtlich der Hygiene. In: Schriftenreihe des Arbeitskreises für die Nutzbarmachung von Siedlungsabfällen (ANS) e.V. (ed) Hygieneaspekte bei der biologischen Abfallbehandlung. p215-p231

393. Philipp W, Haumacher R, Köhler K (1996) Keimemission aus Biotonnen in Abhängigkeit von der Abholfrequenz, dem Behältersystem und der Jahreszeit. In: Schriftenreihe des Arbeitskreises für die Nutzbarmachung von Siedlungsabfällen (ANS) e.V. (ed) Hygieneaspekte bei der biologischen Abfallbehandlung. p159-p179

394. Oberfeld G (1996) Hygieneaspekte bei der Eigenkompostierung. In: Schriftenreihe des Arbeitskreises für die Nutzbarmachung von Siedlungsabfällen (ANS) e.V. (ed) Hygieneaspekte bei der biologischen Abfallbehandlung. p181-p213

395. Arendrup MC, O'Driscoll BR, Petersen E, Denning DW (2006) Acute pulmonary aspergillosis in immunocompetent subjects after exposure to bark chippings. Scand J Infect Dis 38:945-949

396. Staib F (1991) Molds in the masonry. Dtsch Med Wochenschr 116:1331
397. Alwis KU, Mandryk J, Hocking AD (1999) Exposure to biohazards in wood dust: bacteria, fungi, endotoxins, and (1->3)-beta-D-glucans. Appl Occup Environ Hyg 14:598-608

398. Reiß J (1997) Schimmelpilze. Springer, Berlin Heidelberg New York

399. Baumgardner DJ, Paretsky DP (1999) The in vitro isolation of Blastomyces dermatitidis from a woodpile in north central Wisconsin, USA. Med Mycol 37:163-168

400. Beumer R, Bloomfield SF, Exner M et al (1998) Richtlinie zur Verhütung von Infektionen und Kreuzinfektionen im häuslichen Umfeld. Milano

401. Kaufmann F, Engelhart S, Glasmacher A, Exner $M$ (2002) Risk of infection and preventative strategies in the domestic environment of immunosuppressed hematologic oncology patients. Med Klin (Munich) 97:22-29

402. Boost MV, O'Donoghue OMM, Siu KH (2007) Characterisation of methicillin-resistant Staphylococcus aureus isolates from dogs and their owners. Clin Microbiol Infect 13:731-733

403. Herrero IA, Fernandez-Garayzabal JF, Moreno MA, Dominguez L (2004) Dogs should be included in surveillance programs for vancomycinresistant enterococci. J Clin Microbiol 42:13841385

404. Schoefer Y, Zutavern A, Brockow I et al (2008) Health risks of early swimming pool attendance. Int J Hyg Environ Health 211:367-373

405. Barbounis V, Aperis G, Gambletsas E et al (2005) Pneumocystis carinii pneumonia in patients with solid tumors and lymphomas: predisposing factors and outcome. Anticancer Res 25:651655

406. Hughes MA, Parisi M, Grossman S, Kleinberg L (2005) Primary brain tumors treated with steroids and radiotherapy: low CD4 counts and risk of infection. Int J Radiat Oncol Biol Phys 62:14231426

407. Worth LJ, Dooley MJ, Seymour JF et al (2005) An analysis of the utilisation of chemoprophylaxis against Pneumocystis jirovecii pneumonia in patients with malignancy receiving corticosteroid therapy at a cancer hospital. Br J Cancer 92:867872

408. Dowell SF, Bresee JS (1993) Severe varicella associated with steroid use. Pediatrics 92:223-228

409. Ahmed R, Hassall T, Morland B, Gray J (2003) Viridans streptococcus bacteremia in children on chemotherapy for cancer: an underestimated problem. Pediatr Hematol Oncol 20:439-444

410. Danilatou V, Mantadakis E, Galanakis E et al (2003) Three cases of viridans group streptococcal bacteremia in children with febrile neutropenia and literature review. Scand J Infect Dis 35:873-876

411. Gassas A, Grant R, Richardson S et al (2004) Predictors of viridans streptococcal shock syndrome in bacteremic children with cancer and stemcell transplant recipients. J Clin Oncol 22:12221227

412. Lyytikainen O, Rautio M, Carlson P et al (2004) Nosocomial bloodstream infections due to viridans streptococci in haematological and nonhaematological patients: species distribution and antimicrobial resistance. J Antimicrob Chemother 53:631-634

413. Okamoto Y, Ribeiro RC, Srivastava DK et al (2003) Viridans streptococcal sepsis: clinical features and complications in childhood acute myeloid leukemia. J Pediatr Hematol Oncol 25:696-703
414. Paganini $H$, Staffolani $V$, Zubizarreta $P$ et al (2003) Viridans streptococci bacteraemia in children with fever and neutropenia: a case-control study of predisposing factors. Eur J Cancer 39:1284-1289

415. Tunkel AR, Sepkowitz KA (2002) Infections caused by viridans streptococci in patients with neutropenia. Clin Infect Dis 34:1524-1529

416. Anaissie EJ, Kontoyiannis DP, O'Brien S et al (1998) Infections in patients with chronic lymphocytic leukemia treated with fludarabine. Ann Intern Med 129:559-566

417. Hendrick A (2001) Fatal legionella pneumonia after fludarabine treatment in chronic lymphocytic leukaemia. J Clin Pathol 54:412-413

418. $\mathrm{Ng} \mathrm{HJ}$, Lim LC (2001) Fulminant hepatitis B virus reactivation with concomitant listeriosis after fludarabine and rituximab therapy: case report. Ann Hematol 80:549-552

419. Tsutsumi Y, Kanamori H, Mori A et al (2005) Reactivation of hepatitis $B$ virus with rituximab. Expert Opin Drug Saf 4:599-608

420. Westhoff TH, Jochimsen F, Schmittel A et al (2003) Fatal hepatitis B virus reactivation by an escape mutant following rituximab therapy. Blood 102:1930

421. Clave E, Agbalika F, Bajzik V et al (2004) EpsteinBarr virus (EBV) reactivation in allogeneic stemcell transplantation: relationship between viral load, EBV-specific T-cell reconstitution and rituximab therapy. Transplantation 77:76-84

422. Nguyen DD, Cao TM, Dugan K et al (2002) Cytomegalovirus viremia during Campath- $1 \mathrm{H}$ therapy for relapsed and refractory chronic lymphocytic leukemia and prolymphocytic leukemia. Clin Lymphoma 3:105-110

423. Gea-Banacloche JC, Opal SM, Jorgensen J et al (2004) Sepsis associated with immunosuppressive medications: an evidence-based review. Crit Care Med 32:S578-590

424. Winthrop KL (2006) Risk and prevention of tuberculosis and other serious opportunistic infections associated with the inhibition of tumor necrosis factor. Nat Clin Pract Rheumatol 2:602610

425. Dixon WG, Watson K, Lunt M et al (2006) Rates of serious infection, including site-specific and bacterial intracellular infection, in rheumatoid arthritis patients receiving anti-tumor necrosis factor therapy: results from the British Society for Rheumatology Biologics Register. Arthritis Rheum 54:2368-2376

426. Michel BA, Hunder GG, Bloch DA, Calabrese LH (1992) Hypersensitivity vasculitis and HenochSchonlein purpura: a comparison between the 2 disorders. J Rheumatol 19:721-728 


\section{Hier steht eine Anzeige.}

岱 Springer 